\title{
MÉTRICAS DE PARTICIPACIÓN EN AMBIENTES DE TRABAJO COLABORATIVO ORIENTADAS A LA GENERACIÓN DE INTERVENCIONES DIDÁCTICAS
}

Tesista: Lic. Norberto CHARCZUK

Directores: ↔ Dr. Ramón García-Martínez (UNLP-UNLa) y Mg. Alejandra Zangara (UNLP)

Asesor Científico: Dr. Darío Rodríguez (UNLa)

TESIS PRESENTADA PARA OBTENER EL GRADO DE MAGISTER

EN TECNOLOGIA INFORMATICA APLICADA EN EDUCACION

FACULTAD DE INFORMÁTICA

UNIVERSIDAD NACIONAL DE LA PLATA

Diciembre, 2017 



\section{RESUMEN}

Tradicionalmente en la disciplina informática los problemas se han clasificado como de "hardware" o de "software". Sin embargo, se empieza a vislumbrar en proyectos software una tercera dimensión de problemas vinculados a la Interacción humana, los llamados problemas de "humanware". La sociometría provee instrumentos de diagnóstico que permiten al docente realizar acciones para mejorar el rendimiento de los grupos de trabajo áulico. Cuando el trabajo en grupo de la clase se traslada a los espacios virtuales, estos instrumentos deben ser repensados.

En el marco de las tecnologías aplicadas al ámbito educativo y en el caso de los EVTC (entornos virtuales de trabajos colaborativos) donde la presencialidad es reemplazada por la participación de los integrantes en la realización de una tarea cobra importancia la sociometría y el análisis de redes sociales (SNA - Social Network Analysis), que resulta un instrumento de aproximación para la identificación de los distintos roles de los participantes. Este trabajo propone una integración de tres métodos previamente analizados y evaluados con el fin de una correcta intervención didáctica sobre los participantes de los EVTC por el tutor/docente en el logro de los objetivos planteados.

En este contexto, esta tesis formula aportaciones a:

[a] La inferencia del modelado y detección de roles, dentro de dinámicas grupales con interacción en el tiempo mediada por tecnología con énfasis en entornos virtuales de trabajo colaborativo.

[b] La formulación de una propuesta de diseño conceptual de detección temprana de roles, que permita una intervención por parte del docente/tutor para aportar estrategias de ayuda en los casos donde los alumnos se encuentren marginados o rechacen las actividades grupales dentro de un EVTC 



\section{ABSTRACT}

Traditionally in computer science discipline problems have been classified as "hardware" and "software". However, you begin to glimpse software projects a third dimension of problems related to human interaction, so-called problems of "humanware". Sociometry provides diagnostic tools that allows teachers to take action to improve the performance of courtly working groups.

When group work class moved to the virtual spaces, these instruments need to be rethought. As part of the technologies applied to education and in the case of EVTC (virtual environments of collaborative work) where presentiality is replaced with the participation of members in carrying out a task becomes important sociometry and network analysis social (SNA - social Network Analysis), which is an instrument approach for the identification of the different roles of the participants.

This paper proposes a merger of three previously analyzed and evaluated in order to correct educational intervention on participants of EVTC by the tutor / teacher in achieving the goals set methods.

In this context, this thesis makes contributions to:

[A] The inference modeling and detection roles within group dynamics with time interaction mediated by technology with an emphasis on virtual collaborative work environments.

[B] The formulation of a proposal for conceptual design of early detection of roles, allowing an intervention by the teacher / tutor to provide assistance strategies in cases where students are marginalized or reject group activities within a EVTC 



\section{AGRADECIMIENTOS}

A la Facultad de Informática de la Universidad Nacional de la Plata por brindarme con un espíritu abierto y fraterno, la posibilidad de realizar estudios de maestría en tecnología informática aplicada en educación.

A los docentes de la maestría y en especial con aquellos que compartí diálogos enriquecedores (A.Z. - C.S. - M.DG) cómo con su personal administrativo.

Al Grupo de Investigación en Espacios Virtuales para Trabajo Colaborativo del Departamento de Desarrollo Productivo y Tecnológico de la Universidad Nacional de Lanús por recibirme para realizar la investigación y desarrollo proveyendo un ambiente de intercambio de ideas con otros tesistas de postgrado, y apoyarme en todas las instancias del proceso de aprendizaje como docente investigador.

Al Dr. Ramón García-MartínezÆ por dirigir mi trabajo de tesis, entrenándome en el pensamiento científico y guiándome en la construcción de nuevo conocimiento, por su dedicación y paciencia no solo de maestro sino también de amigo; al Dr. Darío Rodríguez (UNLa) y a la Mg. Alejandra Zangara (UNLP) por su acompañamiento en la tarea.

Al Dr. Ramón García-Martínezł y al Dr. Darío Rodríguez, Director del Grupo de Investigación en Espacios Virtuales para Trabajo Colaborativo por ser un estímulo permanente en mi formación profesional.

Dentro de los agradecimientos, no debo de dejar de mencionar a Dios, que en mi etapa personal ha permitido que hoy esté con ustedes y comparta mi alegría.

A mi familia (GR-MCC-PAC-LAC-LMC), a mis amigos que compartieron mis ideas y apoyaron mis estudios (AMC-JR). A mis médicos, tanto particular cómo de Fundación Favaloro (RR-GC-CG), que tanto han realizado y continúan realizando por mí. 



\section{INTRODUCCIÓN}

1.1. Contexto de la Tesis 1

1.2. Objetivo de la Tesis 4

1.3. Temas de Investigación abordados en la Tesis 6

1.4. Líneas Secundarias de Hipótesis 7

1.5. Estructura de la Tesis 8

$\begin{array}{ll}\text { 1.6. } & \text { Publicaciones Vinculadas a la Tesis } \\ & 10\end{array}$

2. ESTADO DE LA CUESTION

2.1. Procesos cognitivos, trabajo colaborativo y tecnología digital 13

2.2. Identificación de Roles en el trabajo colaborativo 16

2.3. El proceso de observación 19

2.4. Análisis de Redes Sociales 21

2.5. Sociometría como Herramienta de Observación de Roles 23

2.6. Los Entornos Virtuales de Trabajo Colaborativo 24

2.7. La Sociometría y su campo de acción 30

2.7.1. Principales leyes sociométricas 40

2.8. La sociometría y los formatos de interacciones 40

2.9. Las interacciones en las organizaciones empresariales 44

2.10. Las modalidades educativas y las interacciones 45 
2.10.1. Modalidades educativas y otros conceptos vinculados al 46 uso de TIC en educación

2.10.1.1. Modalidad "blended learning" $\quad 46$

2.10.1.2. Instituciones bimodales 46

2.10.1.3. Respecto del proceso de mediación 47

2.10.1.4. Respecto de los cuidados especiales 48

3. DELIMITACION DEL PROBLEMA

3.1. Limitaciones del seguimiento de los alumnos en EVTC 51

3.2. Métodos de registro y análisis de interacciones 52

3.3. Indicadores de alerta temprana en actividades colaborativas en un 53 EVTC

3.4. Límites de la hipótesis

4. SOLUCION PROPUESTA

4.1. Identificación de roles

4.2. El proceso de observación

4.3. Análisis de redes sociales

4.4. Sociometría como Herramienta de Observación de Roles

4.5. Elementos de ponderación 65

4.5.1. Definiciones 66

4.5.1.1. Unidad de Interacción 66 
4.5.1.2. Matriz de Interacciones

4.5.1.3. Matriz de Acumulación de 66 Ponderación de Interacciones SujetoGrupo

4.5.1.4. Matriz de Acumulación de

Ponderación de Interacciones GrupoSujeto

4.5.1.5. Densidad de comunicación (DC)

4.5.1.6. Matriz de Interacciones (MB)

4.5.1.7. Matriz de Densidad de

Comunicación Sujeto-Grupo

4.5.1.8. Escalón de Segmentación (ES)

4.5.1.9. Conversión de Valores DC a

Indicadores de Métrica

4.5.1.10 Matriz de Referencia de Densidades de Comunicación Interacciones (MRDCI)

4.5.1.11. Matriz Integración (MI)

4.5.1.12. Índice de Autocolaboración (IACi) 68

4.5.1.13. Índice de Heterocolaboración (IHCi) 68

4.5.1.14. Índice de Realidad-Colaborativa (IRCi)

4.5.1.15. Índice de Realidad-ColaborativoAbsoluto (IRCA)

4.5.1.16. Grado de Colaboración Sujeto-Grupo 
(GCSG)

4.5.1.17. Grado de Colaboración Grupo-Sujeto 71 (GCGS)

4.5.1.18. Canales de Comunicación

4.5.1.19. Porcentajes de canales efectivos de comunicación

4.5.1.20. Porcentaje de carencia de comunicación

4.6. Procedimientos Propuestos

4.6.1. Caso de Estudio Aplicando el Procedimiento A

4.6.2. Caso de Estudio Aplicando el Procedimiento B

4.6.3. Caso de Estudio Aplicando el Procedimiento C

\section{VALIDACIÓN}

5.1.1. Caso de Estudio Aplicando el Procedimiento A

5.1.2. Caso de Estudio Aplicando el Procedimiento B

5.1.3. Caso de Estudio Aplicando el Procedimiento C 


\section{CONCLUSIONES}

6.1. Valoraciones Generales 99

6.2. Aportaciones de la Tesis 100

6.3. Futuras Líneas de Trabajo y Problemas Abiertos 103

$\begin{array}{ll}\text { 7. REFERENCIAS } & 105\end{array}$ 


\section{INTRODUCCIÓN}

En este Capítulo se plantea el contexto de la tesis (sección 1.1), se presentan las publicaciones del tesista vinculadas a la investigación realizada tanto las que corresponden a resultados de interés para la tesis como las correspondientes a trabajos exploratorios relacionados a ella (1.2), se establece su objetivo (sección 1.3), se enuncian los temas de investigación abordados (sección 1.4), líneas secundarias de la tesis (sección 1.5) y se resume la estructura de la tesis (sección 1.6).

\subsection{Contexto de la Tesis}

En el marco de esta tesis, nos encontramos con la falencia/vacancia de varios elementos presentes de forma cotidiana en la tarea del aprendizaje y específicamente en el trabajo colaborativo.

Toda actividad colaborativa, como su nombre lo indica, es una actividad realizada por un conjunto de personas en un momento específico y en un espacio compartido. Las nuevas tecnologías rompen con dicho paradigma y dentro del ámbito educativo, por ser todos personas escolarizadas (hemos transitado por los ámbitos académicos), intuimos las formas estandarizadas de organización y proceso educativo. La falencia que se ha abordado en la siguiente tesis es dentro de un entorno virtual de trabajo colaborativo, donde se hace presente la disrupción del concepto colaborativo con los estándares con los cuales se desarrollan generalmente, que son simultaneidad temporal y física de los participantes.

De ahí la vacancia de contar con instrumentos apropiados por parte del docente/tutor en el seguimiento de las tareas propuestas y las características que presenta cada uno 
de los participantes en la concreción de la tarea. Si a lo anteriormente enunciado, el ámbito de desarrollo es una institución de nivel superior, de grado o postgrado, las implicancias aumentan.

Los participantes de las actividades no cuentan con vínculos previos que permite observar la predisposición individual en la realización de la tarea en formato grupal.

Es menester considerar dentro del marco teórico de esta tesis los elementos que hacen a determinadas consignas del sistema educativo (para no extenderse en la materia), los elementos concernientes a la conducción y la evaluación. De éste último punto surgen varios interrogantes, que son los que se abordaron y analizaron, como ser los vínculos entre pares dentro de un grupo en la realización de una actividad y la forma de interpretar dichos vínculos con la posibilidad de ponderarlos, todo enmarcado en un EVTC donde el medio de comunicación y contacto son los dispositivos tecnológicos. $\mathrm{Al}$ encontrarse el sistema educativo atravesado por distintas estrategias, la cual debe abordar el docente de nivel superior en su ámbito, con las particularidades propias del nivel de estudios y la carga curricular, siendo las mismas modificadas fuertemente por el empleo de la tecnología y han cambiado (o potenciado) otros formatos educativos $(\mathrm{EaD})$. Dentro de la educación superior es abiertamente aceptada otro tipo de modalidad, en la formación de grado y postgrado el empleo de tecnologías educativas que permiten una comunicación asincrónica entre el docente y sus alumnos, en dicha interacción, lo que resulta complejo es el grado de visibilidad presentado por cada alumno, donde solamente lo tenemos presente por su nivel de actividad dentro del ámbito educativo, a diferencia de una modalidad presencial donde cada alumno, en la cotidianeidad de la tarea, intercambia momentos, tareas con sus colegas permitiendo sociabilizar y sociabilizarse, elemento que no ocurre en un Entorno Virtual de Trabajo Colaborativo (EVTC). 
Cada participante mediante la interacción en la resolución de una tarea específica, desarrolla un mayor o menor grado de afinidad, que se encuentra ponderado por las comunicaciones realizadas dentro de un EVTC.

Dentro de los entornos virtuales de trabajo colaborativo, la etapa pedagógica es la más vulnerable porque se encuentra desarrollada la tarea con los formalismos propios a la educación no presencial, con las implicancias de tiempos sincrónicos y asincrónicos por parte de los participantes como la distancia geográfica de ellos.

Otro aspecto que interesa destacar, es el hecho que la interacción se establezca de forma virtual no significa que sea una interacción peor que la presencial; en los entornos virtuales se da una relación de comunicación estrecha [Daugherty y Turner, 2003]. No se puede dejar de reconocer una distancia física entre el profesor y el alumno y entre los alumnos, pero ella no es determinante, la que importa es la distancia cognitiva, la cual influye para construir entornos de calidad [Moore, 1970]. Ésta depende del diseño de enseñanza que se determine y del papel que desempeña el profesor y de cómo movilice o utilice las herramientas de comunicación y las diferentes metodologías que tenga a su disposición [Peters, 1988].

En este contexto la metodología de aprendizaje colaborativo se ha convertido en una de las metodologías más significativas para la formación en red.

Debido a que el trabajo del alumno es fundamental en la construcción autónoma del contenido con la tutoría del docente y en el desarrollo de las competencias que deben adquirir para aportar al perfil del licenciado en sistemas y que, además, facilitan una visión integradora en el análisis de situaciones a través de la aplicación de estrategias que fortalecen la comunicación con las áreas que colaboran en el diseño, implementación, operación, mantenimiento, control de gestión, evaluación, 
coordinación y dirección de las empresas de producción de bienes y servicios, consolidando, de esta manera, su capacidad de ejercitar la creatividad en un método científico especifico y un análisis lógico a fin de obtener los mejores resultados en el aprovechamiento de los recursos materiales y un conocimiento apropiado apto para la evaluación y el discernimiento en el análisis de los elementos productivos más comunes que ofrece la industria.

\subsection{Objetivos de la Tesis}

En este contexto, esta tesis explora:

- El marco teórico para la generación de indicadores de detección de los roles dentro de un grupo de participantes de un EVTC.

- El marco teórico de inferencia de detección de roles con énfasis en la intervención didáctica por parte del docente/tutor.

- El diseño conceptual de un espacio colaborativo donde los protagonistas (los alumnos) generen y detecten sus propios roles y permitan un aporte didáctico por parte del docente/tutor.

- La validación de los roles mediante la interacción de los participantes de un EVTC en el desarrollo de una tarea, mediante una prueba de concepto.

La tesis formula aportaciones a:

- La inferencia del modelado y detección de roles, dentro de dinámicas grupales con interacción en el tiempo mediada por tecnología con énfasis en entornos virtuales de trabajo colaborativo.

- La formulación de una propuesta de diseño conceptual de detección temprana de roles, que permita una intervención por parte del docente/tutor para aportar 
estrategias de ayuda en los casos donde los alumnos se encuentren marginados o rechacen las actividades grupales dentro de un EVTC.

Dentro de los métodos de registro, se encuentran dos líneas diferenciadas, los cualitativos y los cuantitativos en la ponderación de actividades y distancia social.

Los métodos de registro y análisis se encuentran enmarcados dentro de los parámetros de SNA (análisis de redes sociales) [Wasserman y Faust, 1994]. En los mismos se encuentra una taxonomía de las distintas caracterizaciones a las que hacen los distintos roles y sus diferentes funcionalidades. En este caso en particular nos limitamos a un grupo bajo análisis y por lo tanto su limitado abanico de posibilidades (líder, marginado, aceptador, rechazador y normal).

Aplicando herramientas de análisis específicas permite obtener distintos elementos de observación [Pérez-Alvarez ,1991].

Debe de interpretarse como distancia social al conjunto de elementos que surgen del análisis de los distintos indicadores, éstos indicadores como se han enunciado anteriormente, debido a su naturaleza, en la mayoría de los casos se aplican encuestas a los participantes de las actividades y determinan mediante las respuestas a las mismas cuál es el grado de integración y compromiso con cada uno de los participantes, este tipo de indicador puede llegar a constituir un elemento de registro sesgado, por la forma de expresión de la persona, es decir si es tímido o introvertido o su caso contrario, el ser extrovertido [ Litwin, 2000 ; Rosenberg, 2001].

En el caso de los indicadores cuantitativos (en los que se basa éste estudio), la interacción entre los participantes se encuentra mediada por elementos tecnológicos que permiten el registro de dichas interacciones (correos electrónicos), el cual se puede extender en una futura línea de investigación respecto de otros canales o métodos de 
comunicación entre los participantes y el docente a cargo de la tutoría, para arbitrar los medios didácticos necesarios con fin de guiar al grupo [Charczuk et al.,2013].

Doreian (1988) realiza una importante distinción entre la definición de equivalencia y el proceso de detectar la propiedad de equivalencia (como elemento a detectar). Pattison (1988) realiza una distinción similar entre el "modelo" y el algoritmo para detectar el modelo referido a los datos.

El objetivo de la tesis es inferir un modelo que permita detectar de forma temprana los roles dentro de un grupo de alumnos que se encuentran desarrollando una actividad/tarea dentro de un EVTC, para una correcta intervención didáctica del docente/tutor.

\subsection{Temas de Investigación Abordados}

Durante el desarrollo de este proyecto, el tesista abordó la investigación de los siguientes temas:

- Modelos de dinámica grupal centrados en esquemas colaborativos soportados por SNA para la detección de roles.

- Formalismos específicos de la sociometría adaptados al modelado de interacciones en entornos virtuales de trabajo colaborativo.

- Inferencia conceptual de roles dentro de un EVTC.

Dentro de los temas abordados, nos encontramos con las relaciones sociales y la forma de interactuar dentro de un grupo mediado por dispositivos tecnológicos en un EVTC. Los elementos que hacen al relevamiento de actividad, es decir los indicadores utilizados en este trabajo están referidos al tiempo de demora en la respuesta de los correos electrónicos entre participantes y la cantidad de correos dentro de una ventana temporal [Charczuk et al., 2014]. 
Asimismo, otros conjuntos de indicadores permiten observar los distintos tipos de interacciones entre docente y alumnos, como ser la cantidad de veces de acceso a repositorios y la lectura de los documentos ahí localizados (futura línea de investigación).

Los indicadores y sus propiedades permiten realizar el proceso de análisis que determina el grado de participación o no de los alumnos, logrando reducir el grado de incertidumbre por parte de los docentes en la intervención didáctica [Lorrain y White ,1971], [Breiger y Pattison ,1986], [Faust, 1988], [Mandel, 1983], [Pattison, 1988], [Wasserman y Anderson, 1987], [Wasserman y Faust,1992], [White y Reitz, 1981], [Winship,1988], [Winship y Mandel, 1983].

Otro método denominado CONCOR, de su acrónimo por CONvergencia de la CORrelación de las interacciones, ha sido específicamente desarrollado para analizar datos en redes sociales en orden de identificar un sub-conjunto de datos de actores equivalentes. Este método ha sido utilizado por primera vez para análisis de datos en rdes sociales por Harrison White y otros, Breiger, Booman, Arabie, Schwartz; en su investigación sobre la aplicación en redes sociales del estudio algebraico de roles [Breiger et al. 1975; White et al. 1976].

\subsection{Líneas secundarias de hipótesis}

Los elementos que permiten detectar otros roles, que aún no están contemplados en el presente trabajo, son las distintas tareas de participación que se pueden dar en grupos con mayor número de integrantes y el grado de centralismo de cada uno de los participantes. Los roles que se encuentran bajo análisis son los de participación en foros, el de búsqueda de información, colaborador experto, el de observador y otros que permita el intercambio de experiencias entre los distintos actores de una tarea en EVTC con procesos de ponderación, permitiendo una correcta actuación del docente 
en el guiado de la tarea sobre él o los participantes. La taxonomía propuesta por el enfoque SNA con herramientas de análisis cuantitativo sobre el uso de los distintos recursos que hoy ofrece la tecnología de la información en la formación de estudiantes con la modalidad puesta en EVTC es muy amplia; de ahí la necesidad de analizar las distintas propuestas de acción sobre dichos recursos y el impacto tecnológico sobre las distintas plataformas disponibles en los ambientes universitarios.

En los entornos virtuales el vínculo socializador se da a través de las interacciones [Rodríguez y Garcia Martinez, 2012]. Luego, las relaciones todo-partes y partes-todo quedan determinadas por el flujo de las interacciones, esto es consistente con el hecho que los sistemas no se constituyen de "partes" o de "constituyentes", sino de acciones entre unidades complejas, constituidas a su vez por interacciones [Morin, 1980].

\subsection{Estructura de la Tesis}

La tesis se estructura en siete capítulos: Introducción, Estado de la Cuestión, Delimitación del Problema, Solución Propuesta, Validación, Conclusiones y Referencias.

En el Capítulo Introducción se plantea el contexto de la tesis, se establece su objetivo, se enuncian los temas de investigación abordados, se presentan las publicaciones del tesista vinculadas a la investigación realizada las que corresponden a resultados de interés para la tesis como las correspondientes a trabajos exploratorios relacionados y se resume la estructura de la tesis.

En el Capítulo Estado de la Cuestión se presenta el marco teórico sobre el concepto sociométrico y las características del mismo detallándose las distintas definiciones que la comunidad ha ido construyendo sobre líneas de investigación y proyectos, se introduce el marco teórico sobre creación del concepto y sus aplicaciones e implicancias en la sociedad y el proceso comunicacional; se reseña el marco teórico 
sobre modelado conceptual de flujo de interacciones en grupos mediados por tecnología informática describiendo: los conceptos asociados al modelado conceptual de roles de trabajo, los elementos constitutivos de ambientes virtuales de aprendizaje comunes a ambientes de trabajo en grupos mediables por tecnología informática.

En el Capítulo Delimitación del Problema se presentan limitaciones al modelo de seguimiento pedagógico en ambientes mediados por tecnologías de la información, se identifica la falencia de formalismos de modelado de interacciones humanas, se señala la necesidad de definir los requisitos funcionales de los espacios virtuales de formación, y se resumen las preguntas de investigación derivadas de las críticas, vacancias y necesidades señaladas.

En el Capítulo Solución Propuesta se propone un modelo de interacción y seguimiento de los distintos participantes centrado en la interacción, que considera la definición de un plan de análisis y seguimiento de la dinámica grupal.

En el Capítulo Validación se presenta la validación del modelo de interacciones y detección de roles de los participantes de un grupo centrado en la colaboración mediante el uso de los casos de corroboración con detalle de los casos vinculados al desarrollo de actividades colaborativas

En el Capítulo Conclusiones se presentan valoraciones generales de la tesis, se resumen las aportaciones de la tesis, y se identifican futuras líneas de trabajo.

En el Capítulo Referencias se listan todas las publicaciones consultadas para el desarrollo de esta tesis. 


\subsection{Publicaciones Vinculadas a la Tesis}

Durante el desarrollo del trabajo de investigación vinculado a la tesis se fueron obteniendo resultados parciales vinculados a la investigación o exploratorios de temas relacionados con la misma que fueron comunicados a través de las siguientes participaciones y publicaciones:

Charczuk, N., Rodríguez, D., García-Martínez, R. 2013. Propuesta de Técnicas de Diagnóstico Sociométrico de Dinámicas Grupales para Utilizar en Ambientes de Trabajo Colaborativo. Proceedings VIII TEYET. ISBN 978-987-1676-04-0. UNSE

Charczuk, N., Rodríguez, D., García-Martínez, R. 2014. Métricas de Participación en Ambientes de Trabajo Colaborativo Orientadas a la Generación de Intervenciones Didácticas. CACIC. ISBN 978-987-3806-05-6. Universidad Nacional de La Matanza.

Charczuk, N., Rodríguez, D., García-Martínez, 2015. Participation Metrics within Virtual Collaborative Workspaces Oriented to Generation of Didactic Interventions. Computer Science \& Technology Series 2015: XX Argentine Congress of Computer Science Selected Papers / Ovaldo Spositto; Patricia Mabel Pesado; compilado por Ovaldo Spositto; Patricia Mabel Pesado. La Plata: EDULP - ISBN: 978-987-1985-71-5

Charczuk, N., Rodríguez, D., García-Martínez, R. 2015. Integración de Indicadores Sociométricos de Dinámicas Grupales en Ambientes Virtuales de Trabajo Colaborativo Orientados a Intervenciones Didácticas. XVIII Workshop 
Tecnología Informática Aplicada a la Educación. CACIC 2015, 5 al 9 de Octubre, Junín, Buenos Aires, UNNOBA

Rodríguez, D., Charczuk, N., Garbarini, R., García-Martínez, R. Trabajo Colaborativo basado en Espacios Virtuales. Proceedings II Jornadas de Enseñanza de la Ingeniería (JEIN 2012). Pág. 192-199. Programa de Tecnología Educativa y Enseñanza de la Ingeniería (TEyEI). Universidad Tecnológica Nacional. ISSN 2313-9056.

Rodríguez, D., García-Martínez, R., Merlino H., Charczuk, N., Lacabanne, M., Caracciolo, B., Iglesias. Espacios Virtuales para Trabajo Colaborativo. Proceedings del XV Workshop de Investigadores en Ciencias de la Computación, Pág. 1116-1120. WICC 2013, 18 y 19 de Abril 2013, Paraná, Entre Ríos, UADER- ISBN 978-9-872-81796-1.

Rodríguez, D; Baldizzoni, E; Martins, S; Charczuk, N; García-Martínez, R. Líneas de $I+D+I$ del Laboratorio de Investigación y Desarrollo en Espacios Virtuales de Trabajo (LIDEVT GISI UNLa). Proceedings XVI Workshop de Investigadores en Ciencias de la Computación. Pág. 912-915. 2014. WICC 2014, 7 y 8 de Mayo, Ushuaia, Tierra del Fuego, UNTDF 


\section{ESTADO DE LA CUESTION}

\subsection{Procesos cognitivos, trabajo colaborativo y tecnología digital}

Dentro del marco de las nuevas tecnologías y el proceso de enseñanza y aprendizaje, las tecnologías han influenciado la práctica docente y, por consiguiente, la relación entre pares (alumnos) y los docentes.

Las dinámicas grupales se han modificado por los procesos de interacción con los dispositivos y la forma de relación entre los participantes. Las actividades grupales que antes se encontraban enmarcadas por una conjunción espacio-tiempo, hoy han cambiado ese par por los accesos a la tecnología y la consiguiente mirada del grupo de alumnos.

En los EVTC (entornos virtuales de trabajo colaborativo) la implementación y utilización de la tecnología por parte de los participantes permite visibilizar el trabajo grupal. Esta modificación es relevante, ya que la interacción en el grupo cobra una fuerza que en los espacios presenciales podía observarse sólo en los momentos sincrónicos. En estos entornos, las herramientas informáticas permiten hacer un cuidadoso seguimiento y hasta ofrecen la posibilidad de reconstruir las interacciones propias de la colaboración.

Se ha conceptualizado al grupo de aprendizaje como "una estructura formada por personas que interactúan, en un espacio y tiempo común, para lograr ciertos y determinados aprendizajes en los individuos (alumnos), a través de su participación en el grupo. Dichos aprendizajes que se expresan en los objetivos del grupo, son conocidos y sistemáticamente buscados por el grupo a través de la interacción de sus miembros" [Souto, M.,Cap III,p.55,1993].

Se crea tecnología para la enseñanza y se planean o diseñan experiencias de enseñanza donde los docentes asumen el papel de "facilitadores". Esto implicó una suerte de intermediación en la que el papel fundamental en relación con la enseñanza lo desempeñaban los materiales creados para tal fin, en tanto que 
a los docentes sólo les correspondía ponerlos a disposición de los alumnos. [Litwin E.,2000]

Las prácticas con tecnologías pueden permitir el acceso a nuevas maneras de producir el conocimiento mediante trabajos en colaboración que antes eran impensados. A su vez, penetran en las comunidades como modos posibles de producción. En todos los casos dependen de la calidad pedagógica de la propuesta, de la calidad científica de los materiales y su información, y de la ética profesional que impone una modalidad en la que las autorías se comparten en desmedro de las individualidades y potencian la producción de los grupos. [ Litwin, E. 2005].

Es indudable, que la unidad básica de espacio educativo (el aula o la clase) y la unidad básica de tiempo (también suele recibir la denominación de clase) se ven afectadas por la aparición de las nuevas tecnologías de la información en el ámbito educativo. La enseñanza nacida de la industrialización se ha caracterizado hasta ahora y en relación al ambiente instructivo, por seguir una ley de tres unidades: Unidad de tiempo, unidad de lugar y unidad de acción (Todos en el mismo lugar, al mismo tiempo, realizando las mismas actividades de aprendizaje). Este ambiente característico, comienza a desdibujarse al cambiar las coordenadas espaciotemporales que propician las telecomunicaciones, contribuyendo a facilitar el acceso a los recursos de aprendizaje a una mayor diversidad de personas y en diversas circunstancias [Salinas, J. 2009]

El aprendizaje colaborativo mediado por ordenador expresa dos ideas importantes. En primer lugar, la idea de aprender de forma colaborativa. En este sentido, no se contempla al aprendiz como persona aislada sino en interacción con los demás. Se parte de la importancia por compartir objetivos y distribuir responsabilidades son formas deseables de aprendizaje. Además, se enfatiza el papel del ordenador como elemento mediador que apoya este proceso. Se trata pues de aprender a colaborar y colaborar para aprender. [Gros-Salvat, B. 2007] 
Las relaciones entre pares cobran otro sentido dentro de las dinámicas grupales y las formas del relevamiento de dichas dinámicas.

Finalmente, en la actualidad, un elemento adicional aparece en la educación: la virtualidad. Esto hace que se reflexione sobre los actores y las interacciones que se presentan en el triángulo didáctico. [Civarolo, M. M.; 2008]

Del análisis de las interacciones, se obtiene información relevante para el docente que le reporta la métrica respecto de la actividad de cada uno de los participantes.

Para que esto ocurra se plantean cinco pasos, primero seleccionar y diseñar objetivos, segundo y tercero tomar decisiones sobres las estrategias de enseñanza que se desea implementar y desarrollar las actividades respectivamente. En cuarto lugar seleccionar las estrategias de evaluación, y como último paso tratar de no poner a la tecnología por sobre los estudiantes. [Manso. M; Libedinsky, M.; Pérez, P.; Light, D.; Garzón, M. 2011]

El Aprendizaje Colaborativo Apoyado por Computador (CSCL) fomenta la colaboración entre los estudiantes, así que ellos no simplemente reaccionan aisladamente a un conjunto de materiales que se han seleccionado. El aprendizaje se lleva a cabo en espacios donde haya una alta interacción entre los estudiantes. El aprendizaje en los estudiantes se da a través de la formulación de preguntas, del planteamiento de actividades conjuntas, de enseñar a los demás y de observar como los demás estudiantes aprenden. El soporte computacional para tal colaboración es un aspecto central a la aproximación de CSCL al e-learning. Lograr estimular a que los estudiantes interactúen de forma efectiva no es algo fácil de lograr, se requiere una planeación detallada, una coordinación e implementación de un currículo, que integren pedagogía y tecnología. [Stahl, G., Koschmann, T., Suthers, D. 2006]

Los avances en tecnologías basadas en computadoras y redes en la pasada década han ampliado considerablemente las posibilidades de desarrollo de los procesos de enseñanza y aprendizaje. Además, la demanda de enseñanza a distancia en las escuelas, la educación superior y las universidades, preocupadas por su 
supervivencia, se han redefinido en el nombre de la tecnología. Algunas se han convertido en información virtual a nivel mundial en centros y otros han puesto sus bibliotecas en línea. Universidades que cuentan con soportes tecnológicos, permiten que sus alumnos logren realizar estudios de grado mediante su plataforma (Universidad Siglo XXI, UNQ) ¿Cuál es el mensaje que envían a sus estudiantes? Los que están en el aula se complementan mientras tengas un dispositivo de comunicación y una computadora.

Así, a pesar de la retórica de "entusiastas de la información", lo que sugiere que los límites no importan, por lo tanto, deben adaptarse a este nuevo paradigma, las redes y las instituciones antes que comience la innovación alrededor de ellos. [ Brown, J. S., Duguid, P. 2000.]

Las ofertas educativas se han ampliado con estas modalidades, acortando las distancias y permitiendo que los alumnos de distintas áreas compartan experiencias, de ahí la importancia del análisis de cada grupo y la forma en que interactúan sus miembros en el trabajo colaborativo.

\subsection{Identificación de Roles en el trabajo colaborativo}

En [Charczuk et al., 2013], se hace mención de las características que hacen a los roles dentro de un grupo, el cual se encuentra definido en sus tareas, en el caso de ser impuestas por un organizador/administrador de la tarea o la distribución que se realiza entre pares según la funcionalidad del mismo. Dentro de los elementos que hacen a la tarea en cualquier ámbito, pero específicamente dentro del análisis a los que competen en los trabajos colaborativos mediados por la tecnología de la información, se debe tener presente el rol que presenta cada integrante en cada uno de ellos "al status alumnos corresponde una serie de roles. Los roles son los papeles que el alumno debe jugar para cumplir con los requisitos que hacen a ese status" [PérezÁlvares, 1991]. Es decir, que dentro de las tareas colaborativas son completamente aplicables las consideraciones sobre las situaciones que se plantean en el ambiente 
áulico, o en su defecto si las tareas se aplican dentro del ámbito meramente empresario rige la misma situación en donde cada uno de los roles se han de cambiar por el jefe de proyecto y los responsables del mismo. Los roles desempeñados por cada miembro tendrán significado y estarán realmente orientados, si los objetivos y las normas de funcionamiento grupal están claramente definidos y son aceptados y compartidos. Los objetivos se lograrán mejor si los roles que es necesario cumplir están bien definidos; cada miembro debe comprender su tarea, aceptarla y percibir la relación entre la función que él cumple y la que realizan sus compañeros [Cols, 1977].

Las experiencias de trabajos en modalidades de EVTC se apoyan en herramientas que facilitan la distribución de la información (datos) y permiten la comunicación entre los actores. Las distintas herramientas difieren en el potencial de transmitir información en cuanto a la velocidad, naturaleza social, riqueza de información, flexibilidad. Por otra parte, la tarea puede presentar diferentes estructuras interactivas (individualista, cooperativa, colaborativa), en las que difieren los objetivos, funciones y voluntad de la comunicación. [Salinas, J. 2005]

Los roles dentro de los grupos "se visualizan" mediante otro tipo de dispositivo, en éste caso por las interacciones, la dinámica de las tareas dentro de los grupos permiten la mutación de los roles en el transcurso del tiempo, de ahí la importancia de contar con identificadores de alertas tempranas para dirigir el esfuerzo del docente/tutor según el enfoque de la tarea.

Las nuevas tecnologías de la información y comunicación (TIC) han ampliado las posibilidades que anteriormente ofrecían las tecnologías tradicionales y de manera particular, han impactado los procesos de enseñanza y de aprendizaje, las estrategias de enseñanza, los roles que desempeñan los profesores y los estudiantes, y la aparición de nuevas modalidades para llevar adelante estas actividades. La educación, como sistema formal, la formación del individuo para compartir e interactuar con otros y con alta calidad, dado que ellas han dado lugar a la creación de entornos de interacción profesor-estudiante y estudiante-estudiante, a la posibilidad de comunicar 
y recibir información de forma inmediata, pues, ya no existen las barreras espaciotemporales en las que tradicionalmente se ha movido la comunicación.

Todo esto está planteando nuevas formas de interacción humana que se traducen en encuentros bien sea virtuales o bien sea presenciales, con mayor frecuencia de lo habitual y de más alta calidad. [Pérez, M. M.; 2007]

Cuando hablamos del profesor nos estamos refiriendo a alguien que se sumerge en el complejo mundo del aula para comprenderla de forma crítica y vital, implicándose afectiva y cognitivamente en los intercambios inciertos, analizando los mensajes y redes de interacción, cuestionando sus propias creencias y planteamientos proponiendo y experimentando alternativas y participando en la reconstrucción permanente de la realidad escolar. [Schön, 1992].

Las nuevas tecnologías dentro de EVTC (entornos virtuales de trabajo colaborativo) permiten realizar el seguimiento de la interacción de los estudiantes en el trabajo colaborativo en un nivel antes desconocido para los docentes. Además, es hasta posible que los espacios de trabajo se encuentren disponibles de manera ubicua para los estudiantes, de ahí el nuevo significado que cobran los roles dentro de una tarea compartida y la forma en la cual el docente puede indagar el nivel de colaboración para el grupo bajo análisis. El primer grado de visibilidad es la participación de cada miembro dentro de un entorno y la cantidad de interacciones.

Siguiendo a Arango, es posible encontrar algunas recomendaciones para el moderador de este tipo de entornos. Dice: es recomendable que el moderador mantenga el impulso del diálogo hacia nuevos terrenos, mantenga las ideas importantes en primer plano y ayude a que los participantes sean conscientes del potencial no visto del trabajo y de sí mismos. El moderador intenta explorar tensiones o bloqueos conceptuales, identificar suposiciones o barreras respecto a conceptualizaciones nuevas, abordar los asuntos desde diferentes ángulos. Al buscar tensiones, debe explorar los motivos existentes para las creencias, sin asignar valor._[ Arango, M. L. 2003] 
Dado que el presente trabajo se instala en entornos digitales de trabajo colaborativo, se estudiará en profundidad el proceso de aprendizaje con ordenadores para realizar actividades o tareas concretas que representen el desarrollo de una habilidad curricular y socialmente relevante. Por esta razón, se abordará el estudio de grupos colaborativos dentro de clases virtualizadas con diferentes recursos educativos tanto informáticos como de red e intentando aprovechar su potencial.

\subsection{El proceso de observación}

Una correcta observación de la dinámica grupal suele ser un elemento insustituible [Meddley y Mitzel, 1963; Rosenshine, 1973; 1986] pero dado que en el trabajo colaborativo, mediado por la tecnología, el elemento observable se ha de ponderar y registrar por otros indicadores que han de representar los elementos que hacen al entorno virtual, de ahí que la distinción entre observación sistemática y no sistemática engloba otras distinciones efectuadas por diferentes autores:

- Sistemática u ocasional [Reuchlin, 1969]

- Metódica o común [Ranzoni, 1968]

- Sistemática o al azar [“haphasard or opportunistic";Mouly,1963]

- Estructurada o no estructurada [Weick,1968]

Primer significado: "Observar es un proceso que incluye la atención voluntaria y la inteligencia, orientadas por un objetivo terminal u organizador, y que está dirigido sobre un objeto para obtener de él información" [De Ketele, 1980]. Observar es situarse delante (prefijo "ob") de un objeto como esclavo o siervo (primer significado de la raíz "serv") para serle fiel y, a la vez, como maestro para poseerlo o conservarlo (segundo significado de la raíz "serv"). Observar a alguien es proyectar una mirada sobre él, es tomarlo como objeto. Es un proceso que tiene por función primera o inmediata la de recoger información sobre el objeto considerado en función del objetivo organizador. Este proceso supone una actividad de codificación; la 
información bruta seleccionada es traducida gracias a un código para ser transmitida a alguien.

Segundo significado: "Conforme a lo que está prescrito" (ponerse en posición de siervo ante la ley. Así se habla de observancia: se vigila, se observa a alguien frente a la regla para hacerle una observación (advertencia) [De Ketele \& Roegiers, 1995].

Es en este contexto, que algunos de los procedimientos de investigación asumidos desde sus orígenes como cuantitativos y por lo mismo, supuestamente objetivos respecto a su aplicabilidad y resultados, han sido reconsiderados como herramientas útiles y adaptables a los fines de los estudios cualitativos [Cáceres P.,2003]

Consideramos el análisis didáctico como un proceso metodológico que, partiendo de la observación directa de una situación de enseñanza y aprendizaje y con el apoyo de conocimiento teóricos, busca atribuir significado, explicar, interpretar los fenómenos que en dicha situación acontecen.

El análisis tiene siempre una doble apoyatura en la teoría y en los hechos y es a partir de la relación dialéctica entre ellos que se constituye un conocimiento didáctico. Proponemos como metodología de análisis los siguientes pasos:

1) La visión o lectura global de la situación a analizar.

2) El análisis propiamente dicho mediante la construcción de fundamentadas en la teoría y apoyadas en los datos empíricos;

3) La reconstrucción de los significados de la situación a partir de la confrontación de las hipótesis para una síntesis.

4) La elaboración de alternativas de acción que se desprendan del análisis y que tiendan al mejoramiento de la enseñanza.

La observación y el análisis didáctico son herramientas fundamentales para comprender y mejorar las prácticas pedagógicas. Por lo tanto, resulta fundamental que los docentes se formen en estas prácticas. En el caso del trabajo colaborativo desarrollado con tecnología informática, la posibilidad de visibilizar eventos de interacción es de gran valor para acompañar esta formación. 
Todo profesor es consciente de que hay una gran diferencia entre unos cursos y otros. $\mathrm{Y}$ es frecuente que se comente entre compañeros: "Es un curso extraordinario", "Están interesadísimos", "Participan mucho", etc. O bien se diga que es un curso "apático", "problematizado" con subgrupos, difícil de ser implicado en las tareas, etc. Y quien habla de cursos puede hacerlo de la misma manera de cada alumno como individuo, por lo menos a los pocos días de iniciado el curso.

La cuestión está en hacer explícita esta información-opinión, contrastada con otros datos sobre la situación de los estudiantes recogida directamente de ellos o bien indirectamente a través de quienes ya les conocen. Y después saber utilizar toda esa información para adecuar a ella los propósitos, estructura y dinámica de la programación [Zabalza, M. A .1987]

La evaluación del aula puede tener un impacto en el rendimiento y la motivación de los estudiantes. En su reseña, Crooks citó pruebas de que la evaluación puede proporcionar estudiantes con conocimiento de los resultados retroalimentación correctiva, ayudar a los estudiantes a propio progreso e influir en la continuidad de la motivación y sus percepciones de su autoeficacia como aprendices. [Crooks, T. J. 1988].

\subsection{Análisis de Redes Sociales}

La sociometría es la técnica que investiga el índice de centralismo, canales de comunicación y vivencias dentro de un grupo humano. Fue creada por el psiquiatra Jacob Levy Moreno (psiquiatra americano nacido en Bucarest, Rumania, 1889-1974), y continuada por otros, cómo Harrison C. White, que han inspirado trabajos, en dicho campo, entre los que se observan los de Liton C. Freeman, Katherin Faust, Stanley Wasserman, entre los más destacados.

Entre las técnicas desarrolladas en esta disciplina se encuentran los test sociométricos y de percepción sociométrica, cuyo objetivo es el estudio sistemático de las propiedades psicológicas de la población, poniendo en acción una técnica experimental fundada sobre métodos cuantitativos. 
Jacob-Levi Moreno (1889-1971) describió la sociometría. Sostiene que las personas están conectadas por tres posibles relaciones: simpatía, antipatía, indiferencia. Dentro de un grupo, estas relaciones pueden medirse mediante un cuestionario, y la tabulación revela las relaciones socio-afectivas y la cohesión grupal. La representación gráfica de estos enlaces se denomina sociograma. Por lo tanto, tratan de darnos una demostración describiendo el concepto de grupo y las varias formas encontradas. Nos dan una cronología de la investigación, teorías y métodos que permitieron la comprensión de los grupos de una manera psicológica. A continuación, informan

de los fenómenos de los grupos que encontramos (poder, estructura, comunicación, interacción, afectividad) y finalmente relacionar los campos de aplicación (dinámica de grupo comparada, círculos profesionales - formación, psicoterapia grupal). [Anzieu, D., Martin, J. Y. 1968]

La mayor diferencia entre un dato convencional y un dato de una red es que en el convencional el dato esta su foco puesto en los actores y sus atributos, en cambio en los datos obtenidos de una red, el foco está entre sus actores y las relaciones del mismo. Esta diferencia pone énfasis en las consecuencias de los cambios que se han de detectar y decidir la interpretación de los mismos, un ejemplo de ello son las interacciones entre sus participantes, desarrollar un instrumento de medida y manejar los datos obtenidos. Estos datos, no son simplemente un análisis de lo que representa una red, sino el impacto social dentro de un grupo que puede determinar diferentes características de los participantes.

La capacidad de trabajar juntos de manera efectiva en equipos, dentro de las comunidades profesionales y comunicarse eficazmente con colegas, se considera generalmente como crítico para el éxito tanto vocacional como personal.

Teniendo en cuenta empíricamente el efecto de participación en entornos de CSCL Bodemer y Dehler [2011], en su análisis, priorizan la importancia de investigar el desarrollo de análisis de grupos (GA) para mejorar los procesos de colaboración en CSCL, así como el impacto esperado en el logro de los objetivos de aprendizaje, 
tanto individualmente como en grupos. Al mismo tiempo, la participación en las actividades de aprendizaje por parte del estudiante genera un impacto positivo en el desarrollo de la GA, lo que a su vez debería mejorar los resultados de las tareas colaborativas.

En el mismo sentido, la visualización de la participación también se puede utilizar para discutir el funcionamiento y / o cómo se pueden mejorar los procesos del grupo [Bodemer, D., Dehler, J., 2011]

\subsection{Sociometría como Herramienta de Observación de Roles}

La sociometría es la técnica que investiga el índice de centralismo, canales de comunicación y vivencias dentro de un grupo humano [Freeman, 2004].

Entre las aplicaciones en el campo educativo podemos citar el trabajo dentro de educación inicial realizado por Bastín (1966), en el nivel primario por Leibovich (1980), por Pérez-Alvarez (1991) en el primario / secundario; los cuales por el proceso que se despliega son utilizables con una tabla de interpretación de resultados, aplicable al ámbito colaborativo no presencial y asincrónico. Las técnicas sociométricas se utilizan para descubrir cuáles son los roles de actores de la dinámica de un grupo de trabajo, tales como: líderes, marginados, rechazados, normales, entre otros.

Es un problema abierto poder determinar este tipo de roles en grupos que interactúan mediados por tecnología informática, sean grupos áulicos o de trabajo mediados por un entorno virtual.

En los entornos virtuales el vínculo socializador se da a través de las interacciones [Rodríguez y Garcia Martinez, 2012]. Luego, las relaciones todo-partes y partes-todo quedan determinadas por el flujo de las interacciones, esto es consistente con el hecho que los sistemas no se constituyen de "partes" o de "constituyentes", sino de acciones entre unidades complejas, constituidas a su vez por interacciones [Morin, 1980]. Con inspiración en técnicas sociométricas como el test de Bastín (1966) y 
Leibovich (1980), surge el interés de desarrollar técnicas sociométricas para grupos de desarrollo de proyectos mediado por EVTC.

El trabajo se encuentra orientado a desarrollar instrumentos de análisis que pongan en evidencia la estructura subyacente del grupo mediado por EVTC, permitiendo plantear hipótesis con base cuantitativa sobre preferencias y rechazos de los individuos entre si y en relación a la tarea colaborativa [Cirigliano \& Villaverde, 1966].

\subsection{Los Entornos Virtuales de Trabajo Colaborativo}

En la actualidad la "tele-formación" se lleva a cabo en "aulas virtuales", entornos caracterizados por la flexibilidad e interactividad que facilitan los recursos de información y los medios de comunicación como son el correo electrónico, los foros de discusión, chat; permitiendo superar las barreras de tiempo y espacio, creando así un nuevo ámbito de enseñanza y aprendizaje a distancia, o como complemento de la enseñanza áulica.

Si bien podemos realizar algunas analogías, cuando hablamos de virtualidad no podemos cometer el error de intentar reproducir miméticamente lo mismo que hacemos en la presencialidad.

En las aulas virtuales los tutores y alumnos interactúan entre sí y acceden a los contenidos utilizando herramientas de información y medios de comunicación web.

La tecnología pedagógica principal utilizada en la enseñanza en línea es el aprendizaje cooperativo, Tiffin y Ragasingham (1997) plantean el aprendizaje cooperativo como un proceso de aprendizaje que enfatiza el grupo o los esfuerzos colaborativos entre profesores y estudiantes. Destacan la participación activa y la interacción tanto de estudiantes como profesores. El conocimiento es visto como un constructo social, y por tanto el proceso educativo es facilitado por la interacción social en un entorno que facilita la interacción, la evaluación y la cooperación entre iguales. 
Dentro de las actividades en un EVTC las claves metodológicas de la formación es el aprendizaje colaborativo, por lo que las actividades son el punto central de un modelo formativo interactivo, flexible y autónomo. El docente/tutor se convierte en facilitador y dinamizador y los participantes asumen la responsabilidad de su propio aprendizaje. Dada su importancia didáctica y educativa, el aprendizaje se basa en actividades de grupo, en las que se da una interdependencia positiva entre sus miembros, es decir, que se necesitan unos a otros. Cada miembro del grupo es responsable no sólo de su aprendizaje sino también del de sus compañeros.

- Cada miembro del grupo tiene la responsabilidad de aportar su trabajo al producto final, por lo que se requiere de la implicación activa y la responsabilidad individual de todos los componentes del grupo.

- El liderazgo del grupo es compartido, todos los miembros tiene un papel fundamental y una función o rol dentro del grupo.

- El aprendizaje colaborativo requiere destrezas y habilidades sociales de comunicación y negociación necesarias para la organización y desarrollo de las tareas en grupo.

- El docente/tutor es un facilitador de los procesos de organización y funcionamiento de los grupos de trabajo y un dinamizador de su actividad autónoma.

- Los grupos se establecen favoreciendo la diversidad y heterogeneidad de sus miembros en todos los aspectos, para que el aprendizaje sea más enriquecedor.

El docente/tutor no es la única fuente de información y conocimiento, sino que promueve actividades de búsqueda de nuevas fuentes y recursos. 
Las actividades de aprendizaje se centran en la experimentación, la búsqueda y evaluación de información, la discusión y la resolución de problemas en grupo, es decir, en actividades que implican "aprender a aprender", más que la consolidación de un conjunto de conocimientos ya elaborados.

La utilización de estrategias de aprendizaje colaborativo en la formación a dentro de un entorno virtual o a distancia ha demostrado, en distintos ámbitos educativos, tener ventajas considerables respecto a otros tipos de metodologías más individualistas y directivas.

Según Hernández Contreras, Amezcua Alcantar y Vega de la Garza (2012), éstos son algunos de los beneficios que proporciona a los participantes el aprendizaje colaborativo:

- Favorece la capacidad de resolver problemas de forma creativa, a partir de estrategias de negociación y mediación y la búsqueda cooperativa de alternativas.

- Proporciona oportunidades para aprender a "ponerse en el lugar de otros" y genera empatía hacia los compañeros. No sólo se aprenden conceptos, sino también actitudes y valores.

- Genera un clima de aprendizaje basado en la distribución equitativa de roles, el respeto, la participación y la cooperación.

- Proporciona oportunidades de éxito a todos los participantes, por lo que mejora el rendimiento y la autoestima que, a su vez, repercute en una mayor seguridad y compromiso con el grupo.

- Mejora las relaciones interpersonales en grupos heterogéneos, puesto que la diversidad se valora positivamente. Permite reducir estereotipos y prejuicios entre distintos grupos socioculturales, ya que los compañeros son percibidos como fuente de aprendizaje y no como competidores para alcanzarlo. 
- Mejora la motivación y las actitudes hacia la materia de estudio, hacia la figura del docente/tutor y hacia la función de la institución formativa.

- Favorece estrategias y procesos mentales de alto nivel que suponen un reto tanto intelectual, afectivo como conductual para el participante.

Según Sales Ciges, A. (2009) cualquier docente/tutor que se decida a desarrollar estrategias colaborativas en sus cursos debería considerar los siguientes aspectos:

- La construcción y organización de los grupos es un punto clave para su posterior funcionamiento: debemos asegurarnos de que los participantes no sólo desarrollan las actitudes y valores adecuados para el trabajo colaborativo, sino que también reconocen y tienen en cuenta sus propios procesos internos y hacen los ajustes necesarios. En ocasiones el trabajo en grupo no funciona por la falta de habilidades y estrategias de comunicación y negociación de sus miembros.

- Es conveniente garantizar un periodo de rodaje y habituación a la dinámica en grupo hasta que éste adquiere seguridad y autonomía en su funcionamiento.

- Puede que el docente/tutor plantee la metodología de su curso basándose en el aprendizaje colaborativo, es decir, proponiendo a los participantes actividades a realizar en equipo. Sin embargo, acostumbrado a dirigir y controlar su trabajo, se puede convertir en una actividad demasiado directiva bien porque el docente/tutor estructure en exceso el tipo de tareas o bien porque intervenga con demasiada frecuencia en la organización interna del grupo. Por otro lado, 
se puede interpretar como una resta de autonomía al grupo y por otro, los participantes pueden llegar a percibir que no se confía en ellos y que se valora poco el trabajo colaborativo.

- Es conveniente dar pautas de organización y tareas en un principio, tratando de dar una autonomía progresiva al grupo de aprendizaje.

- Trabajar en grupos colaborativos heterogéneos significa atender de forma positiva la diversidad, así pues, el docente/tutor tendrá especial cuidado en evitar posibles prejuicios y estereotipos hacia los participantes y entre ellos mismos. En muchas ocasiones, y de manera inconsciente, se transmiten en nuestros comentarios y valoraciones de su trabajo expectativas negativas hacia determinadas personas, lo que influye negativamente en su participación y motivación respecto al grupo y a la tarea a realizar.

- Es conveniente valorar la aportación de todos los miembros del grupo y animar a pedir ayuda a los demás cuando se necesite.

- Puede ocurrir que el docente/tutor, tratando de favorecer la autonomía del grupo en su organización, prefiera dejar que sean sus propios miembros quienes generen sus propias funciones y normas internas para trabajar. Pero si los participantes no se conocen bien o están poco habituados a trabajar en grupo pueden tener serias dificultades para iniciar la actividad y el bloqueo inicial puede desorientarles demasiado y desmotivarlos.

- Para garantizar el funcionamiento eficaz y la participación de todos los miembros del grupo es conveniente establecer roles específicos dentro del grupo, de manera que se distribuyan 
equitativamente las tareas $\mathrm{y}$ todos cumplan un papel importante en el equipo.

En este sentido, cobran relevancia las estrategias didácticas de intervención docente tanto en los materiales como en el servicio tutorial-, desde las nociones de mediación simbólica y relacional, generando espacios educativos en una distancia transaccional óptima que resignifica el proceso de comunicación con la integración de las TIC. Las nuevas tecnologías han dado origen a nuevas formas culturales, nuevos modos de conocer y nuevas formas de aprender. Sin embargo, la relación pedagógica sigue y seguirá siendo insustituible.

Ya no hablamos de distancia física sino psicológica y simbólica sustentada en la interacción comunicacional y el enorme potencial que los desarrollos tecnológicos nos aportan.

Esta visión compromete a una enseñanza concebida no solo como mediada y mediatizada, sino también distribuida y colaborativa, en la que toda la organización se integra en la enseñanza desde sus diversos subsistemas.

Es concebir coherencia e integración entre la propuesta de los materiales didácticos, el servicio docente/tutorial y los soportes comunicacionales poniendo el acento en las intervenciones didácticas, potenciando espacios para la construcción y coconstrucción de conocimientos a través de estrategias que generen nuevas orientaciones, nuevas competencias y fundamento para la elaboración de criterios en la autogestión de los aprendizajes y la regulación del propio ritmo de avance [Rossa de Riaño, María Beatriz; Gallino, Mónica; Singeser, Olga 2002].

La función del docente/tutor se ve facilitada gracias a las nuevas tecnologías de comunicación. Las nuevas tecnologías han dado a los EVTC y a la EAD herramientas innovadoras, capaces de producir fuertes modificaciones prácticas y operacionales en la capacitación. 
En los últimos años, con el uso de la tecnología, ha empezado a surgir nuevos ambientes de aprendizaje, que son una forma diferente de organizar la enseñanza y el aprendizaje presencial y a distancia. Estos ambientes consisten en la creación de una situación educativa centrada en el alumno, que fomenta el autoaprendizaje, el pensamiento crítico y creativo y el desarrollo como individuo mediante el trabajo en grupo cooperativo y el empleo de tecnología [Álvarez, Margarita María 2007].

El diseño de los nuevos ambientes de aprendizaje se impone por las características de la posmodernidad y propician una formación de más calidad, ya que pretenden desarrollar habilidades cognitivas, psicomotoras, afectivas y sociales. Se hace hincapié no sólo en el aprendizaje sino también en el desarrollo del individuo.

El tutor posibilita el diálogo didáctico mediatizado. La tutoría es el nexo interactuante entre la organización general y los alumnos, capaz de captar las expectativas, necesidades, intereses y reacciones, y de intervenir en el proceso de retroalimentación académico y pedagógico [Mena, 2005].

\subsection{La sociometría y su campo de acción}

El estudio de las redes sociales, se encuentra enmarcado básicamente por cuatro tópicos, los cuales son:

- La intuición de una estructura

- Un dato relacional sistemático

- Un conjunto de imágenes-gráficos (del entorno)

- Un modelo matemático o computacional

Dentro de la sociología no podemos dejar de mencionar a Augusto Comte, como el precursor de dicha especialidad, dentro de sus escritos, el hecho del cual "la observación de un elemento no real de cualquier especie de fenómeno es posible, 
excepto que por más lejano sea su primer foco, y finalmente interpretado por alguna teoría", y sobre la observación, la importancia en los fenómenos sociales [Martineau, 1853/2000, v. II, p. 181].

Dentro de la sociología, la sociometría como disciplina, tiene su punto de partida a comienzos del siglo XX y está determinado por Moreno en 1934, desde el surgimiento de ideas de Moreno-Jennings sobre los grupos y los posicionamientos de los participantes en el mismo, sus aproximaciones han sido esencialmente estructurales, es decir mostrar las relaciones insospechadas de sus participantes.

Moreno escribió dos libros, "Quien podrá sobrevivir?” y "Liderazgo y aislamiento", en ambos no se debe dejar de lado la importancia de Jennings. Moreno no tenía la capacidad y dedicación a la investigación, no le interesaba la investigación sistemática, pero no lo era el caso de Jennings.

Moreno no hace alusión solamente al concepto de redes, sino también a "los efectos entre dos personas y su grupo inmediato", como una interacción de pares.

Otra investigación enfocada en la estructura social fue realizada por Harvard en 1920, centrada en la escuela de graduados de Administración y Negocios. En dicho estudio participaron un gran número de facultades, dicho estudio está basado en los trabajos de Warner, quien se llamaba a sí mismo "W. Lloyd Warner".

En el año 1925 se recibió de antropólogo, y en la universidad de Berkeley se encontró con dos antropólogos, Robert Lowies y el británico Alfred Reginald RadcliffeBrown, quién se encontraba momentáneamente en Berkeley, de su viaje de Oxford a la Universidad de Sydney. Warner viajó luego a Sydney y por consejo de RadcliffeBrown se dedicó al estudio del grado de parentesco de las comunidades. Dicho estudio le permitió a Warner la utilización de dichos métodos en comunidades industriales, lo que implementó en el estudio realizado en Harvard. 
Esto generó una investigación orientada a las redes interpersonales, los datos recolectados fueron de varios años y de muchos graduados, dicha información le permitió realizar diagramas jerárquicos y de grupos, en donde se apreciaba el estatus social de los participantes.

Luego de un conjunto de investigadores, en la década del 60 y 70' Harrison White, en los cursos y seminarios de grado sobre temas como estratificación, modelos matemáticos y organizaciones complejas, produce una importante serie de documentos de modelados con la compañía de sus alumnos. Los modelos que desarrollo, con afinidad a modelos físicos, tienen gran importancia en el paradigma del análisis de redes sociales, dentro de los cuales se encuentra el modelo CONCOR, denominado así por "convergence of iteracted correlations/convergencia de correlaciones de iteracciones".

Claramente, la universidad de Harvard durante dicho período bajo la estimulación de dichos estudios, ha sido el centro de investigación sobre las estructuras sociales. Abbott en 1994 ha hecho la mención sobre White y sus trabajos como "un hombre que comenzó la revolución social introduciendo nuevas técnicas y capacitó a un grupo de brillantes alumnos en dicha disciplina" [Freeman,L ; pag:127, 2004].

Los trabajos en sociometría han evolucionado en éste último período gracias a modelado y elementos de cálculo que no se encontraban disponibles en otros momentos.

El siguiente trabajo de recopilación de información está basado en la visión de los entornos virtuales de trabajo colaborativo a los cuales se le aporta la detección de las relación de los participantes y su eventual apoyo didáctico con intervención en el factor pedagógico (que es el de mayor grado de vulnerabilidad) por no encontrarse 
presente el responsable del curso "observando" la tarea asignada a los participantes del grupo en cuestión.

Dentro del análisis de los roles, “...el análisis de las experiencias y propuestas ha mostrado una gran dispersión en cuanto a descripción y caracterización de roles.

El lenguaje natural empleado en estos casos para definir un rol, con sus obligaciones y necesidades no ayuda a una posible interpretación compartida por la comunidad CSCL (Computer Supported Collaborative Learning), sino más bien al contrario, la dificulta. Por otro lado, el reconocimiento del dinamismo del aprendizaje implica tener en cuenta los posibles cambios de rol que puedan producirse en la práctica real, así como las variaciones en cuanto a obligaciones o necesidades de un participante o un grupo que desempeña un rol. Sería muy interesante que un sistema pudiera estar al tanto de estas variaciones, para poder responder automática o semiautomáticamente a las mismas. Si durante el desarrollo de una actividad colaborativa, un alumno empieza a comportarse según un rol no deseado, el profesor o el sistema deberían ser informados para reaccionar de forma que se pueda corregir dicha situación.

El objetivo de detectar cambios en el comportamiento de las personas que están desempeñando un determinado rol nos lleva a la necesidad de analizar las tareas, el proceso o los contenidos de la colaboración, para poder conocer si estos cambios se están produciendo, o bien si un participante al que se le ha asignado un rol al comienzo de una actividad dada se comporta o no de acuerdo a ese rol..." [García, J., pág 46, 2012].

Dentro de los modelos que se analizan, es compleja la taxonomía de los distintos roles que se pueden presentar en el grupo, de ahí la importancia del seguimiento de las relaciones que se producen por las interacciones de los mismos. Sin tener la asignación de roles como premisa. 
Dichos modelos permiten inferir determinadas conductas de los participantes, que en distintos análisis presentan las desviaciones de conductas previamente fijadas y su consiguiente grado de subjetividad al determinar cada rol.

“...Para que este análisis pueda realizarse de forma automática o semiautomática sería necesario crear un marco o una estructura capaz de plasmar las descripciones de los roles de tal forma que sean manejables computacionalmente. Esto permitiría diseñar herramientas capaces de realizar los análisis de roles y avisar a los usuarios de los cambios o variantes que les puedan interesar. Una caracterización formal y sistemática de estas características permitiría automatizar el apoyo a los roles involucrados, así como la posibilidad de detectar sus transiciones..." [García, J.,pág. $46,2012]$.

De ahí la detección de conductas más que el desvío de los roles pre-asignados “...Algunos roles están asociados a tareas específicas, por lo que sus definiciones son muy concretas en cuanto a obligaciones y necesidades. El nivel de granularidad al que están definidos es tan detallado que posiblemente las contestaciones a nuestras preguntas pasarían por desarrollar una solución propia para cada caso o para un grupo reducido de casos similares..." [García, J., pág. 46, 2012].

Dentro de la interpretación y evaluación de los bloques de modelos, realizado por Faust y Wasserman (1992), podemos apreciar dos nociones, por un lado la posición social y por otro el rol.

“...Los bloques de modelos son hipótesis acerca de la estructura de una relación dentro de una estructura social. A través de los bloques de modelos pueden aparecer relaciones de patrones que pueden presentar una propiedad estructural..." [Faust, K. \& Wasserman, S .1992. pág 15] 
“... el análisis de un conjunto de datos de una red social es asumida por una estructura de rol dentro del grupo y la posición de los individuos dentro del grupo..." [Faust, K. \& Wasserman, S .1992.pág 5]

“...hay dos elementos esenciales del análisis de redes sociales, la posición y el rol dentro del grupo; identificando la posición social como el conjunto de participantes que tiene el mismo grado de relación con otros pares, y el modelo social de rol como un sistema de relaciones sobre los participantes o la posición (status)..." [Faust, K. \& Wasserman, S .1992. pág 6]

“...uno de los caminos más sencillos para interpretar los bloques de modelos es por medio de los atributos de los participantes que describen su posición. Si hay una diferencia sistemática entre la posición y la característica de los participantes, entonces se ha de validar externamente...” [Faust, K. \& Wasserman, S .1992. pág 31]

La posición dentro del grupo, en un entorno social ha de determinar una de las características, la de líder o marginado, entre los participantes del grupo.

“... existen dos aproximaciones para evaluar lo bien que funcionan los bloques de modelos $\mathrm{u}$ otra representación matemática del promedio de un conjunto de participantes, uno de ellos es basado en un formato descriptivo y otro de ellos es más estadístico, y ciertamente más paramétrico...” [Faust, K. \& Wasserman, S .1992. pág 43]

Analizando el concepto de centralidad en redes de afiliación (participativas), Katherine Faust enuncia “...muchas relaciones en redes sociales consiste en enlaces entre personas que participan en una actividad social o son miembros de una 
colectividad. Por lo tanto, el conjunto de participantes de dicha red contempla dos elementos, el conjunto de participantes y el sub conjunto de datos que aparecen entre los participantes, denominados "eventos". [Faust, K. \& Wasserman, S .1992. pág 12]

El concepto de "centralidad" lo podemos definir como liderazgo dentro de un grupo bajo análisis, porque Faust (1997) considera la actividad dentro de la red, si otros participantes recurren a dicho participante para contactarse con otros, si el resto de los participantes intercambian comunicaciones con el líder.

En general la noción de centralidad va acompañada por un número de diferentes aspectos de los participantes dentro de la red, que hacen a la tarea en muchos casos del líder, como es la "importancia" o la "visibilidad".

Freeman (1979) presenta tres conjuntos de índices para formalizar la idea de centralidad (líder) una de ellas es el grado/actividad, la cercanía y la empatía de participante.

Las relaciones que se deben también tener presente son aquellas que se den en el marco de los denominados participantes primarios y secundarios. Interpretando a los primeros como el líder del grupo y aquellos que producen los eventos comunicacionales cuando el líder genera la participación en el grupo.

En el caso de estudio realizado por Martha Daugherty y Jeff Turner (2003) sobre las implicancias de los aspectos sociométricos dentro de la evaluación de dinámicas en entorno web, utiliza un sistema de relevamiento de datos que surge de una encuesta, la cual consta de 13 preguntas que han de ponderar los participantes y en base a la misma desarrollan el estudio estadístico. 
El desarrollo del método utilizado por Daugherty y Turner basado en principios estadísticos y corrimientos del valor medio difiere del método propuesto, en dos aspectos, el primero, consiste en el relevamiento de datos que es producido por cada participante respecto al grado de afinidad con el resto de los participantes y segundo, la forma del el análisis de los mismos.

Referido a la recolección de datos, ésta propuesta está basada en el grado de interacciones de cada participante, con ello permite "observar" el nivel de actividad que surge de cada uno de los participantes.

Un breve repaso de los objetivos de la sociometría y de los trabajos de investigación que ha suscitado nos dicen que:

Pretende medir el grado en que los sujetos son integrados en la estructura preferencial del grupo, las relaciones interpersonales existentes entre los individuos y las estructura del grupo.

- Como técnica de análisis consiste en preguntar a cada sujeto a qué miembros del grupo preferiría para compartir determinadas situaciones o para colaborar en ciertas actividades específicas.

- Los criterios de elección utilizados incluyen por lo general, distintos aspectos de asociación preferencial: tareas, diversión, intimidad, etc.

- El número de preguntas varía entre 1 y 8 o más, en función de los objetivos del análisis.

- El número de preferencias manifestadas por cada sujeto puede ser fijo $(1,2$, $3, .$.$) o variable según los objetivos del análisis.$

La confiabilidad y la validez de las aplicaciones sociométricas han sido muy investigadas. 
Según Cornejo, J (2003) de los resultados más significativos indican que:

- las correlaciones entre items pares-impares (Coef. de Correlación de Loeb) oscilan entre $\mathrm{r}=.65 \mathrm{y} \mathrm{r}=.85$

- Loeb split-halves: $\mathrm{r}=.53$ a .85

- Northway, utilizando criterios generales: $\mathrm{r}=.64$ a .84

- Northway, utilizando un criterio de habilidades: $\mathrm{r}=.37$ a .50

- La correlación entre puntuaciones en diferentes momentos: $r=.74$

- Constancia en la elección al cabo de un tiempo r=.69

- La correlación entre elecciones sociométricas repetidas al cabo de 8semanas arrojaron valores entre $r=.76$ y .89

- La comparación con el juicio de los profesores fue de $r=.59$

Etimológicamente, sociometría significa la métrica de lo social, en un sentido amplio y dinámico. Como orientación teórica [González M.P. y Vendrell, E. 1988] se separa tanto del psicoanálisis como de la teoría marxista, desarrollando una microsociología basada en la acción espontánea y creativa de los sujetos.

Como actividades terapéuticas de acción social, engloba un conjunto de técnicas ideadas por J.L. Moreno en torno a la teoría del rol: el test del primer encuentro, el test sociométrico, el test del rol, el test de la interacción, el test de la espontaneidad, el psicodrama, el sociodrama, el diario hablado a varias voces y la película cinematográfica terapéutica.

En un sentido más específico, la Sociometría se refiere al estudio matemático de las redes de interrelación entre los componentes de un grupo o colectividad.

La Sociometría así considerada, tiene por objeto el estudio matemático de las propiedades psicológicas de los grupos y consiste en medir la red de atracción y 
repulsión observada entre los individuos que componen un grupo. Desde un punto de vista metodológico, consiste en presentar de modo sencillo y gráfico toda la estructura de relaciones que existe en un momento dado entre los componentes de un cierto grupo, sus principales líneas de comunicación y sus pautas de elección o de rechazo.

Moreno sitúa al hombre en su doble perspectiva individual y relacional. En lo individual, el núcleo es la acción espontánea y creativa. En lo relacional, su concepto de 'tele' estructura el campo grupal. La integración entre individuo y grupo en la conducta se realiza a través de los roles.

No se limita sólo a observar y medir, considera la sociometría como una terapéutica de la vida social en dos momentos, diagnosticar las estructuras sociales y transformarlas. Es simultáneamente una ciencia y una práxis (la sociatría), tendiente a reorganizar la vida social hacia formas y estructuras organizacionales satisfactorias para el desarrollo colectivo e individual.

La Sociometría ha planteado de manera general la posibilidad de operacionalizar el análisis del concepto dinámico de 'interacción entre los elementos de un sistema' cualquiera que éste sea. A través de la ideación de las matrices sociométricas (elementos $\mathrm{x}$ elementos) se da expresión a la noción de contexto grupal y se posibilita el análisis de los flujos de relación que estructuran el grupo.

El espacio de interacción puede representarse por la estructura relacional $\mathrm{S}=\{\mathrm{H}$, $\mathrm{R}, \mathrm{E}$ \} [Bunge, 1981] donde $\mathrm{H}$ es un conjunto definido de individuos, $\mathrm{R}$ es un conjunto definido de relaciones entre los miembros de $\mathrm{H}$ y $\mathrm{E}$ es el medio en el que éstos interactúan. Se trata por tanto en el sociograma de captar una totalidad concreta analizable en su composición H, en su estructura R y en su medio E. [Cornejo J., 2003] 


\subsubsection{Principales leyes sociométricas}

1. Ley de la gravitación: los grupos humanos forman una unidad orgánica y social. Las diferentes partes de esta unidad se sienten atraídas o rechazadas entre sí por distintas tendencias y fuerzas.

2. Ley socio-dinámica: dentro de cada grupo, las elecciones se distribuyen de forma desigual entre los miembros del grupo. Estas diferencias se acentúan cuanto mayor es el grupo.

3. Ley del átomo social: a medida que los integrantes de los grupos proyectan entre sí sus emociones, aparecen pautas de atracciones y de rechazos que permanecen relativamente constantes dentro del grupo. El átomo social es el individuo tomado como foco de la red de interrelaciones. [Cornejo, J., 2003]

\subsection{La sociometría y los formatos de interacciones}

Dentro de los trabajos realizados sobre aproximaciones en planeamiento y conducción de encuentros virtuales encontramos a Wang, Haake y Rubart (2002, 2004) donde se enfocan en la implementación de una plataforma/herramienta con las características fundamentales que consideran sobre los encuentros virtuales (virtual meeting).

Dentro de la conceptualización trabaja por dichos autores respecto a las características intrínsecas de los encuentros virtuales, definen las necesidades de los mismos y sus características.

“...los encuentros son producidos por acontecimientos de carácter social o de negocios cuando un número de personas se encuentran en un cierto tiempo y espacio con un fin determinado, tal como una discusión o la generación de toma de decisiones..." [Wang,W. , Haake, J. \& Rubart, J. , 2004] 
Un buen encuentro (meeting) debe contar con ciertas premisas para que el mismo tenga resultados satisfactorios:

- Que cuente con una agenda estratégicamente diseñada

- Que sea claro, consensuado para el logro de los objetivos y propuestas.

- Sentido de pertenencia

- Con preocupación en los participantes

- Con un mediador

Basados en estos roles (impuestos) los participantes cuentas con un conjunto de reglas y accesos que se les determinan en el entorno mediante la aplicación de una herramienta informática.

Los encuentros virtuales, como lo plantea el enunciado (virtuales) poseen la característica de realizarse de manera sincrónica o en su defecto asincrónica.

En el primero de los casos se plantea la intersección de las dimensiones temporal y física, siendo ésta última con características particulares. Dicha particularidad es la posición geográfica del participante, que al ser "virtual" denota otro lugar para el encuentro.

En otro aspecto, puede ser asincrónica en el caso de encontrarse geográficamente en el mismo lugar pero con la dimensión temporal fuera encontrarse unificada.

Existe otro caso en donde ambas dimensiones, la geográfica y temporal, ambas se encuentran desvinculadas en el conjunto de los participantes. Ésta última presenta una clara similitud con la educación a distancia, punto que se ha desarrollado en el apartado anterior, con todas las implicancias de dicha modalidad.

Dentro del modelado y elementos que consideran Wang, Haake y Rubart para un proceso cooperativo y exitoso para un encuentro virtual, se encuentran:

- Un especio común para la información con un entorno visual atractivo

- Modelado y control de procesos flexibles de encuentro 
- Integración en la administración de documentos

- Administración de encuentros basados en sesiones y una fácil puesta a punto de aplicaciones distribuidas.

Como se puede apreciar el análisis y estudio de los encuentros virtuales se encuentra fuertemente orientado a los conceptos asociados al software y al hardware, los elementos detallados asumen los roles de los participantes, no realizando un seguimiento de dichos roles dentro de la propuesta cooperativa/colaborativa.

Los roles en dicho estudio se encuentran asignados previamente y la herramienta no cuenta con características que hacen al desarrollo de las interacciones en el conjunto de los participantes.

La herramienta desarrollada por dichos autores cubre ampliamente las características tecnológicas respecto a los encuentros virtuales y la necesidad de interconexión de los grupos de desarrollo en un ambiente globalizado.

Del análisis de dichas herramientas confluyen de dos aspectos el técnico y el social, de éste último aspecto es el más vulnerable. Referido a la dimensión social, se han desarrollado nuevas herramientas con fuerte sintonía en el análisis de las redes sociales (SNA).

Dentro de las interacciones es posible detectar y visualizar las relaciones que se encuentran ocultas dentro de un grupo, las mismas mediante la aplicación de métodos de análisis de redes sociales permiten generar sistemas de soporte colaborativo. Haciendo visible una red informal, dicha red permite una correcta administración y evaluación de los participantes en el ambiente colaborativo [Cross y Borgatti, 2004].

Las organizaciones donde se pone en énfasis la flexibilidad y el ambiente colaborativo, mediante los denominados "trabajadores del conocimiento" es de suma importancia las redes informales dentro de la organización. 
La importancia de la evolución de las redes informales, en muchos casos no solamente permite el crecimiento del capital social individual, sino también el del grupo y de la organización [Coleman, 1988; Burt, 1992, 1997; Hansen, 1999; Podolny y Baron, 1997; Nahapiet y Ghoshal, 1997; Leenders y Gabbay, 1999; Cohen y Prusak, 2000; Lin, 2001].

Pero éstas son de difícil evaluación por el tipo de informalidad de dicha red en la organización. De ahí la importancia que cobra el análisis de las interacciones dentro de los grupos de trabajo.

Las relaciones informales son generalmente invisibles o parcialmente visibles, lo cual determina un problema para los administradores, lo que implica un seguimiento de actividades en las organizaciones de carácter global o en los encuentros virtuales, mientras muchos administradores a menudo piensan que entienden las redes en su entorno, los estudios determinan que puede variar de manera significativa el grado de precisión de dichas redes y sus participantes [Krackhardt, 1987 y 1990; Casciaro, 1998].

Dentro de los procesos comunicativos se han detectado que los participantes tienden a realizar un mayor conjunto de interacciones dependiendo de un conjunto de atributos sociales, los cuales tienden a ser, por ejemplo: raza, género, edad, nivel educativo [Marsden, 1988; Carley, 1991; Ibarra, 1992, 1995; Brass, 1995].

En toda burocracia, el conocimiento se divide en forma horizontal y se reagrupa en forma vertical, éste tipo de disposición mecánica funcionaba apropiadamente cuando los canales de comunicación solamente se mantienen en el formato pre establecido, o denominado "oficial". Una razón que se ha pasado por alto es el porqué las corporaciones japonesas han resultado mejores hasta el momento en los canales informales y su interacción. 
Mientras que las empresas occidentales dependen de su sistema administrativo, el cual ha migrado en la última década, de ser estructurado a un sistema interconectado con formato global (entiéndase dentro y fuera de la organización), las empresas japonesas también cuentas con dichos sistemas, complementado con el sistema informal denominado dokikai.

En una firma japonesa, todos los empleados que se incorporan a ella al mismo tiempo - lo que se denomina "quinta de ingreso" o una "cohorte" - mantienen contacto entre ellos durante toda su permanencia dentro de la organización, en la que van ascendiendo a medida que se van haciendo más veteranos. Al transcurrir tiempo del ingreso a la organización, los componentes del dokikai están distribuidos en diversas funciones y áreas. Esta cofradía, sigue unida y mantiene un fluido intercambio de información. Éstos elementos no se encuentran registrados en muchos casos en el canal formal, por lo tanto, el intercambio o las interacciones que se producen determinan las características de los distintos roles independientemente de los cargos funcionales en la organización [Toffler A.,Toffler H., 1990].

\subsection{Las interacciones en las organizaciones empresariales}

El esquema de una organización basada en la información puede parecer convencional, sin embargo, una organización de ese tipo se comporta de una manera muy diferente y exige un comportamiento diferente por parte de sus miembros. La estructura basada en la información es plana, con muchos menos niveles de administración de los que requieren las convencionales.

La estructura basada en la información hace irrelevante el famoso principio del espacio de control, según el cual el número de subordinados que puede informar a un superior es estrictamente limitado. Poco a poco ocupa su lugar un nuevo principio, al que se tiende a denominar, espacio de comunicación. El número de personas que 
presentan sus informes a un superior es limitado únicamente por la disposición a asumir la responsabilidad de sus propias comunicaciones y relaciones, hacia arriba, hacia los costados y hacia abajo.

Al mismo tiempo la re-estructura basada en la información permite, y en muchos casos exige, muchos más empleados autónomos (por las capacidades con que cuenta, a nivel intelectual y de decisiones), la organización basada en la información se funda en la responsabilidad, el flujo es circular, se lo puede interpretar al igual que una orquesta donde cada uno de los participantes conocen sus destrezas y habilidades, cada uno toca una parte diferente, tocan juntos, pero dentro de una complementación, esta complementación favorece el trabajo grupal y los canales de comunicación deben reflejar el intercambio en el grupo [Drucker,1986].

El nivel de intercambio aporta, si la organización tiene o cuenta con modelos que permiten inferir los tipos de roles en la misma.

Los equipos autoiniciados son aquellos donde el impacto de las interacciones y las nuevas tecnologías cobran fuerza, suelen ser convocados mediante una red interna de la empresa para un nuevo proyecto o en algunos de los casos por iniciativa propia, éste tipo de proyecto tiene la virtud de trabajar en distintos ámbitos y horarios (virtual meeting), por lo tanto cada participante informa los logros, dificultades y trayectoria que tiene en el proyecto con el cual se encuentra involucrado [Toffler A.,Toffler H., 1990].

\subsection{Las modalidades educativas y las interacciones}

Dentro de las modalidades educativas donde tiene alto impacto las relaciones interpersonales y la forma de detectar roles dentro de grupos, los cuales son mediados por tecnología, los de mayor relevancia son los entornos virtuales, con los beneficios y falencias que presenta cada uno de los casos bajo estudio. 
La educación a distancia presenta las características de no presencialidad (espacio geográfico) y temporalidad no compartido, a diferencia de una clase presencial.

\subsubsection{Modalidades educativas y otros conceptos vinculados al uso de TIC en educación}

\subsubsection{Modalidad "blended learning"}

B-learning es una metodología de enseñanza que combina los contenidos elearning de clases virtuales y los de la formación tradicional presencial. Este modelo de formación hace uso de las ventajas de la formación 100\% on-line y la formación presencial, combinándolas en un solo tipo de formación que agiliza la labor tanto del formador como del alumno.

El diseño instruccional del programa académico para el que se ha decidido adoptar una modalidad b-learning deberá incluir tanto actividades on-line como presenciales, pedagógicamente estructuradas.

De acuerdo a Rosenberg (2001) los mejores planes de aprendizaje usualmente reclaman por más experiencias dentro del aula de clase distribuidas de manera que la aplicación, la consejería, el aprendizaje en línea y la integración de nuevo conocimiento con lo que ya se sabe puedan tomar lugar entre los eventos (entre las clases presenciales)

\subsubsection{Instituciones bimodales}

En las instituciones bimodales conviven en una misma institución la modalidad de educación presencial con la educación a distancia (se intenta elevar la calidad de la educación que ofrece la institución).

En este modelo integrado se ofrecen ambas modalidades en igualdad de condiciones, creando sólo un equipo especializado que desarrolla y dirige los cursos. Cada Departamento académico ofrece las dos modalidades en igualdad 
de condiciones. Esto genera una serie de ventajas o beneficios de tipo institucional y políticos:

Económica: racional utilización de los recursos académicos, humanos, administrativos, materiales y de infraestructura que posee la institución.

Democratización educativa: brinda posibilidades a un mayor número del sistema institucional (por ejemplo el universitario) sin trabas ni limitaciones al acceso, solución a la masividad estudiantil, con una mejor atención a los alumnos al descomprimir aulas

- Cuando en una institución coexisten ambas modalidades, la educación presencial y a distancia estamos frente a una educación bimodal. En cambio hablamos de un blended learning, cuando hay una formación conjunta entre la presencial y a distancia determinado por cátedras y no por todo el sistema educativo, quedando cátedras con sistemas mixto (b-learning en algunos de los casos y presenciales en el otro)

\subsubsection{Respecto del proceso de mediación:}

- Según el Dr. Daniel Prieto Castillo (2010) en el texto "Mediación pedagógica y tecnologías", Mediar no significa negar, rechazar en bloque, descalificar a ciegas. Significa ofrecer oportunidades de lectura diferente, recursos para preguntar, espacios para jugar.

- La mediación construye lazos para el aprendizaje desde todos los horizontes de vida y de creación del ser humano. Los ámbitos de mediación son: la búsqueda y selección en el conjunto de las redes para aportar a nuestra tarea, capacitación de los estudiantes para esas búsquedas e investigaciones, valor agregado a la información que incorporamos sobre todo el valor pedagógico, de aprendizaje por parte de los estudiantes, creatividad, comunicabilidad y construcciones hipertextuales y multimediales. 
- Según la Dra. Beatriz Fainholc (1999) en "La interactividad en la educación a distancia", Las mediaciones, aparecen como una subclase del fenómeno de interactividad. Estas constituyen el tratamiento de los contenidos y las formas de expresión y relación comunicativa que posibilitan el aprendizaje a distancia.

- Las tecnologías han dado a la educación no presencial herramientas innovadoras, capaces de producir fuertes modificaciones prácticas y operacionales en la capacitación a distancia. Sin embargo, tales tecnologías no pueden por sí mismas reemplazar a la pedagogía sino que deben subordinarse a su servicio. El texto impreso, comunicacional, etc. cobrará vida en la interacción mediatizada que realiza el estudiante y que desafía la investigación desde el punto de vista del diseño didáctico, la producción técnica, la implementación, etc.

- El aprendizaje a distancia no se puede entender ni explicar, sólo como resultado entre el estudiante y el material, o de los estudiantes entre sí o con el tutor.

\subsubsection{Respecto de los cuidados especiales}

Según Hanna, Donald E. et al (2000) al enseñar en grupos "on line”:

- Cuidar que los grupos no sean numerosos para garantizar contacto y calidad en las interacciones. Un número máximo sugerido por los autores es 5 participantes.

- Ofrecer variedad de estilos de enseñanza y de aprendizaje para tratar de que todos puedan participar cómodamente.

- Tener en cuenta los conocimientos previos de los integrantes, ya sea en cuanto al manejo tecnológico como a los conocimientos de la materia de estudio.

- Estimular el uso de la netiquette para garantizar la armonía en el grupo. 
- Habilitar vías de comunicación informales, un cyber café por ejemplo, que favorezcan la expresión individual y grupal.

- Proponer diversas formas de interacción: alumno-docente, alumno-alumno, alumno-invitado, alumno-herramientas (software), alumno-contenido (información), alumno-entorno (recursos disponibles: bibliotecas).

- Crear confianza y lazos (rapport).

- Impulsar el uso de comunidades de práctica y enfatizar el diálogo.

- Clarificar roles y contribuciones esperadas de los miembros del grupo.

- Alentar que se cumplan los plazos previamente establecidos, ofrecer agendas fácilmente accesibles y siempre disponibles.

- Abrir canales de comunicación con el docente y los demás alumnos. 


\section{DELIMITACION DEL PROBLEMA}

En este capítulo se muestran las vicisitudes que presentan las actividades de seguimiento del alumno o del grupo en entornos virtuales de trabajos colaborativos (Sección 3.1); se identifican diferentes métodos de registro y análisis de interacciones dentro del grupo (Sección 3.2), se reconoce la necesidad de contar con indicadores de actividad dentro del conjunto de participantes como elemento de alerta temprana para una intervención didáctica (Sección 3.3); se observan distintas líneas secundarias de hipótesis referidas a la investigación (Sección 3.4).

\subsection{Limitaciones del seguimiento de los alumnos en EVTC}

Dentro de los entornos virtuales de trabajo colaborativo, la etapa pedagógica es la más compleja porque se encuentra desarrollada la tarea con los formalismos propios de la educación no presencial, con las implicancias de tiempos sincrónicos y asincrónicos por parte de los participantes conjuntamente con la distancia geográfica de los mismos. Otro aspecto que interesa destacar, es el hecho que la interacción, aún cuando se establezca de forma virtual no significa que sea una interacción peor que la presencial; en los entornos virtuales se da una relación de comunicación estrecha y los elementos a favor o en contra de dicha modalidad de aprendizaje no pueden ser correctamente evaluados, pero si permite un abordaje por parte del docente/tutor con el fin de mejorar la relación y cohesión dentro del grupo [Daugherty y Turner, 2003]. No se puede dejar de reconocer una distancia física entre el profesor y el alumno y entre los alumnos, pero ella no es determinante, la que importa es la distancia cognitiva, la cual influye para construir entornos de calidad [Moore, 1970], de ahí la importancia de determinar la distancia social y el tipo de actividad de los integrantes del grupo bajo análisis. 
Ésta depende del diseño de enseñanza que se determine y del papel que desempeña el profesor y de cómo movilice o utilice las herramientas de comunicación y las diferentes metodologías que tenga a su disposición [Peters, 1988].

En este contexto la metodología de aprendizaje colaborativo se ha convertido en una de las metodologías más significativas para la formación en red.

Debido a que el trabajo del alumno es fundamental en la construcción autónoma del contenido, con la tutoría del docente y en el desarrollo de las competencias que deben adquirir para aportar al perfil del licenciado/profesional en sistemas.

Además, facilitan una visión integradora en el análisis de situaciones a través de la aplicación de estrategias que fortalecen la comunicación con las áreas que colaboran en el diseño, implementación, operación, mantenimiento, control de gestión, evaluación, coordinación y dirección de las empresas de producción de bienes y servicios.

Consolidando su capacidad de ejercitar la creatividad en un método científico especifico y un análisis lógico a fin de obtener los mejores resultados en el aprovechamiento de los recursos materiales y un conocimiento apropiado apto para la evaluación y el discernimiento en el análisis de los elementos productivos más comunes que ofrece la industria.

\subsection{Métodos de registro y análisis de interacciones}

Dentro de los métodos de registro, se encuentran en dos líneas diferenciadas, los cualitativos y los cuantitativos en la ponderación de actividades y distancia social.

Los métodos de registro y análisis se encuentran enmarcados dentro de los parámetros de SNA (análisis de redes sociales) [Wasserman y Faust, 1994]. En los mismos se encuentra una taxonomía de las distintas caracterizaciones a las que hacen los distintos roles y sus diferentes funcionalidades. En este caso en particular nos limitamos a un 
grupo bajo análisis y por lo tanto su limitado abanico de posibilidades (líder, marginado, aceptador, rechazador y normal).

Aplicando herramientas de análisis específicas permite obtener distintos elementos de observación [Pérez-Alvarez ,1991].

Debe de interpretarse como distancia social al conjunto de elementos que surgen del análisis de los distintos indicadores, éstos indicadores debido a su naturaleza, en la mayoría de los casos se aplican encuestas a los participantes de las actividades y determinan mediante las respuestas a las mismas cuál es el grado de integración y compromiso con cada uno de los participantes, este tipo de indicador se encuentra cargado de subjetividad, la cual puede llegar a constituir un elemento de registro sesgado, por la forma de expresión de la persona, es decir si es tímido o introvertido o su caso contrario, el ser extrovertido [ Litwin, 2000 ; Rosenberg, 2001].

Doreian (1988) realiza una importante distinción entre la definición de equivalencia y el proceso de detectar la propiedad de equivalencia (como elemento a detectar, rol y estatus). Pattison (1988) realiza una distinción similar entre el "modelo" y el algoritmo para detectar el modelo referido a los datos.

En el caso de los indicadores cuantitativos (en los que se basa éste estudio), la interacción entre los participantes se encuentra mediada por elementos tecnológicos que permiten el registro de dichas interacciones (correos electrónicos), el cual se puede extender en una futura línea de investigación respecto de otros canales o métodos de comunicación entre los participantes y el docente a cargo de la tutoría, para arbitrar los medios didácticos necesarios con fin de guiar al grupo [Charczuk et al.,2013].

\subsection{Indicadores de alerta temprana en actividades colaborativas en un EVTC}

Los indicadores de alertas temprana propuestos en este trabajo están referidos a: 
a) tiempo de demora en la respuesta de los correos electrónicos entre participantes [Charczuk et al., 2013];

b) cantidad de correos dentro de una ventana temporal [Charczuk et al., 2014]; y

c) combinación de ambos indicadores [Charczuk et al., 2015].

Dichos indicadores permitirían inferir la conducta de los participantes en un EVTC, dentro de los perfiles sociales apreciables, podemos destacar los siguientes roles Importante (Líder), Rechazador, Aceptador, Marginado y los considerados Normales dentro del grupo bajo estudio.

Asimismo, otros conjuntos de indicadores permiten observar los distintos tipos de interacciones entre docente y alumnos, como ser la cantidad de veces de acceso a repositorios y la lectura de los documentos ahí localizados.

Los indicadores y sus propiedades permiten realizar el proceso de análisis que determina el grado de participación o no de los alumnos, logrando reducir el grado de incertidumbre por parte de los docentes en la intervención didáctica [Lorrain y White ,1971], [Breiger y Pattison ,1986], [Faust, 1988], [Winship y Mandell, 1983], [Pattison , 1988], [Wasserman y Anderson, 1987], [Wasserman y Faust ,1992 ], [White y Reitz, 1981], [Winship,1988],[Winship y Mandel, 1983].

Las características observables por los indicadores y el rol detectable, le permiten al docente, determinar, de forma temprana y, en uno de los casos, si un participante es aislado por el grupo bajo análisis, posibilitando al mismo un abordaje que permita traccionar al alumno hacia la actividad del grupo en la concreción de la tarea propuesta en el EVTC

Otro método denominado CONCOR, de su acrónimo por CONvergencia de la CORrelación de las interacciones, ha sido específicamente desarrollado para analizar datos en redes sociales en orden de identificar un sub-conjunto de datos de actores equivalentes. Este método ha sido utilizado por primera vez para análisis de datos en 
redes sociales por Harrison White y otros, Breiger, Booman, Arabie, Schwartz; en su investigación sobre la aplicación en redes sociales del estudio algebraico de roles [Breiger et al. 1975; White et al. 1976].

\subsection{Límites de la hipótesis}

El manejo de los tiempos y recursos asignados por el momento pedagógico situacional, es decir un grupo de alumnos en un determinado tiempo en un espacio en particular con un docente; hoy aparece modificado por los dispositivos y medios tecnológicos que se encuentran al alcance de grandes grupos poblacionales.

De ahí la necesidad de centrar el estudio en los EVTC, con un indicador de alerta temprana y una tarea acotada que permita identificar e inferir los distintos tipos de conductas/roles propuestos en este trabajo.

Las investigaciones que se reportan en éste trabajo de tesis han sido financiadas parcialmente por el Proyecto de Investigación 33A166 del Departamento de Desarrollo Productivo y Tecnológico de la Universidad Nacional de Lanús, Argentina.

Los valores de actividad entre los grupos participantes (espacio muestral), corresponden a la cátedra Ingeniería del Software, de la carrera en Licenciatura de Sistemas de la Universidad Nacional de Lanús, correspondiente al período comprendido en el segundo cuatrimestre del 2013, dónde participaron 15 alumnos del curso, que luego se dividieron en 3 sub-grupos de 5 participantes. Para un posterior análisis se trabajó con un grupo de 4 alumnos. El desarrollo de las interacciones por parte de los alumnos consiste en la resolución de un trabajo práctico de la asignatura. 
Las preguntas formuladas como centro de la investigación propuesta:

Pregunta 1: ¿Se puede inferir un modelo de roles según SNA (Análisis de redes sociales) aplicable a un EVTC?

Pregunta 2: ¿De poder definir el modelo, que características posee o que roles son posibles de detectar?

Pregunta 3: ¿Los roles dentro de la dinámica colaborativa que el modelo permite es medible, o enriquecido por otros indicadores propios de la tecnología informática?

Pregunta 4: ¿De ser medible la interacción de los participantes por tecnología informática, cuál es el impacto que producen éstos nuevos indicadores en el conjunto de roles aún no detectados/analizados?

Pregunta 5: ¿Se puede utilizar alguno de los formalismos de modelado informáticos, o desarrollar una extensión de los mismos para analizar los roles de los participantes dentro de un EVTC?

Pregunta 6: La métrica desarrollada para la detección de roles de cada participante y la respectiva alerta temprana, ¿qué información de interés le reporta al docente? 


\section{SOLUCION PROPUESTA}

En este capítulo se propone un conjunto de métricas aplicables a entornos virtuales de trabajos colaborativos (EVTC) que permitan determinar el grado de pertenencia de sus participantes mediante la identificación de roles (Sección 4.1) los que se determinan por los procesos de observación en entornos virtuales (Sección 4.2) con foco en las técnicas de análisis de redes sociales (4.3 y 4.4),el conjunto de las definiciones en donde se parametrizan los elementos que se han de definir como indicadores de ponderación (Sección 4.5), los elementos de ponderación (Sección 4.6) y los procedimientos propuestos (4.7)

\subsection{Identificación de Roles}

La fortaleza de la fuerza del análisis de redes sociales comienza con Jacob Levy Moreno, el cual he sido una figura que ha generado polémicas, por sus características personales, y por otro lado los estudios concernientes a las relaciones sociales, es decir un intelectual innovador y por el otro lado, su personalidad.

Respecto a las redes sociales, que es el aspecto más importante de su vida es la demostración de lo concerniente a las estructuras sociales, y de ahí sus primeros diagramas sociométricos.

Dentro del análisis de los roles, “...el análisis de las experiencias y propuestas ha mostrado una gran dispersión en cuanto a descripción y caracterización de roles.

El lenguaje natural empleado en estos casos para definir un rol, con sus obligaciones y necesidades no ayuda a una posible interpretación compartida por la comunidad CSCL (Computer Supported Collaborative Learning), sino más bien al contrario, la dificulta.

Por otro lado, el reconocimiento del dinamismo del aprendizaje implica tener en cuenta los posibles cambios de rol que puedan producirse en la práctica real, así como 
las variaciones en cuanto a obligaciones o necesidades de un participante o un grupo que desempeña un rol. Sería muy interesante que un sistema pudiera estar al tanto de estas variaciones, para poder responder automática o semiautomáticamente a las mismas.

Si durante el desarrollo de una actividad colaborativa, un alumno empieza a comportarse según un rol no deseado, el profesor o el sistema deberían ser informados para reaccionar de forma que se pueda corregir dicha situación.

El objetivo de detectar cambios en el comportamiento de las personas que están desempeñando un determinado rol nos lleva a la necesidad de analizar las tareas, el proceso o los contenidos de la colaboración, para poder conocer si estos cambios se están produciendo, o bien si un participante al que se le ha asignado un rol al comienzo de una actividad dada se comporta o no de acuerdo a ese rol..." [García, J., 2012].

Dentro de los modelos que se analizan, es compleja la taxonomía de los distintos roles que se pueden presentar en el grupo, de ahí la importancia del seguimiento de las relaciones que se producen por las interacciones de los mismos. Sin tener la asignación de roles como premisa.

Dichos modelos permiten inferir determinadas conductas de los participantes, que en distintos análisis presentan las desviaciones de conductas previamente fijadas y su consiguiente grado de subjetividad al determinar cada rol.

\subsection{El proceso de observación}

La detección de los roles dentro de un ambientes de trabajo mediado por tecnología informática con la característica de su formato comunicacional, se diferencia ampliamente de otras formas de comunicación, las cuales se encuentran interpretadas por los dos sistemas analizados (CSCW y Groupware), pero con la carencia de 
observar (interprétese que dicho proceso es fundamental dentro de la sociometría, porque permite cuantificar la distancia social entre pares) o tipificar de forma aproximada la taxonomía de cada uno de los participantes y su consecuente intervención didáctica.

Ambos ambientes, fuertemente enfocados a la herramienta (colaborativa/cooperativa) se encuentran difundidos ampliamente donde la implicancia de los roles y el grado de participación de los mismos se encuentra limitado a la función específica determinada para cada participante.

La asignación de roles y su consiguiente seguimiento, responde a un modelo preestablecido.

El trabajo propuesto no cuenta con roles pre-definidos dentro del entorno (EVTCEntorno Virtual de Trabajo Colaborativo), los mismos surgen del análisis de los elementos que se han de ponderar mediante la observación de distintos indicadores (tiempo de respuesta entre correos electrónicos y cantidad de correos en una ventana de tiempo) de ahí la diferenciación de las propuestas anteriores.

Los sistemas apuntan al modelado de tareas y especificaciones de requerimiento del caso bajo análisis, pero la intervención sobre alguno de los participantes y la forma de interactuar con el resto del grupo, es una de las propuestas de los puntos a fortalecer.

Dentro de los ambientes colaborativos, se debe de tener en cuentan dos aspectos relacionados directamente con el tipo de tarea y actividad como lo es el CSCW y Groupware de los cuales se detallan a continuación.

CSCW: Los sistemas que soportan el trabajo en grupo en entornos de trabajo compartidos se desarrollan bajo el paradigma denominado trabajo cooperativo 
soportado por computadores (en inglés Computer Support Cooperative Work o CSCW).

El término CSCW fue definido originalmente por Irene Greif y Paul Cashman en 1984 como "una vía para describir cómo la tecnología de los computadores puede ayudar a los usuarios a trabajar conjuntamente en grupos" [Bannon et.al., 1989, pág 358 ].

"Sistemas basados en computadores que apoyan a un grupo de personas que trabajan en una tarea o meta común y que aprovecha una interfaz o un ambiente compartido" [Ellis, Gibbs \& Rein ,1993].

Groupware: Definido por primera vez por Peter y Trdy Jonson-Lenz en 1978 del siguiente modo: "Procesos y procedimientos grupales internacionales para propósitos específicos y herramientas de software diseñadas para apoyar y facilitar el trabajo grupal."

Según Ayala (1997), también existen otras formas de definirlo: "Colección de tecnologías que nos permiten representar procesos complejos centrados en las actividades cognitivas humanas, o bien, elementos de software que permiten la comunicación, colaboración y cooperación efectiva en un grupo de agentes activos distribuidos que trabajan de manera coordinada"

Dentro del modelado de grupos en entornos colaborativos en grupos de investigación, se puede citar el trabajo de Sosa, Zarco y Postiglioni (2006) en donde se detalla "el objetivo de modelar un entorno colaborativo es representar todos los aspectos referidos a cómo colaboran los usuarios para lleva a cabo el trabajo en grupo (tareas cooperativas)" (pág 27).

En el proceso de modelado se consideran las relaciones entre los siguientes elementos: actor, tarea y objeto, ya que una colaboración efectiva se logra mediante la interacción 
de los participantes o actores involucrados en tareas comunes donde se utilizan diferentes objetos tales como documentos, información, entre otros.

Para representar las tareas realizadas por los diferentes usuarios, se utiliza como técnica de modelado CTT (Concur Task Trees) desarrollada por Paternó $(1997,1998)$.

- Tareas de Usuario

- Tareas de Aplicación

- Tareas de Interacción

- Tareas Abstractas

- Tareas Cooperativas

\subsection{Análisis de Redes Sociales}

Del análisis sociométrico en la interacción de grupos mediados por tecnologías, dentro de un EVTC, podemos realizar el paralelismo con conceptos de la educación a distancia y el enriquecimiento que dicha modalidad educativa aporta al estudio de los valores y resultados obtenidos respecto a la inferencia del comportamiento de los diferentes partícipes de dicha modalidad educativa.

Un elemento distintivo en los textos siguientes es la interactividad de los participantes y el abordaje didáctico que se puede instrumentar con herramientas de diagnóstico pertinentes, aplicando modelos sociométricos.

Dentro del marco referencial, cobra importancia el concepto de Moore sobre distancia transaccional, interpretando cada transacción como una interacción en un lapso de tiempo determinado. 
Moore afirma que los distintos programas educativos pueden diferenciarse según el grado existente de estructura (o la cantidad de control ejercida por el formador o la institución educativa) y diálogo (o la cantidad de control ejercida por el alumno). Éstos eran los macrofactores que definían el campo.

A mayor estructura, se produce un aumento de la distancia, mientras que a mayor diálogo menor distancia. Por tanto, la educación a distancia no está definida por la separación geográfica entre el profesor y el alumno, sino por la cantidad de diálogo y estructura existentes.

De ahí la importancia de interpretar las interacciones de los participantes y la detección temprana de posibles patrones de conducta que puedan inferir el perfil de cada alumno, con la importancia que radica en una intervención didáctica con el menor grado de incertidumbre a la hora de la toma de decisión.

\subsection{Sociometría como Herramienta de Observación de Roles}

Como se puede apreciar el análisis y estudio de los encuentros virtuales se encuentra fuertemente orientado a los conceptos asociados al software y al hardware, los elementos detallados asumen los roles de los participantes, no realizando un seguimiento de dichos roles dentro de la propuesta cooperativa/colaborativa.

Los roles en dicho estudio se encuentran asignados previamente y la herramienta no cuenta con características que hacen al desarrollo de las interacciones en el conjunto de los participantes.

Es ahí donde cobra importancia el trabajo de los indicadores sociométricos.

Dentro de los trabajos realizados sobre aproximaciones en planeamiento y conducción de encuentros virtuales encontramos a Wang, Haake y Rubart $(2002,2004)$ donde se enfocan en la implementación de una implementación de una plataforma/herramienta 
con las características fundamentales que consideran sobre los encuentros virtuales (virtual meeting).

Dentro de la conceptualización trabaja por dichos autores respecto a las características intrínsecas de los encuentros virtuales, definen las necesidades de los mismos y sus características.

“...los encuentros son producidos por acontecimientos de carácter social o de negocios cuando un número de personas se encuentran en un cierto tiempo y espacio con un fin determinado, tal como una discusión o la generación de toma de decisiones...” [Wang, W. , Haake, J., \& Rubart, J., 2002, pág 71].

Un buen encuentro (meeting) debe contar con ciertas premisas para que el mismo tenga resultados satisfactorios:

- Que cuente con una agenda estratégicamente diseñada

- Que sea claro, consensuado para el logro de los objetivos y propuestas.

- Sentido de pertenencia

- Con preocupación en los participantes

- Con un mediador

Basados en estos roles (impuestos) los participantes cuentas con un conjunto de reglas $\mathrm{y}$ accesos que se les determinan en el entorno mediante la aplicación de una herramienta informática.

Los encuentros virtuales, como lo plantea el enunciado (virtuales) poseen la característica de realizarse de manera sincrónica o en su defecto asincrónica. 
En el primero de los casos se plantea la intersección de las dimensiones temporal y física, siendo ésta última con características particulares. Dicha particularidad es la posición geográfica del participante, que al ser "virtual" denota otro lugar para el encuentro.

En otro aspecto, puede ser asincrónica en el caso de encontrarse geográficamente en el mismo lugar, pero con la dimensión temporal fuera encontrarse unificada.

Existe otro caso en donde ambas dimensiones, la geográfica y temporal, ambas se encuentran desvinculadas en el conjunto de los participantes. Ésta última presenta una clara similitud con la educación a distancia, punto que se ha desarrollado en el apartado anterior, con todas las implicancias de dicha modalidad.

Según Wang, Haake y Rubart (2002) dentro del modelado y hay elementos que consideran exitosos para un proceso cooperativo y para un encuentro virtual:

- Un espacio común para la información con un entorno visual atractivo

- Modelado y control de procesos flexibles de encuentro

- Integración en la administración de documentos

- Administración de encuentros basados en sesiones y una fácil puesta a punto de aplicaciones distribuidas.

La herramienta desarrollada por dichos autores cubre ampliamente las características tecnológicas respecto a los encuentros virtuales y la necesidad de interconexión de los grupos de desarrollo en un ambiente globalizado.

El análisis de dichas herramientas confluye de dos aspectos, el técnico y el social, de éste último aspecto es el más vulnerable. Referido a la dimensión social, se han 
desarrollado nuevas herramientas con fuerte sintonía en el análisis de las redes sociales (SNA).

\subsection{Elementos de Ponderación}

En esta sección se presentan definiciones a utilizar para la reformulación de técnicas de diagnóstico sociométrico de dinámicas grupales para usar en ambientes de trabajo colaborativo (sección 4.5.1) y se presenta los procesos de cálculo de los indicadores de diagnóstico de la dinámica grupal (sección 4.5.2).

Cabe destacar que los elementos de ponderación propuestos y colocados bajo análisis están enmarcados en el proceso de interacciones de un grupo que participa en un EVTC.

Éstos elementos de análisis se encuentran desarrollados con un tronco común de análisis bajo tres indicadores, los cuales se han evaluado por separado y han permitido un abordaje sistémico dentro de los EVTC, con el fin de inferir la generación de modelos que hacen a las características de las interacciones de los participantes, con la posterior intervención del docente/tutor en caso de ser necesario para redirigir la tarea en función del objetivo propuesto.

Dentro de la ponderación del tiempo de respuesta de los correos electrónicos enviados/recibidos entre los participantes.

Los valores asignados al proceso de ponderación referidos a la densidad de correos en una unidad de tiempo (ventana temporal), surgen de los quintiles que se obtienen del cociente del valor obtenido de la resta del máximo valor de densidad de comunicación respecto al menor valor. 


\subsubsection{Definiciones}

En esta sección se definen los siguientes conceptos:

\subsubsection{Unidad de Interacción}

Es el tiempo de respuesta de los mensajes que le envía el sujeto $S_{\mathrm{i}}$ al sujeto $S_{\mathrm{j}}$.

\subsubsection{Matriz de Interacciones (MA)}

Asignando un valor de ponderación al tiempo t (que se muestra en la Tabla 1), se puede construir la matriz MA de interacciones del grupo de trabajo, siendo $\mathrm{MA}(\mathrm{i}, \mathrm{j})$ la ponderación de tiempos entre mensajes enviados / contestados por el sujeto $S_{\mathrm{i}}$ al sujeto $\mathrm{S}_{\mathrm{j}}$.

\subsubsection{Matriz de Acumulación de Ponderación de Interacciones Sujeto-Grupo ( $\Pi \mathrm{SG})$}

Se construye con base en la Matriz MA y contiene en la posición $\Pi \mathrm{SG}\left(\mathrm{i}_{\mathrm{i}, \mathrm{j}}\right)$ la cantidad de ponderaciones ${ }_{j}$ (ver tabla 1) que tiene el sujeto Si respecto de cada miembro del grupo.

\begin{tabular}{|l|c|}
\hline $\begin{array}{l}\text { Caracterización de los tiempos entre mensajes } \\
\text { enviados/contestados }\end{array}$ & Ponderación \\
\hline $\begin{array}{l}\text { Difícilmente responde al primer mail, excepto } \\
\text { que le envié otro }\end{array}$ & 1 \\
\hline Demora más de 48 hs en responder el mail. & 2 \\
\hline $\begin{array}{l}\text { La respuesta se encuentra entre las } 24 \text { y } 48 \text { hs } \\
\text { de enviado el mail. }\end{array}$ & 3 \\
\hline Responde dentro de las 24 hs de enviado el mail & 4 \\
\hline $\begin{array}{l}\text { Responde dentro de las } 24 \text { hs de enviado el mail } \\
\text { y con posibles soluciones/sugerencias para } \\
\text { resolver la inquietud }\end{array}$ & 5 \\
\hline $\begin{array}{l}\text { Además de responder el mail antes de las } 24 \text { hs } \\
\text { con una solución/sugerencia posible, intenta } \\
\text { otra vía de comunicación }\end{array}$ & \\
\hline
\end{tabular}

Tabla 1. Ponderación de
tiempos entre mensajes
enviados/contestados
por el sujeto $\mathrm{S}_{\mathrm{i}}$ al sujeto
$\mathrm{S}_{\mathrm{j}}$.


4.5.1.4. Matriz de Acumulación de Ponderación de Interacciones Grupo-Sujeto (ПGS)

Se construye con base en la Matriz M y contiene en la posición $\Pi \mathrm{GS}(\mathrm{i}, \mathrm{j})$ la cantidad de ponderaciones ${ }_{\mathrm{j}}$ que cada miembro del grupo (ver tabla 1) tiene respecto al sujeto $\mathrm{Si}$.

\subsubsection{Densidad de comunicación (DC)}

Es la cantidad de mensajes enviados por unidad de tiempo que le envía el sujeto $S_{i}$ al sujeto $S_{j}$

\subsubsection{Matriz de Interacciones (MB)}

Se puede construir la matriz $M$ de interacciones del grupo de trabajo, siendo $M B(i, j)$ la cantidad de mensajes enviados / contestados por el sujeto $S_{i}$ al sujeto $S_{j}$, dentro de un lapso de tiempo.

\subsubsection{Matriz de Densidad de Comunicaciones Sujeto-Grupo (MDCSG)}

Se construye con base en la Matriz MB y contiene en la posición $\operatorname{MDCSG}\left({ }_{i}, j\right)$ la densidad que tiene el sujeto Si respecto de cada miembro del grupo.

\subsubsection{Escalón de segmentación (ES)}

Es el valor obtenido de la división de la resta del mayor valor de Densidad de Comunicación menos el menor por 5 (genera 5 quintiles)

\subsubsection{Conversión de Valores DC a Indicadores de Métrica}

Es el valor que se obtiene de asignar a cada valor de DC dentro de los rangos generados por la distribución en quintiles.

4.5.1.10. Matriz de Referencia de Densidades de Comunicación Interacciones (MRDCI) 
Se construye con base en la Matriz MDC y contiene en la posición $\operatorname{MRDCI}(\mathrm{i}, \mathrm{j})$ el valor resultante de la conversión del parámetro de densidad de comunicación referenciado dentro del rango de segmentación de cada miembro del grupo tiene respecto al sujeto Si.

\subsubsection{Matriz Integración (MI)}

Se construye con los valores obtenidos de multiplicar el elemento de la matriz $\operatorname{MA}\left({ }_{i, j}\right)$ por el elemento de la matriz $\operatorname{MDCSG}(i, j)$

\subsubsection{2. Índice de Autocolaboración $\left(\mathrm{IAC}_{\mathrm{i}}\right)$}

Es el valor representativo del grado de colaboración que tiene el sujeto Si respecto de sí con relación al grupo. Este indice se calcula mediante la expresión (Donde: $\mathrm{x}$ representa el valor de ponderación, $\mathrm{n}$ representa la frecuencia relativa del valor $\mathrm{x}, \mathrm{N}$ representa la frecuencia absoluta):

$$
I A C=\frac{\sum_{i=1}^{n} x i \cdot n i}{N}
$$

\subsubsection{3. Índice de Heterocolaboración $\left(\mathrm{IHC}_{\mathrm{i}}\right)$}

Es un valor representativo del grado de colaboración que tiene el grupo respecto al sujeto $\mathrm{Si}$. Este indice se calcula mediante la expresión $\left(\mathrm{x}, \mathrm{n}, \mathrm{N}\right.$; iden $\left.\mathrm{IAC}_{\mathrm{i}}\right)$ :

$$
I H C=\frac{\sum_{i=1}^{n} x i \cdot n i}{N}
$$




\subsubsection{4. Índice de Realidad-Colaborativa ( $\left.\mathrm{IRC}_{\mathrm{i}}\right)$}

Es un valor que representa la diferencia entre los indices anteriores y permite determinar el grado de colaboración sujeto-grupo/grupo-sujeto. Este indice se calcula mediante la expresión:

$$
\mathrm{IRC}_{\mathrm{i}}=10 *\left(\mathrm{IAC}_{\mathrm{i}}-\mathrm{IHC}_{\mathrm{i}}\right)
$$

Dicho valor tiene el coeficiente 10 que multiplica la diferencia entre índices, debido a que la diferencia entre valores puede resultar un valor que por redondeo no resulte lo suficientemente significativo. Se propone que este índice se interprete según la siguiente regla de decisión:

- $\quad \mathrm{IRC}_{\mathrm{i}}>0 \quad$ El sujeto $\mathrm{Si}$ se sobre-estima en referencia a lo estimado por el grupo en el proceso colaborativo.

- $\quad \mathrm{IRC}_{\mathrm{i}}=0 \quad$ La valoración del sujeto $\mathrm{Si}$ coincide con la que tiene el grupo de él.

- $\quad \mathrm{IRC}_{\mathrm{i}}<0 \quad$ El sujeto $\mathrm{Si}$ se considera por debajo en referencia a lo estimado por el grupo respecto de la colaboración.

\subsubsection{5. Índice de Realidad Colaborativo Absoluto (IRCA)}

Es el valor absoluto del índice de realidad-colaborativa de un sujeto y la de un grupo se obtiene por acumulación del IRCA de los sujetos. El valor medio del índice de realidad absoluto (MIRCA), indica la valoración global del grupo, si el mismo es cercano a cero, es un grupo muy maduro en lo referente a su grado colaborativo, cuanto más alejado del valor nulo indica lo contrario. Se determina por la siguiente expresión (donde $\mathrm{L}$ representa la cantidad de sujetos del grupo): 


$$
\mathrm{V}_{\mathrm{MIRCA}}=\frac{\sum_{i=1}^{n} \operatorname{IRCAi}}{L}
$$

\subsubsection{Grado de Colaboracion Sujeto-Grupo (GCSG)}

El GCSG del sujeto $S_{i}$ permiten observar mediante el agrupamiento de las cantidades de interacciones entre el sujeto $S_{i}$ y el resto de los miembros del grupo cual es la conducta de $\mathrm{Si}$ en interacción con el grupo. Se denotara con $\operatorname{GCSG}\left(\mathrm{S}_{\mathrm{i}}, \mathrm{P}\right)$ la Cantidad de Ponderaciones con valor P que tiene el sujeto Si. La valoración de GCSG del sujeto Si estará dada por el vector:

(aceptadori, normali, rechazadori)

Donde:

$$
\begin{aligned}
& \text { aceptadori }_{\mathrm{i}}=\operatorname{GCSG}\left(\mathrm{S}_{\mathrm{i}}, 5\right)+\operatorname{GCSG}\left(\mathrm{S}_{\mathrm{i}}, 4\right) \\
& \text { normali }=\operatorname{GCSG}\left(\mathrm{S}_{\mathrm{i}}, 3\right)+\operatorname{GCSG}\left(\mathrm{S}_{\mathrm{i}}, 2\right) \\
& \text { rechazadori }=\operatorname{GCSG}\left(\mathrm{S}_{\mathrm{i}}, 1\right)+\operatorname{GCSG}\left(\mathrm{S}_{\mathrm{i}}, 0\right)
\end{aligned}
$$

Las reglas de decisión que se proponen en este trabajo son:

- $\mathrm{S}_{\mathrm{i}}$ es aceptador del grupo si $\quad$ aceptadori $_{\mathrm{i}} \geq$ normali + rechazadori $_{\mathrm{i}}$

- $\mathrm{S}_{\mathrm{i}}$ es normal del grupo si $\quad$ normali $\geq$ aceptadori + rechazador $\mathrm{i}$

- $\mathrm{S}_{\mathrm{i}}$ es rechazador del grupo si $\quad$ rechazadori $\geq$ normali $^{+}$aceptadori

En caso que la ponderación se encuentre con el mismo valor en dos de los tres componentes (Aceptador, Normal, Rechazador), serán compartidos los atributos de la ponderación. 


\subsubsection{Grado de Colaboracion Grupo-Sujeto (GCGS)}

El GCGS del Grupo respecto al sujeto $S_{i}$ permite observar mediante el agrupamiento de las cantidades de interacciones entre el resto de los miembros del grupo y de $\mathrm{S}_{\mathrm{i}}$ cual es la conducta del grupo en interacción con el sujeto $\mathrm{S}_{\mathrm{i}}$. Se denotara con GCGS $\left(\mathrm{S}_{\mathrm{i}}, \mathrm{Q}\right)$ la Cantidad de Ponderaciones con valor Q que tiene el grupo respecto del sujeto $\mathrm{S}_{\mathrm{i}}$. La valoración de GCGS del sujeto $\mathrm{S}_{\mathrm{i}}$ estará dada por el vector:

(importante $i$, normali, marginadoi)

Donde:

importante $_{\mathrm{i}}=$ GCGS $\left(\mathrm{S}_{\mathrm{i}}, 5\right)+$ GCGS $\left(\mathrm{S}_{\mathrm{i}}, 4\right)$

normal $_{\mathrm{i}}=$ GCGS $\left.\left(\mathrm{S}_{\mathrm{i}}, 3\right)+\mathrm{GCGS}_{(\mathrm{i}}, 2\right)$

marginado $i=\operatorname{GCGS}\left(\mathrm{S}_{\mathrm{i}}, 1\right)+\operatorname{GCGS}\left(\mathrm{S}_{\mathrm{i}}, 0\right)$

Las reglas de decisión que se proponen en este trabajo son:

- $\mathrm{S}_{\mathrm{i}}$ es importante del grupo si importante $_{\mathrm{i}} \geq$ normal $_{\mathrm{i}}+$ marginado $_{\mathrm{i}}$

- $\mathrm{S}_{\mathrm{i}}$ es normal del grupo si normal $_{\mathrm{i}} \geq$ importante $_{\mathrm{i}}+$ marginado $_{\mathrm{i}}$

- $\mathrm{S}_{\mathrm{i}}$ es marginado del grupo si $\operatorname{marginado}_{\mathrm{i}} \geq$ normal $_{\mathrm{i}}+$ importante $_{\mathrm{i}}$

En caso que la ponderación se encuentre con el mismo valor en dos de los tres componentes (Importante, Normal, Marginado), serán compartidos los atributos de la ponderación. El rol "importante" puede corresponder a un líder potencial.

\subsubsection{Canales de comunicación}

Que se denotaran con la letra K, son las distintas vías por las cuales todos los sujetos del grupo se pueden comunicar. Siendo que la cantidad máxima de posibles canales de 
comunicación se encuentra determina por la siguiente expresión (donde L representa la cantidad de sujetos del grupo):

$$
K=\frac{L}{2} *(L-1)
$$

\subsubsection{Porcentaje de canales efectivos de comunicación}

Representa el valor porcentual de los casos correspondientes a una comunicación efectiva, se propone interpretar como comunicación efectiva a los casos en los cuales la ponderación analizada se corresponde a la mitad superior de la Tabla 1. Siendo $\mathrm{Ft}_{\mathrm{i}}(5,4,3)$ la suma de las frecuencias relativas correspondientes a las ponderaciones con valor 5, 4 y 3 en la submatriz triangular inferior de la matriz de interacciones y $\mathrm{Ft}_{\mathrm{s}}(5,4,3)$ el análogo para la submatriz triangular superior. De ambas submatrices se obtiene un valor, se selecciona el menor de los mismos interpretando el caso más desfavorable en el proceso comunicacional, que dividido la cantidad máxima de canales permite obtener

$$
\% \text { Canales efectivos de Comunicación }=\frac{F(5,4,3)}{K} * 100
$$

\subsubsection{Porcentaje de carencia de comunicación}

La carencia de comunicación está determinada por los valores totales de Ceros (no existe comunicación según el criterio de ponderación de la tabla 1) divido la cantidad posible de comunicaciones en la Matriz de Interacciones.

$$
\% \text { Carencia de Comunicación }=\frac{\text { Cantidad de Ceros }}{(L-1) * L} * 100
$$




\subsection{Procedimientos Propuestos}

En el caso del procedimiento A se ha analizado el tiempo de respuesta en el intercambio de mails entre los participantes, en el procedimiento $\mathrm{B}$, se han estudiado la relación entre la cantidad de mails enviados recibidos dentro de un lapso de tiempo (densidad de comunicación) entre los participantes y en el procedimiento $\mathrm{C}$ se han instrumentado ambos procesos en la integración de los indicadores (el tiempo de demora y la cantidad de mails enviados/recibidos entre los participantes)

Los tres procesos permiten obtener una tabla de doble entrada con la cantidad obtenida por cada uno de los indicadores, que luego permite obtener los valores representativos que se han de utilizar para tipificar los distintos roles de los participantes dentro de un EVTC.

\subsubsection{Caso de Estudio Aplicando el Procedimiento A}

\begin{tabular}{|c|c|}
\hline Paso 1: & Construcción de la Matriz de Interacciones $M A(i, j)$ \\
\hline Paso 2: & Cálculo del $I A C_{n+1, j} \mathrm{y}$ del $I H C_{i, n+1}$ \\
\hline Paso 3: & $\begin{array}{l}\text { Cálculo del Indice de interpretación realidad-colaborativa } \\
\text { (IRCi) para el sujeto } S_{i} \text {. }\end{array}$ \\
\hline Paso 4: & $\begin{array}{l}\text { Interpretacion del Indice de interpretaciónrealidad- } \\
\text { colaborativa (IRCi) resultante para cada sujeto } S_{i} \text {. }\end{array}$ \\
\hline Paso 5: & $\begin{array}{l}\text { Construcción de las Matrices de Acumulación de } \\
\text { Ponderaciones de Interacciones Sujeto-Grupo ( } \Pi \mathrm{SG}) \text { y } \\
\text { Grupo-Sujeto ( } \Pi \mathrm{GS}) \text {. }\end{array}$ \\
\hline Paso 6: & $\begin{array}{l}\text { Orlado de la Matriz de Acumulación de Ponderaciones de } \\
\text { Interacciones Sujeto-Grupo ( } \Pi \mathrm{SG}) \text { con la matriz fila Grado } \\
\text { de Colaboracion Sujeto-Grupo (GCSG) }\end{array}$ \\
\hline Paso 7: & $\begin{array}{l}\text { Interpretación de la Matriz de Acumulación de } \\
\text { Ponderaciones de Interacciones Sujeto-Grupo (ISG) }\end{array}$ \\
\hline Paso 8: & $\begin{array}{l}\text { Orlado de la Matriz de Acumulación de Ponderaciones de } \\
\text { Interacciones Grupo-Sujeto ( } / \text { GS) con la matriz columna } \\
\text { Grado de Colaboracion Grupo-Sujeto (GCGS). }\end{array}$ \\
\hline
\end{tabular}




\begin{tabular}{|l|l|}
\hline Paso 9: & $\begin{array}{l}\text { Interpretación de la Matriz de Acumulación de } \\
\text { Ponderaciones de Interacciones Grupo-Sujeto (IGS). }\end{array}$ \\
\hline Paso 10: & $\begin{array}{l}\text { Cálculo de: canales de comunicación, porcentaje de canales } \\
\text { efectivos de comunicación, y porcentaje de carencia de } \\
\text { comunicación. }\end{array}$ \\
\hline Paso 11: & Interpretación de los resultados del Cálculo de Canales. \\
\hline
\end{tabular}

\subsubsection{Caso de Estudio Aplicando el Procedimiento B}

\begin{tabular}{|c|c|}
\hline Paso 1: & $\begin{array}{l}\text { Relevamiento de los valores de mensajes } \\
\text { enviados/recibidos y registro de lapso de tiempo. }\end{array}$ \\
\hline Paso 2: & $\begin{array}{l}\text { Construcción de la Matriz de Interacciones de } \\
\text { Comunicación. } \operatorname{MB}\left({ }_{i, j}\right) \text {. }\end{array}$ \\
\hline Paso 3: & $\begin{array}{l}\text { Construcción de la Matriz de Interacciones de Densidad de } \\
\text { Comunicación. } \operatorname{MDC}(\mathrm{i}, \mathrm{j}) \text {. }\end{array}$ \\
\hline Paso 4: & Cálculo del escalón de segmentación (ES). \\
\hline Paso 5: & $\begin{array}{l}\text { Asignación de los valores de DC comprendidos entre los } \\
\text { correspondientes rangos de los escalones de segmentación. }\end{array}$ \\
\hline Paso 6: & $\begin{array}{l}\text { Reinterpretación de la tabla MDC }\left({ }_{i}, \mathrm{j}\right) \text { asignando los } \\
\text { parámetros a la tabla I y Tabla II }\end{array}$ \\
\hline Paso 7: & Construcción de la Matriz MRDCI $(\mathrm{i}, \mathrm{j})$. \\
\hline Paso 8: & Cálculo del $\mathrm{IAC}_{\mathrm{n}+1}, \mathrm{j}$ y del $\mathrm{IHC}_{\mathrm{i}, \mathrm{n}+1}$ \\
\hline Paso 9: & $\begin{array}{l}\text { Cálculo del Índice de realidad colaborativa }\left(\mathrm{IRC}_{\mathrm{i}}\right) \text { para el } \\
\text { sujeto } \mathrm{S}_{\mathrm{i}} \text {. }\end{array}$ \\
\hline Paso 10: & $\begin{array}{l}\text { Interpretación del Índice de realidad colaborativa }\left(\mathrm{IRC}_{\mathrm{i}}\right) \\
\text { resultante para cada sujeto } \mathrm{S}_{\mathrm{i}} \text {. }\end{array}$ \\
\hline Paso 11: & $\begin{array}{l}\text { Orlado de la Matriz MRDCI de Interacciones Sujeto-Grupo } \\
\text { (SG) con la fila Grado de Colaboración Sujeto-Grupo } \\
\text { (GCSG) }\end{array}$ \\
\hline Paso 12: & $\begin{array}{l}\text { Interpretación de la Matriz MRDCI de Interacciones Sujeto- } \\
\text { Grupo (SG) }\end{array}$ \\
\hline Paso 13: & $\begin{array}{l}\text { Orlado de la Matriz MRDCI de Interacciones Grupo-Sujeto } \\
\text { (GS) con la columna Grado de Colaboración Grupo-Sujeto } \\
\text { (GCGS). }\end{array}$ \\
\hline Paso 14: & $\begin{array}{l}\text { Cálculo de: canales de comunicación, porcentaje de canales } \\
\text { efectivos de comunicación, y porcentaje de carencia de } \\
\text { comunicación. }\end{array}$ \\
\hline Paso 15: & Interpretación de los resultados del Cálculo de Canales. \\
\hline Paso 16: & DC respecto de su \\
\hline
\end{tabular}




\begin{tabular}{|l|l|}
\hline & valor medio \\
\hline Paso 17: & $\begin{array}{l}\text { Graficación de la desviación de DC y el valor medio, } \\
\text { respecto de los enlaces de comunicación. }\end{array}$ \\
\hline
\end{tabular}

\subsubsection{Caso de Estudio Aplicando el Procedimiento C}

\begin{tabular}{|c|c|}
\hline Paso 1: & $\begin{array}{l}\text { Relevamiento de los valores de tiempo de respuesta y } \\
\text { mensajes enviados/recibidos en un lapso de tiempo. }\end{array}$ \\
\hline Paso 2: & $\begin{array}{l}\text { Construcción de las Matrices de Interacciones. MA }(i, j) \\
\operatorname{MB}(i, j) \text {. }\end{array}$ \\
\hline Paso 3: & $\begin{array}{l}\text { Construcción de las Matrices de Densidad de } \\
\text { Comunicaciones Sujeto-Grupo (MDCSG) y la Matriz } \\
\text { Integración. }\end{array}$ \\
\hline Paso 5: & Cálculo del $\mathrm{IAC}_{\mathrm{n}+1}, \mathrm{j}$ y del $\mathrm{IHC}_{\mathrm{i}, \mathrm{n}+1}$ \\
\hline Paso 6: & $\begin{array}{l}\text { Cálculo del Índice de realidad colaborativa }\left(\operatorname{IRC}_{\mathrm{i}}\right) \text { para el } \\
\text { sujeto } \mathrm{S}_{\mathrm{i}} \text {. }\end{array}$ \\
\hline Paso 7: & $\begin{array}{l}\text { Interpretación del Índice de realidad colaborativa }\left(\mathrm{IRC}_{\mathrm{i}}\right) \\
\text { resultante para cada sujeto } \mathrm{S}_{\mathrm{i}} \text {. }\end{array}$ \\
\hline Paso 8: & Cálculo del escalón de segmentación (ES). \\
\hline Paso 9: & $\begin{array}{l}\text { Asignación de los valores comprendidos entre los } \\
\text { correspondientes rangos de los escalones de segmentación. }\end{array}$ \\
\hline Paso 10: & $\begin{array}{l}\text { Orlado de la Matriz MI de Interacciones Sujeto-Grupo } \\
\text { (SG) con la fila Grado de Colaboración Sujeto-Grupo } \\
\text { (GCSG) }\end{array}$ \\
\hline Paso 11: & $\begin{array}{l}\text { Interpretación de la Matriz MI de Interacciones Sujeto- } \\
\text { Grupo (SG) }\end{array}$ \\
\hline Paso 12: & $\begin{array}{l}\text { Orlado de la Matriz MI de Interacciones Grupo-Sujeto } \\
\text { (GS) con la columna Grado de Colaboración Grupo-Sujeto } \\
\text { (GCGS). }\end{array}$ \\
\hline Paso 13: & $\begin{array}{l}\text { Cálculo de: canales de comunicación y porcentaje de } \\
\text { carencia de comunicación. }\end{array}$ \\
\hline Paso 14: & $\begin{array}{l}\text { Cálculo de la desviación del valor de } \mathrm{MI}(\mathrm{i}, \mathrm{j}) \text { respecto del } \\
\text { valor medio del indice de integración. }\end{array}$ \\
\hline Paso 15: & $\begin{array}{l}\text { Graficación de la desviación del parámetro de integración } \\
\text { y el valor medio, respecto de los enlaces de comunicación. }\end{array}$ \\
\hline
\end{tabular}


El conjunto de los procedimientos propuestos se han descripto con amplitud en el capítulo 5, correspondiente a la validación de la solución. 


\section{VALIDACIÓN}

En este capítulo se propone la validación de un conjunto de métricas aplicables a entornos virtuales de trabajos colaborativos (EVTC), en donde se parametrizan los elementos que se han definido como indicadores de ponderación, los procedimientos propuestos (Sección 5.1) y las conclusiones a fin de realizar una intervención (Sección $5.2)$.

\subsection{Procedimientos propuestos}

En esta sección se pueden observar los procesos propuestos para los casos de validación, los cuales, parten de indicadores diferentes, que se han enfocado en un método de análisis en común, que permite arribar a conclusiones de los participantes en un EVTC con el fin de una intervención didáctica. Los indicadores están enfocados al análisis de las interacciones, los procedimientos propuestos están basados en el proceso comunicacional de los integrantes de un grupo dentro de un EVTC.

Cabe mencionar que el proceso de análisis cuenta con una metodología común para los tres casos, pero se ha realizado una adaptación a los distintos indicadores propuestos.

En el caso del procedimiento A se ha analizado el tiempo de respuesta en el intercambio de mails, en el procedimiento $\mathrm{B}$, se han estudiado la relación entre la cantidad de mails enviados recibidos dentro de un lapso de tiempo (densidad de comunicación) y en el procedimiento $\mathrm{C}$ se han instrumentado ambos procesos en la integración de los indicadores (el tiempo de demora y la cantidad de mails enviados/recibidos) 


\section{Procedimiento A}

\begin{tabular}{|c|c|}
\hline Paso 1: & $\begin{array}{l}\text { Construcción de la Matriz de Interacciones } \\
M A(i, j)\end{array}$ \\
\hline Paso 2: & Cálculo del $I A C_{n+1, j}$ y del $I H C_{i, n+1}$ \\
\hline Paso 3: & $\begin{array}{l}\text { Cálculo del Indice de realidad-colaborativa } \\
\text { (IRCi) para el sujeto } S_{i} \text {. }\end{array}$ \\
\hline Paso 4: & $\begin{array}{l}\text { Interpretacion del Indice de realidad- } \\
\text { colaborativa (IRCi) resultante para cada } \\
\text { sujeto } S_{i} \text {. }\end{array}$ \\
\hline Paso 5: & $\begin{array}{l}\text { Construcción de las Matrices de } \\
\text { Acumulación de Ponderaciones de } \\
\text { Interacciones Sujeto-Grupo (IISG) y Grupo- } \\
\text { Sujeto (IGS). }\end{array}$ \\
\hline Paso 6: & $\begin{array}{l}\text { Orlado de la Matriz de Acumulación de } \\
\text { Ponderaciones de Interacciones Sujeto- } \\
\text { Grupo (ISSG) con la matriz fila Grado de } \\
\text { Colaboracion Sujeto-Grupo (GCSG) }\end{array}$ \\
\hline Paso 7: & $\begin{array}{l}\text { Interpretación de la Matriz de Acumulación } \\
\text { de Ponderaciones de Interacciones Sujeto- } \\
\text { Grupo ( }(\mathrm{SG})\end{array}$ \\
\hline Paso 8: & $\begin{array}{l}\text { Orlado de la Matriz de Acumulación de } \\
\text { Ponderaciones de Interacciones Grupo- } \\
\text { Sujeto ( } \Pi \mathrm{GS} \text { ) con la matriz columna Grado } \\
\text { de Colaboracion Grupo-Sujeto (GCGS). }\end{array}$ \\
\hline Paso 9: & $\begin{array}{l}\text { Interpretación de la Matriz de Acumulación } \\
\text { de Ponderaciones de Interacciones Grupo- } \\
\text { Sujeto (IGGS). }\end{array}$ \\
\hline Paso 10: & $\begin{array}{l}\text { Cálculo de: canales de comunicación, } \\
\text { porcentaje de canales efectivos de } \\
\text { comunicación, y porcentaje de carencia de } \\
\text { comunicación. }\end{array}$ \\
\hline Paso 11: & $\begin{array}{l}\text { Interpretación de los resultados del Cálculo } \\
\text { de Canales. }\end{array}$ \\
\hline
\end{tabular}




\subsubsection{Caso de Estudio Aplicando el Procedimiento A}

Paso 1: En base a la Tabla 1, se completa la matriz de Interacciones, en este caso se han analizado 15 sujetos con sus respectivos grados de ponderación de los tiempos de los mensajes enviados /contestados

\begin{tabular}{|l|c|c|c|c|c|c|c|c|c|c|c|c|c|c|c|}
\hline & S1 & S2 & S3 & S4 & S5 & S6 & S7 & S8 & S9 & S10 & S11 & S12 & S13 & S14 & S15 \\
\hline S1 & $\#$ & 0 & 3 & 3 & 1 & 2 & 3 & 1 & 3 & 2 & 1 & 2 & 1 & 2 & 2 \\
\hline S2 & 1 & $\#$ & 1 & 5 & 1 & 1 & 1 & 5 & 2 & 0 & 0 & 1 & 1 & 0 & 0 \\
\hline S3 & 2 & 2 & $\#$ & 3 & 3 & 1 & 3 & 3 & 2 & 5 & 2 & 3 & 3 & 3 & 3 \\
\hline S4 & 3 & 5 & 3 & $\#$ & 3 & 3 & 3 & 5 & 3 & 2 & 1 & 1 & 2 & 1 & 0 \\
\hline S5 & 1 & 0 & 2 & 2 & $\#$ & 3 & 3 & 1 & 1 & 1 & 3 & 1 & 3 & 1 & 1 \\
\hline S6 & 1 & 2 & 3 & 4 & 4 & $\#$ & 4 & 3 & 5 & 3 & 4 & 3 & 3 & 5 & 3 \\
\hline S7 & 2 & 3 & 3 & 3 & 5 & 3 & $\#$ & 3 & 3 & 3 & 5 & 2 & 5 & 3 & 2 \\
\hline S8 & 1 & 5 & 4 & 5 & 3 & 3 & 3 & $\#$ & 1 & 2 & 1 & 0 & 3 & 4 & 1 \\
\hline S9 & 3 & 2 & 3 & 3 & 3 & 5 & 3 & 2 & $\#$ & 2 & 4 & 2 & 3 & 3 & 2 \\
\hline S10 & 1 & 1 & 5 & 3 & 4 & 3 & 4 & 2 & 3 & $\#$ & 2 & 4 & 4 & 4 & 3 \\
\hline S11 & 1 & 1 & 3 & 2 & 5 & 3 & 4 & 1 & 4 & 2 & $\#$ & 4 & 4 & 2 & 3 \\
\hline S12 & 2 & 1 & 1 & 1 & 3 & 1 & 2 & 1 & 1 & 4 & 3 & $\#$ & 3 & 4 & 4 \\
\hline S13 & 0 & 2 & 4 & 1 & 5 & 3 & 5 & 2 & 2 & 4 & 4 & 3 & $\#$ & 3 & 2 \\
\hline S14 & 1 & 1 & 2 & 2 & 3 & 3 & 2 & 2 & 3 & 4 & 3 & 2 & 2 & $\#$ & 3 \\
\hline S15 & 2 & 0 & 3 & 1 & 2 & 1 & 2 & 1 & 2 & 1 & 3 & 3 & 2 & 2 & $\#$ \\
\hline
\end{tabular}




\section{Paso 2:}

Cálculo del $\mathrm{IAC}_{\mathrm{n}+1, \mathrm{j}} \mathrm{y}$ del $\mathrm{IHC}_{\mathrm{i}, \mathrm{n}+1}$

\begin{tabular}{|c|c|}
\hline & IAC \\
\hline S1 & 1,818 \\
\hline S2 & 1,357 \\
\hline S3 & 2,714 \\
\hline S4 & 2,500 \\
\hline S5 & 1,643 \\
\hline S6 & 3,357 \\
\hline S7 & 3,214 \\
\hline S8 & 2,571 \\
\hline S9 & 2,857 \\
\hline S10 & 3,071 \\
\hline S11 & 2,786 \\
\hline S12 & 2,214 \\
\hline S13 & 2,857 \\
\hline S14 & 2,357 \\
\hline S15 & 1,786 \\
\hline
\end{tabular}

\begin{tabular}{|c|c|}
\hline & IHC \\
\hline S1 & 1,500 \\
\hline S2 & 1,786 \\
\hline S3 & 2,857 \\
\hline S4 & 2,714 \\
\hline S5 & 3,214 \\
\hline S6 & 2,500 \\
\hline S7 & 3,000 \\
\hline S8 & 2,286 \\
\hline S9 & 2,500 \\
\hline S10 & 2,500 \\
\hline S11 & 2,571 \\
\hline S12 & 2,214 \\
\hline S13 & 2,786 \\
\hline S14 & 2,643 \\
\hline S15 & 2,071 \\
\hline
\end{tabular}

Paso 3:

Cálculo del Índice de realidad-colaborativa $\left(\mathrm{IRC}_{\mathrm{i}}\right)$ para el sujeto $\mathrm{S}_{\mathrm{i}}$.

\begin{tabular}{|c|c|c|c|c|}
\hline & IRC & IAC & IHC & $\begin{array}{c}\text { IRC } \\
\text { Absoluto }\end{array}$ \\
\hline S1 & 3,571 & 1,857 & 1,500 & 3,571 \\
\hline
\end{tabular}




\begin{tabular}{|c|c|c|c|c|}
\hline S2 & $-4,286$ & 1,357 & 1,786 & 4,286 \\
\hline S3 & $-1,429$ & 2,714 & 2,857 & 1,429 \\
\hline S4 & $-2,143$ & 2,500 & 2,714 & 2,143 \\
\hline S5 & $-15,714$ & 1,643 & 3,214 & 15,714 \\
\hline S6 & 8,571 & 3,357 & 2,500 & 8,571 \\
\hline S7 & 2,143 & 3,214 & 3,000 & 2,143 \\
\hline S8 & 2,857 & 2,571 & 2,286 & 2,857 \\
\hline S9 & 3,571 & 2,857 & 2,500 & 3,571 \\
\hline S10 & 5,714 & 3,071 & 2,500 & 5,714 \\
\hline S11 & 2,143 & 2,786 & 2,571 & 2,143 \\
\hline S12 & 0,000 & 2,214 & 2,214 & 0,000 \\
\hline S13 & 0,714 & 2,857 & 2,786 & 0,714 \\
\hline S14 & $-2,857$ & 2,357 & 2,643 & 2,857 \\
\hline S15 & $-2,857$ & 1,786 & 2,071 & 2,857 \\
\hline
\end{tabular}

\section{Paso 4:}

Interpretación del Índice de realidad-colaborativa $\left(\mathrm{IRC}_{\mathrm{i}}\right)$ resultante para cada sujeto $\mathrm{Si}$.

Se denota con el signo + cuando el sujeto $\mathrm{Si}$ se sobre-estima en referencia a lo estimado por el grupo en el proceso colaborativo

Se denota con el signo - cuando el sujeto $S_{i}$ se considera por debajo en referencia a lo estimado por el grupo respecto de la colaboración.

Se denota con 0 en el caso que la valoración del sujeto $S_{i}$ coincide con la que tiene el grupo de él. 


\begin{tabular}{|c|c|c|c|}
\hline & IRC & $\begin{array}{c}\text { IRC } \\
\text { Absoluto }\end{array}$ & Interp. \\
\hline S1 & 3,571 & 3,571 & + \\
\hline S2 & $-4,286$ & 4,286 & - \\
\hline S3 & $-1,429$ & 1,429 & - \\
\hline S4 & $-2,143$ & 2,143 & - \\
\hline S5 & $-15,714$ & 15,714 & - \\
\hline S6 & 8,571 & 8,571 & + \\
\hline S7 & 2,143 & 2,143 & + \\
\hline S8 & 2,857 & 2,857 & + \\
\hline S9 & 3,571 & 3,571 & + \\
\hline S10 & 5,714 & 5,714 & + \\
\hline S11 & 2,143 & 2,143 & + \\
\hline S12 & 0,000 & 0,000 & 0 \\
\hline S13 & 0,714 & 0,714 & + \\
\hline S14 & $-2,857$ & 2,857 & - \\
\hline S15 & $-2,857$ & 2,857 & - \\
\hline & & \\
\hline
\end{tabular}

\section{Paso 5/6:}

Construcción de las Matrices de Acumulación de Ponderaciones de Interacciones Sujeto-Grupo (ISG). 


\begin{tabular}{|c|c|c|c|c|c|c|}
\hline & $\begin{array}{l}0 \\
\mathbb{0} \\
0\end{array}$ & $\begin{array}{l}+ \\
\stackrel{\otimes}{0}\end{array}$ & $\begin{array}{l}m \\
0 \\
0\end{array}$ & $\begin{array}{l}\mathbb{N} \\
\mathbb{0}\end{array}$ & $\frac{-}{0}$ & $\begin{array}{l}0 \\
0 \\
0\end{array}$ \\
\hline S1 & 0 & 0 & 4 & 5 & 4 & 1 \\
\hline S2 & 2 & 0 & 0 & 1 & 7 & 4 \\
\hline S3 & 1 & 0 & 8 & 4 & 1 & 0 \\
\hline S4 & 2 & 0 & 6 & 2 & 3 & 1 \\
\hline S5 & 0 & 0 & 4 & 2 & 7 & 1 \\
\hline S6 & 2 & 4 & 6 & 1 & 1 & 0 \\
\hline S7 & 3 & 0 & 8 & 3 & 0 & 0 \\
\hline S8 & 2 & 2 & 4 & 1 & 4 & 1 \\
\hline S9 & 1 & 1 & 7 & 5 & 0 & 0 \\
\hline $\mathrm{S} 10$ & 1 & 5 & 4 & 2 & 2 & 0 \\
\hline S11 & 1 & 4 & 3 & 3 & 3 & 0 \\
\hline S12 & 0 & 3 & 3 & 2 & 6 & 0 \\
\hline S13 & 2 & 3 & 3 & 4 & 1 & 1 \\
\hline S14 & 0 & 1 & 5 & 6 & 2 & 0 \\
\hline S15 & 0 & 0 & 3 & 6 & 4 & 1 \\
\hline & & & & & & 10 \\
\hline
\end{tabular}

Cantidad de Ceros

De los resultados se observa la cantidad de "0", en este caso 10. Este valor, representa la carencia de comunicación entre los participantes, y es empleado para el cálculo del porcentaje de Carencia de Comunicación.

\section{Interacciones Sujeto-Grupo}




\section{Paso 7:}

Interpretación de los resultados Sujeto-Grupo( $\Pi \mathrm{SG})$.

\begin{tabular}{|c|c|c|c|c|}
\hline & 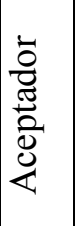 & 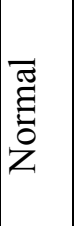 & 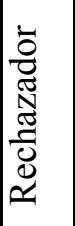 & 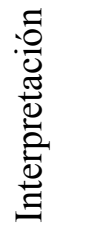 \\
\hline$\overline{S_{1}}$ & 0 & 9 & 5 & $\overline{\mathrm{N}}$ \\
\hline$\overline{S_{2}}$ & 2 & 1 & 11 & $\bar{R}$ \\
\hline $\mathrm{S}_{3}$ & 1 & 12 & 1 & $\mathrm{~N}$ \\
\hline $\mathrm{S}_{4}$ & 2 & 8 & 4 & $\mathrm{~N}$ \\
\hline $\mathrm{S}_{5}$ & 0 & 6 & 8 & $\mathrm{R}$ \\
\hline $\mathrm{S}_{6}$ & 6 & 7 & 1 & $\mathrm{~N}$ \\
\hline $\mathrm{S}_{7}$ & 3 & \begin{tabular}{|l|}
11 \\
\end{tabular} & $\overline{0}$ & $\mathrm{~N}$ \\
\hline $\mathrm{S}_{8}$ & 4 & 5 & 5 & $\mathrm{~N} / \mathrm{R}$ \\
\hline $\mathrm{S}_{9}$ & 2 & 12 & 0 & $\mathrm{~N}$ \\
\hline $\mathrm{S}_{10}$ & 6 & 6 & 2 & $\mathrm{~A} / \mathrm{N}$ \\
\hline$\overline{S_{11}}$ & 5 & 6 & 3 & N/A \\
\hline$S_{12}$ & 3 & 5 & 6 & $\mathrm{R} / \mathrm{N}$ \\
\hline$S_{13}$ & 5 & 7 & 2 & $\mathrm{~N}$ \\
\hline $\mathrm{S}_{14}$ & 1 & 11 & 2 & $\mathrm{~N}$ \\
\hline $\mathrm{S}_{15}$ & 0 & 9 & 5 & $\mathrm{~N}$ \\
\hline
\end{tabular}

Interpretación de los resultados Sujeto-Grupo ( $\Pi \mathrm{GS})$. La interpretación se hace en base a las siguientes convenciones: A significa que prevale Aceptador; $\mathrm{N}$ significa que prevalece Normal; R significa que prevalece Rechazador; N/R significa que tiene ambas conductas, es decir no prevalece una de ellas solamente, sino ambas Normal y 
Rechazador, con el mismo nivel de ponderación o con una diferencia mínima (1 unidad, en donde de existir dicha diferencia, al alterar el orden preestablecido Aceptador, Normal, Rechazador, la primer letra indica el de mayor ponderación); al igual que el análisis anterior $\mathrm{A} / \mathrm{N}$ significa que tiene ambas conductas, es decir no prevalece una de ellas solamente, sino ambas Aceptador y Normal; N/A significa que tiene ambas conductas, es decir no prevalece una de ellas solamente, al estar cambiado el orden pre-establecido, indica Normal/Aceptador sino ambas, $\mathrm{R} / \mathrm{N}$ significa Rechazador/Normal, al igual que en el caso anterior.

Paso 8:

Ponderaciones de Interacciones Grupo-Sujeto ( $\Pi \mathrm{GS})$

\begin{tabular}{|l|r|r|r|r|r|r|r|r|r|r|r|r|r|r|r|}
\cline { 2 - 12 } \multicolumn{1}{c|}{} & S1 & S2 & S3 & S4 & S5 & S6 & S7 & S8 & S9 & S10 & S11 & S12 & S13 & S14 & S15 \\
\hline Cant. de 5 & 0 & 2 & 1 & 2 & 3 & 1 & 1 & 2 & 1 & 1 & 1 & 0 & 1 & 1 & 0 \\
\hline Cant. de 4 & 0 & 0 & 2 & 1 & 2 & 0 & 3 & 0 & 1 & 3 & 3 & 2 & 2 & 3 & 1 \\
\hline Cant. de 3 & 2 & 1 & 7 & 5 & 6 & 8 & 6 & 3 & 5 & 2 & 4 & 4 & 6 & 4 & 5 \\
\hline Cant. de 2 & 4 & 4 & 2 & 3 & 1 & 1 & 3 & 4 & 4 & 5 & 2 & 4 & 3 & 3 & 4 \\
\hline Cant. de 1 & 7 & 4 & 2 & 3 & 2 & 4 & 1 & 5 & 3 & 2 & 3 & 3 & 2 & 2 & 2 \\
\hline Cant. de 0 & 1 & 3 & 0 & 0 & 0 & 0 & 0 & 0 & 0 & 1 & 1 & 1 & 0 & 1 & 2 \\
\hline
\end{tabular}

Interpretación de la Matriz de Acumulación de Ponderaciones de Interacciones GrupoSujeto ( $\Pi \mathrm{GS})$. En la que M significa Marginado, N significa Normal, I significa Importante. 


\begin{tabular}{|c|c|c|c|c|c|c|c|c|c|c|c|c|c|c|c|}
\cline { 2 - 5 } & S1 & S2 & S3 & S4 & S5 & S6 & S7 & S8 & S9 & S10 & S11 & S12 & S13 & S14 & S15 \\
\hline IMPORTANTE & 0 & 2 & 3 & 3 & 5 & 1 & 4 & 2 & 2 & 4 & 4 & 2 & 3 & 4 & 1 \\
\hline NORMAL & 6 & 5 & 9 & 8 & 7 & 9 & 9 & 7 & 9 & 7 & 6 & 8 & 9 & 7 & 9 \\
\hline Interpretación & $\mathrm{M}$ & $\mathrm{M}$ & $\mathrm{N}$ & $\mathrm{N}$ & $\mathrm{N}$ & $\mathrm{N}$ & $\mathrm{N}$ & $\mathrm{N}$ & $\mathrm{N}$ & $\mathrm{N}$ & $\mathrm{N}$ & $\mathrm{N}$ & $\mathrm{N}$ & $\mathrm{N}$ & $\mathrm{N}$ \\
\hline
\end{tabular}

\section{Paso 9:}

Interpretación de la Matriz de Acumulación de Ponderaciones de Interacciones GrupoSujeto ( $\Pi \mathrm{GS})$.

Matriz de los canales efectivos de comunicación, de los valores presentes en la Matriz de interacciones se realiza lo descripto en el apartado Definiciones de lo que se puede observar:

\begin{tabular}{|c|c|c|c|c|c|c|c|c|}
\hline & S1 & S2 & S13 & S14 & S15 & 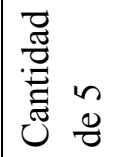 & 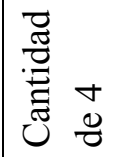 & 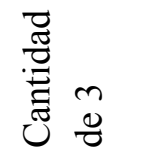 \\
\hline S1 & $\#$ & 0 & 1 & 2 & 2 & 0 & 0 & 4 \\
\hline $\mathrm{S} 2$ & 1 & \# & 1 & 0 & 0 & 2 & 0 & 0 \\
\hline S3 & 2 & 2 & 3 & 3 & 3 & 1 & 0 & 8 \\
\hline S4 & 3 & 5 & 2 & 1 & 0 & 1 & 0 & 5 \\
\hline S5 & 1 & 0 & 3 & 1 & 1 & 0 & 0 & 4 \\
\hline S6 & 1 & 2 & 3 & 5 & 3 & 2 & 4 & 6 \\
\hline S7 & 2 & 3 & 5 & 3 & 2 & 2 & 0 & 7 \\
\hline $\mathrm{S}_{8}$ & 1 & 5 & 3 & 4 & 1 & 0 & 2 & 4 \\
\hline $\mathrm{S}_{9}$ & 3 & 2 & 3 & 3 & 2 & 0 & 1 & 6 \\
\hline $\mathrm{S}_{10}$ & 1 & 1 & 4 & 4 & 3 & 0 & 5 & 4 \\
\hline
\end{tabular}




\begin{tabular}{|c|r|r|r|r|r|r|r|r|r|}
\hline $\mathrm{S}_{11}$ & 1 & 1 & & 4 & 2 & 3 & 0 & 4 & 3 \\
\hline $\mathrm{S}_{12}$ & 2 & 1 & & 3 & 4 & 4 & 0 & 3 & 3 \\
\hline $\mathrm{S}_{13}$ & 0 & 2 & & $\#$ & 3 & 2 & 0 & 3 & 3 \\
\hline $\mathrm{S}_{14}$ & 1 & 1 & & 2 & $\#$ & 3 & 0 & 1 & 5 \\
\hline $\mathrm{S}_{15}$ & 2 & 0 & & 2 & 2 & $\#$ & 8 & 23 & 62 \\
\hline Cant.de 5 & 0 & 2 & & 0 & 0 & 9 & & & 93 \\
\hline Cant.de 4 & 0 & 0 & & 0 & 0 & 12 & & & \\
\hline Cant.de 3 & 2 & 1 & & 0 & 0 & 31 & 52 & & \\
\end{tabular}

Paso 10:

Cálculo de: canales de comunicación, porcentaje de canales efectivos de comunicación, y porcentaje de carencia de comunicación.

\begin{tabular}{|lc|}
\hline Cantidad de posibles canales de comunicación: & 105 \\
\hline Porcentaje de Carencia de Comunicación: & $4,76 \%$ \\
\hline Porcentajes de canales de comunicación: & $49,52 \%$ \\
\hline
\end{tabular}

\subsubsection{Caso de Estudio Aplicando el Procedimiento B}

\begin{tabular}{|l|l|}
\hline Paso 1: & $\begin{array}{l}\text { Relevamiento de los valores de mensajes enviados/recibidos y } \\
\text { registro de lapso de tiempo. }\end{array}$ \\
\hline Paso 2: & $\begin{array}{l}\text { Construcción de la Matriz de Interacciones de Comunicación. } \\
\text { MB }(\mathrm{i}, \mathrm{j}) .\end{array}$ \\
\hline Paso 3: & $\begin{array}{l}\text { Construcción de la Matriz de Interacciones de Densidad de } \\
\text { Comunicación. MDC }(\mathrm{i}, \mathrm{j}) .\end{array}$ \\
\hline Paso 4: & Cálculo del escalón de segmentación (ES). \\
\hline Paso 5: & $\begin{array}{l}\text { Asignación de los valores de DC comprendidos entre los } \\
\text { correspondientes rangos de los escalones de segmentación. }\end{array}$ \\
\hline
\end{tabular}




\begin{tabular}{|c|c|}
\hline Paso 6: & $\begin{array}{l}\text { Reinterpretación de la tabla } \mathrm{MDC}(\mathrm{i}, \mathrm{j}) \text { asignando los parámetros a la } \\
\text { tabla I y Tabla II }\end{array}$ \\
\hline Paso 7: & Construcción de la Matriz MRDCI $(\mathrm{i}, \mathrm{j})$ \\
\hline Paso 8: & Cálculo del $\mathrm{IAC}_{\mathrm{n}+1, \mathrm{j}} \mathrm{y}$ del $\mathrm{IHC}_{\mathrm{i}, \mathrm{n}+1}$ \\
\hline Paso 9: & Cálculo del Índice de realidad colaborativa (IRC ${ }_{\mathrm{i}}$ ) para el sujeto $\mathrm{Si}$. \\
\hline Paso 10: & $\begin{array}{l}\text { Interpretación del Índice de realidad colaborativa }\left(\mathrm{IRC}_{\mathrm{i}}\right) \text { resultante } \\
\text { para cada sujeto } \mathrm{S}_{\mathrm{i}} \text {. }\end{array}$ \\
\hline Paso 11: & $\begin{array}{l}\text { Orlado de la Matriz MRDCI de Interacciones Sujeto-Grupo (SG) con } \\
\text { la fila Grado de Colaboración Sujeto-Grupo (GCSG) }\end{array}$ \\
\hline Paso 12: & $\begin{array}{l}\text { Interpretación de la Matriz MRDCI de Interacciones Sujeto-Grupo } \\
\text { (SG) }\end{array}$ \\
\hline Paso 13: & $\begin{array}{l}\text { Orlado de la Matriz MRDCI de Interacciones Grupo-Sujeto (GS) con } \\
\text { la columna Grado de Colaboración Grupo-Sujeto (GCGS). }\end{array}$ \\
\hline Paso 14: & $\begin{array}{l}\text { Cálculo de: canales de comunicación, porcentaje de canales efectivos } \\
\text { de comunicación, y porcentaje de carencia de comunicación. }\end{array}$ \\
\hline Paso 15: & Interpretación de los resultados del Cálculo de Canales. \\
\hline Paso 16: & Cálculo de la desviación del valor de DC respecto de su valor medio \\
\hline Paso 17: & $\begin{array}{l}\text { Graficación de la desviación de DC y el valor medio, respecto de los } \\
\text { enlaces de comunicación. }\end{array}$ \\
\hline
\end{tabular}

Paso 1: Se completa la matriz MB de Interacciones, en este caso se han analizado 4 sujetos con sus respectivos mensajes enviados /contestados y el tiempo dentro del cual se ha producido dicho intercambio.

Paso 2: Construcción de la Matriz de Densidad de Comunicación. $\operatorname{MDC}\left({ }_{i}, \mathrm{j}\right)$.

Paso 3: Cálculo del escalón de segmentación (ES).

$\mathrm{ES}=(3,045-0,182) / 5$

$\mathrm{ES}=0,57272$

Paso 4: Rangos de los escalones de segmentación

Paso 5: Asignación de Rangos de los valores de DC 


\begin{tabular}{|l|l|l|l|l|}
\hline & S1 & S2 & S3 & S4 \\
\hline S1 & & 5 & 5 & 4 \\
\hline S2 & 12 & & 12 & 10 \\
\hline S3 & 55 & 55 & & 67 \\
\hline S4 & 48 & 48 & 60 & \\
\hline
\end{tabular}

Resultado Paso 2: Cantidad de tiempo: 22 días

\begin{tabular}{|l|l|l|l|l|}
\hline & S1 & S2 & S3 & S4 \\
\hline S1 & & 0,23 & 0,23 & 0,18 \\
\hline S2 & 0,55 & & 0,55 & 0,45 \\
\hline S3 & 2,50 & 2,50 & & 3,05 \\
\hline S4 & 2,18 & 2,18 & 2,73 & \\
\hline
\end{tabular}

Resultado Paso 3 a. $2,473-3,045$

b. $1,900-2,473$

c. $1,327-1,900$

d. $0,755-1,327$

e. $0,182-0,755$

Resultado Paso 4

\begin{tabular}{|c|c|c|c|}
\hline \multicolumn{3}{|c|}{ Tabla I } \\
\hline $\begin{array}{c}\text { Sujeto } \\
\text { i }\end{array}$ & $\begin{array}{c}\text { Sujeto } \\
\text { j }\end{array}$ & DC & Nro. Orden \\
\hline S3 & S4 & 3,045 & 1 \\
\hline S4 & S3 & 2,727 & 2 \\
\hline S3 & S2 & 2,500 & 3 \\
\hline S3 & S1 & 2,500 & 4 \\
\hline S4 & S1 & 2,182 & 5 \\
\hline S4 & S2 & 2,182 & 6 \\
\hline S2 & S1 & 0,545 & 7 \\
\hline S2 & S3 & 0,545 & 8 \\
\hline S2 & S4 & 0,455 & 9 \\
\hline S1 & S2 & 0,227 & 10 \\
\hline S1 & S3 & 0,227 & 11 \\
\hline S1 & S4 & 0,182 & 12 \\
\hline R & & \\
\hline
\end{tabular}

Resultado Paso 5 


\section{Paso 6 y 7: Construcción de la Matriz MRDCI}

\begin{tabular}{|c|c|c|c|c|c|c|c|c|c|c|c|c|c|c|}
\hline & S1 & S2 & S3 & S4 & $\begin{array}{l}n \\
\stackrel{n}{E} \\
\tilde{U}\end{array}$ & 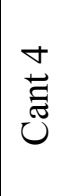 & 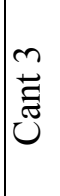 & $\stackrel{\stackrel{N}{E}}{\underset{\Xi}{\Xi}}$ & 䔍 & $\begin{array}{l}\stackrel{0}{E} \\
\underset{E}{E}\end{array}$ & 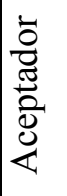 & 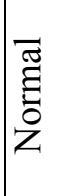 & 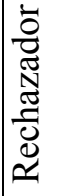 & IAC \\
\hline $\mathrm{S} 1$ & & 1 & 1 & 1 & & & & & 3 & & 0 & 0 & 3 & 1,00 \\
\hline $\mathrm{S} 2$ & 1 & & 1 & 1 & & & & & 3 & & 0 & 0 & 3 & 1,00 \\
\hline S3 & 5 & 5 & & 5 & 3 & & & & & & 3 & 0 & 0 & 5,00 \\
\hline S4 & 4 & 4 & 5 & & 1 & 2 & & & & & 3 & 0 & 0 & 4,33 \\
\hline Cant 5 & 1 & 1 & 1 & 1 & & & & & & & & & & \\
\hline
\end{tabular}

\begin{tabular}{|l|l|l|l|l|l|} 
& 1 & 1 & & & \\
\hline Cant 4 & 1 & 1 & & & Cantidad de 5,4,3:
\end{tabular}

\begin{tabular}{|c|c|c|c|c|}
\hline Cant 3 & & & & \\
\hline Cant 2 & & & & \\
\hline Cant 1 & 1 & 1 & 2 & 2 \\
\hline Cant 0 & & & & \\
\hline IMPORT. & 2 & 2 & 1 & 1 \\
\hline NORMAL & & & & \\
\hline MARGINADO & 1 & 1 & 2 & 2 \\
\hline IHC & 3,33 & 3,33 & 2,33 & 2,33 \\
\hline
\end{tabular}

Cantidad de

5,4,3: 
Paso 8, 9 y 10 :

\begin{tabular}{|c|c|c|c|c|c|}
\hline & IRC & IAC & IHC & IRCA & $\begin{array}{c}\text { Int. } \\
\text { IRC }\end{array}$ \\
\hline S1 & $-2,33$ & 1,00 & 3,33 & 2,33 & - \\
\hline S2 & $-2,33$ & 1,00 & 3,33 & 2,33 & - \\
\hline S3 & 2,67 & 5,00 & 2,33 & 2,67 & + \\
\hline S4 & 2,00 & 4,33 & 2,33 & 2,00 & + \\
\hline
\end{tabular}

Paso 11,12 y 13 se encuentran incluidos en la matriz MRDCI del paso 6 y 7.

Paso 14,15y 16:

\begin{tabular}{|l|c|}
\hline Cantidad de canales de comunicación: & 6 \\
\hline $\begin{array}{l}\text { Porcentaje de canales efectivos de } \\
\text { comunicación: }\end{array}$ & 100 \\
\hline Porcentaje de carencia de comunicación: & 0 \\
\hline
\end{tabular}

Paso 17: Cálculo de la desviación del valor de DC respecto de su valor medio

Paso 18: Graficación de la desviación de DC y el valor medio, respecto de los enlaces de comunicación

\begin{tabular}{|c|c|c|}
\hline DC & $\begin{array}{c}\text { Valor } \\
\text { Medio }\end{array}$ & Desviación \\
\hline 3,045 & 1,44318 & 1,602 \\
\hline 2,727 & 1,44318 & 1,284 \\
\hline 2,500 & 1,44318 & 1,057 \\
\hline 2,500 & 1,44318 & 1,057 \\
\hline
\end{tabular}




\begin{tabular}{|c|c|c|}
\hline 2,182 & 1,44318 & 0,739 \\
\hline 2,182 & 1,44318 & 0,739 \\
\hline 0,545 & 1,44318 & $-0,898$ \\
\hline 0,545 & 1,44318 & $-0,898$ \\
\hline 0,455 & 1,44318 & $-0,989$ \\
\hline 0,227 & 1,44318 & $-1,216$ \\
\hline 0,227 & 1,44318 & $-1,216$ \\
\hline 0,182 & 1,44318 & $-1,261$ \\
\hline
\end{tabular}

Resultado Paso 17

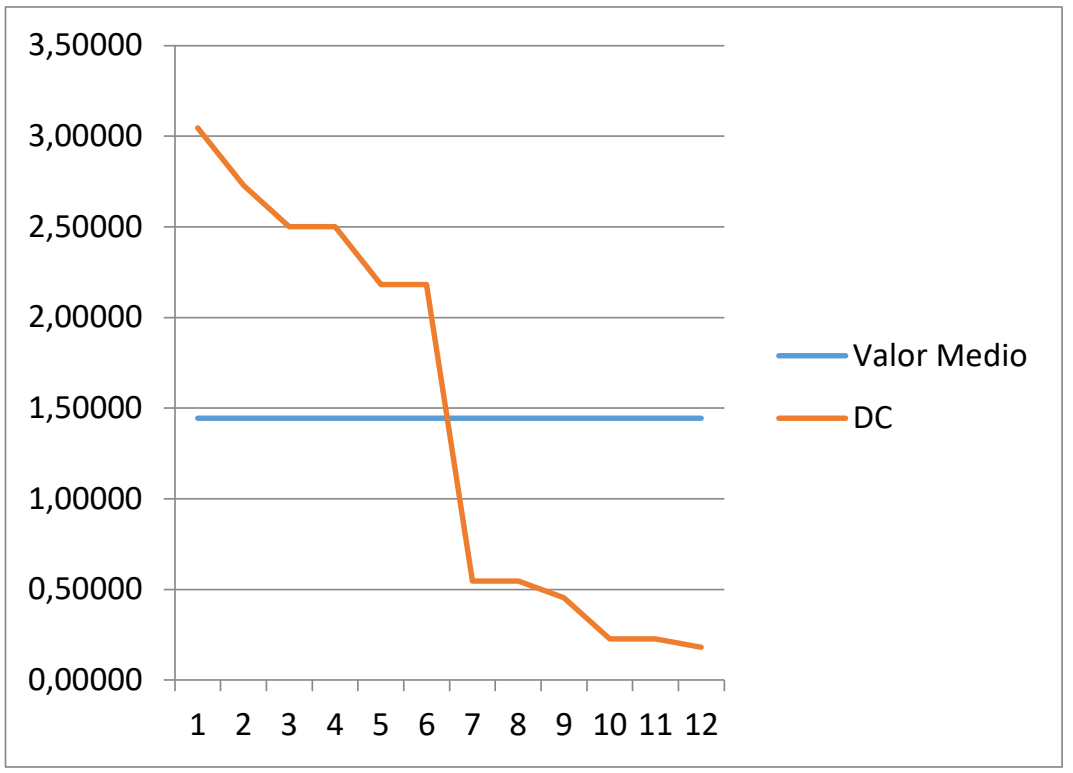

Resultado Paso 18

La interpretación del Índice de realidad-colaborativa $\left(\mathrm{IRC}_{\mathrm{i}}\right)$ resultante para cada sujeto $\mathrm{Si}$; se denota con el signo + cuando el sujeto $\mathrm{Si}$ se sobre-estima en referencia a lo estimado por el grupo en el proceso colaborativo. Se denota con el signo - cuando el sujeto Si se considera por debajo en referencia a lo estimado por el grupo respecto de 
la colaboración. Se denota con 0 en el caso que la valoración del sujeto Si coincide con la que tiene el grupo de él. De los resultados se observa la cantidad de "O0". Este valor, representa la carencia de comunicación entre los participantes, y es empleado para el cálculo del porcentaje de Carencia de Comunicación.

\subsubsection{Caso de Estudio Aplicando el Procedimiento C}

\begin{tabular}{|l|l|}
\hline Paso 1: & $\begin{array}{l}\text { Relevamiento de los valores de tiempo de respuesta y mensajes } \\
\text { enviados/recibidos en un lapso de tiempo. }\end{array}$ \\
\hline Paso 2: & Construcción de las Matrices de Interacciones. MA $(\mathrm{i}, \mathrm{j}), \mathrm{MB}(\mathrm{i}, \mathrm{j})$ \\
\hline Paso 3: & $\begin{array}{l}\text { Construcción de las Matrices de Densidad de Comunicaciones } \\
\text { Sujeto-Grupo (MDCSG) y la Matriz Integracion. }\end{array}$ \\
\hline Paso 5: & Cálculo del IAC $\mathrm{n}_{\mathrm{n}+1, \mathrm{j}} \mathrm{y}$ del $\mathrm{IHC}_{\mathrm{i}, \mathrm{n}+1}$ \\
\hline Paso 6: & Cálculo del Índice de realidad colaborativa (IRC $\left.\mathrm{i}_{\mathrm{i}}\right)$ para el sujeto Si. \\
\hline Paso 7: & $\begin{array}{l}\left.\text { Interpretación del Índice de realidad colaborativa (IRC } \mathrm{I}_{\mathrm{i}}\right) \text { resultante } \\
\text { para cada sujeto } \mathrm{S}_{\mathrm{i} .}\end{array}$ \\
\hline Paso 8: & Cálculo del escalón de segmentación (ES). \\
\hline Paso 9: & $\begin{array}{l}\text { Asignación de los valores comprendidos entre los correspondientes } \\
\text { rangos de los escalones de segmentación. }\end{array}$ \\
\hline Paso 10: & $\begin{array}{l}\text { Orlado de la Matriz MI de Interacciones Sujeto-Grupo (SG) con la } \\
\text { fila Grado de Colaboración Sujeto-Grupo (GCSG) }\end{array}$ \\
\hline Paso 11: & Interpretación de la Matriz MI de Interacciones Sujeto-Grupo (SG) \\
\hline Paso 12: & $\begin{array}{l}\text { Orlado de la Matriz MI de Interacciones Grupo-Sujeto (GS) con la } \\
\text { columna Grado de Colaboración Grupo-Sujeto (GCGS). }\end{array}$ \\
\hline Paso 13: & $\begin{array}{l}\text { Cálculo de: canales de comunicación y porcentaje de carencia de } \\
\text { comunicación. }\end{array}$ \\
\hline Paso 14: & $\begin{array}{l}\text { Cálculo de la desviación del valor de MI(i,j) respecto del valor } \\
\text { medio del índice de integración. }\end{array}$ \\
\hline Paso 15: & $\begin{array}{l}\text { Graficación de la desviación del parámetro de integración y el } \\
\text { valor medio, respecto de los enlaces de comunicación. }\end{array}$ \\
\hline
\end{tabular}

Paso 1-2: Se completa la matriz MA de Interacciones, en este caso se han analizado 4 sujetos con referencia al tiempo de respuesta de los participantes de cada interacción sus respectivos mensajes enviados/contestados. Ponderados según la Tabla I. 


\begin{tabular}{|l|c|}
\hline Caracterización de los tiempos entre mensajes enviados/contestados & Ponderación \\
\hline Difícilmente responde al primer mail, excepto que le envié otro & $\mathbf{0}$ \\
\hline Demora más de 48 hs en responder el mail. & $\mathbf{2}$ \\
\hline La respuesta se encuentra entre las 24 y 48 hs de enviado el mail. & $\mathbf{3}$ \\
\hline Responde dentro de las 24 hs de enviado el mail & 4 \\
\hline $\begin{array}{l}\text { Responde dentro de las } 24 \text { hs de enviado el mail y con posibles } \\
\text { soluciones/sugerencias para resolver la inquietud }\end{array}$ & $\mathbf{5}$ \\
\hline $\begin{array}{l}\text { Además de responder el mail antes de las } 24 \text { hs con una solución/sugerencia } \\
\text { posible, intenta otra vía de comunicación }\end{array}$ & \\
\hline
\end{tabular}

Tabla I. Ponderación de tiempos entre mensajes enviados/contestados por el sujeto $S_{i}$ al sujeto $S_{j}$.

\begin{tabular}{|c|c|c|c|c|}
\hline & S1 & S2 & S3 & S4 \\
\hline S1 & 0 & 4 & 3 & 3 \\
\hline S2 & 4 & 0 & 4 & 4 \\
\hline S3 & 4 & 4 & 0 & 2 \\
\hline S4 & 1 & 1 & 1 & 0 \\
\hline
\end{tabular}

Matriz MA correspondiente a los valores de la tabla I

La segunda propuesta de adaptación de técnicas sociométricas se encuentra basada en la cantidad de mensajes enviados/recibidos dentro de un rango de tiempo; permitiendo obtener un factor que hemos denominado densidad de comunicación.

\begin{tabular}{|l|l|l|l|l|}
\hline & S1 & S2 & S3 & S4 \\
\hline S1 & & 41 & 35 & 33 \\
\hline S2 & 40 & & 47 & 44 \\
\hline S3 & 44 & 43 & & 21 \\
\hline S4 & 12 & 15 & 18 & \\
\hline
\end{tabular}

Matriz MB. Cantidad de mensajes enviados/recibidos en un intervalo de tiempo.

Intervalo de la muestra: 35 días 


\section{Paso 3-4:}

\begin{tabular}{|l|l|l|l|l|}
\hline & S1 & S2 & S3 & S4 \\
\hline S1 & & 1,171 & 1 & 0,943 \\
\hline S2 & 1,143 & & 1,343 & 1,257 \\
\hline S3 & 1,257 & 1,229 & & 0,6 \\
\hline S4 & 0,343 & 0,429 & 0,514 & \\
\hline
\end{tabular}

Matriz MDCSG

\begin{tabular}{|l|l|l|l|l|}
\hline & S1 & S2 & S3 & S4 \\
\hline S1 & & 4,69 & 3,00 & 2,83 \\
\hline S2 & 4,57 & & 5,37 & 5,03 \\
\hline S3 & 5,03 & 4,91 & & 1,20 \\
\hline S4 & 0,34 & 0,43 & 0,51 & \\
\hline
\end{tabular}

Matriz Integración

\section{Paso 5-6-7:}

\begin{tabular}{|l|l|l|l|l|l|}
\hline & S1 & S2 & S3 & S4 & IAC \\
\hline S1 & & 4,686 & 3,000 & 2,829 & 3,505 \\
\hline S2 & 4,571 & & 5,371 & 5,029 & 4,990 \\
\hline S3 & 5,029 & 4,914 & & 1,200 & 3,714 \\
\hline S4 & 0,343 & 0,429 & 0,514 & & 0,429 \\
\hline IHC & 3,314 & 3,343 & 2,962 & 3,019 & \multicolumn{1}{|l}{} \\
\cline { 1 - 2 } & & & \multicolumn{4}{|l}{}
\end{tabular}

\begin{tabular}{|c|c|c|c|}
\hline & IAC & IHC & IRC \\
\hline S1 & 3,505 & 3,314 & 1,9048 \\
\hline $\mathrm{S} 2$ & 4,990 & 3,343 & 16,476 \\
\hline S3 & 3,714 & 2,962 & 7,5238 \\
\hline S4 & 0,429 & 3,019 & 25,905 \\
\hline & & MIRCA & 12,952 \\
\hline
\end{tabular}

Paso

7-8-9:

\begin{tabular}{|r|}
\hline Escalón de Segmentación \\
\hline 5,371 \\
\hline 4,366 \\
\hline 3,360 \\
\hline 2,354 \\
\hline 1,349 \\
\hline 0,343 \\
\hline
\end{tabular}

\begin{tabular}{|l|l|l|l|l|l|l|}
\hline & $\mathrm{A}$ & $\mathrm{B}$ & $\mathrm{C}$ & $\mathrm{D}$ & $\mathrm{E}$ & 0 \\
\hline 5,371 & & & & & & \\
\hline 4,366 & & & & & & \\
\hline 3,360 & & & & & & \\
\hline 2,354 & & & & & & \\
\hline 1,349 & & & & & & \\
\hline 0,343 & & & & & & \\
\hline
\end{tabular}


Paso 10-11-12:

\begin{tabular}{|c|c|c|c|c|c|c|c|c|c|c|c|c|c|c|}
\hline & \multicolumn{14}{|c|}{ RANGOS } \\
\hline & & S1 & $\mathrm{S} 2$ & $\mathrm{~S} 3$ & S4 & A & B & $\mathrm{C}$ & $\mathrm{D}$ & E & ) & Acep & Nor & Rec \\
\hline & S1 & & 4,686 & 3,000 & 2,829 & 1 & & 2 & & & & & $*$ & \\
\hline & $\mathrm{S} 2$ & 4,571 & & 5,371 & 5,029 & 3 & & & & & & $*$ & & \\
\hline & S3 & 5,029 & 4,914 & & 1,200 & 2 & & & & 1 & & $*$ & & \\
\hline & S4 & 0,343 & 0,429 & 0,514 & & & & & & 3 & & & & $*$ \\
\hline \multirow{9}{*}{$\begin{array}{l}2 \\
Z \\
2 \\
0 \\
0 \\
0\end{array}$} & A & 2 & 2 & 1 & 1 & & & & & \\
\hline & B & & & & & & & & & & & \multicolumn{3}{|c|}{ Aceptador } \\
\hline & $\mathrm{C}$ & & & 1 & 1 & & & & & & & \multicolumn{3}{|c|}{ Normal } \\
\hline & $\mathrm{D}$ & & & & & & & & & & & \multicolumn{3}{|c|}{ Rechazador } \\
\hline & $\mathrm{E}$ & 1 & 1 & 1 & 1 & & & & & & & & & \\
\hline & 0 & & & & & & & & & & & & & \\
\hline & I & * & * & & & \multicolumn{5}{|c|}{ Importante } & & & & \\
\hline & $\mathrm{N}$ & & & * & * & \multicolumn{5}{|c|}{ Normal } & & & & \\
\hline & $\mathrm{M}$ & & & & & \multicolumn{5}{|c|}{ Marginado } & & & & \\
\hline
\end{tabular}

Paso 13: Canales de Comunicación: 6

\section{Paso 14-15:}

\begin{tabular}{|r|r|r|}
\hline Sujetos & Indice & Valor Medio \\
\hline S2-S3 & 5,371 & 3,160 \\
\hline S2-S4 & 5,029 & 3,160 \\
\hline S3-S1 & 5,029 & 3,160 \\
\hline S3-S2 & 4,914 & 3,160 \\
\hline S1-S2 & 4,686 & 3,160 \\
\hline S2-S1 & 4,571 & 3,160 \\
\hline S1-S3 & 3,000 & 3,160 \\
\hline S1-S4 & 2,829 & 3,160 \\
\hline S3-S4 & 1,200 & 3,160 \\
\hline S4-S3 & 0,514 & 3,160 \\
\hline S4-S2 & 0,429 & 3,160 \\
\hline S4-S1 & 0,343 & 3,160 \\
\hline
\end{tabular}

Porcentaje de Carencia de Comunicación: 0

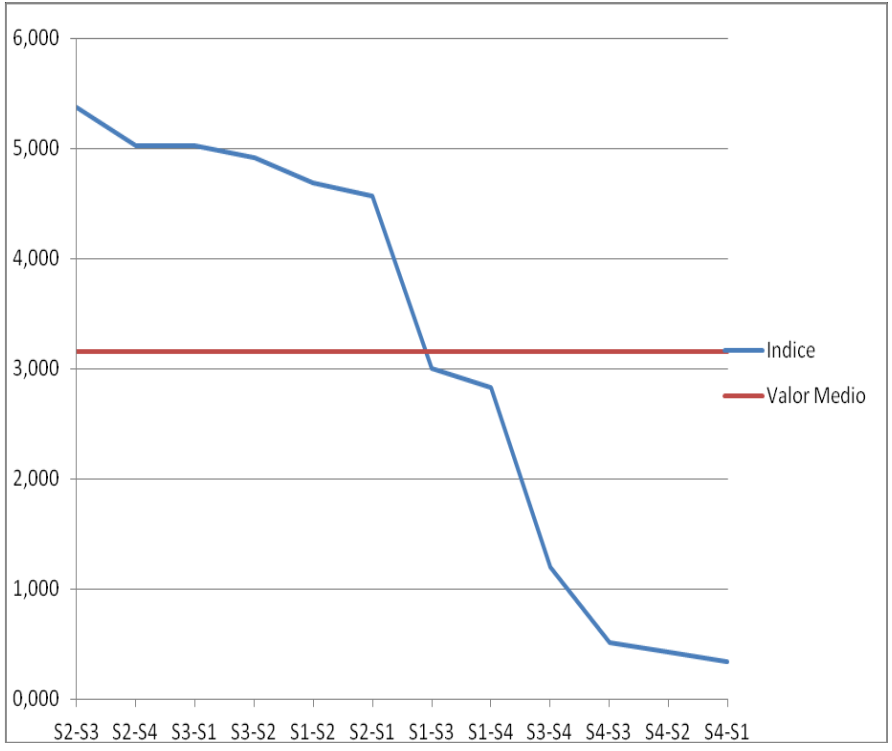




\subsection{Interpretación de Resultados Obtenidos}

\subsubsection{Procedimiento A:}

De los resultados $\left(\mathrm{IRC}_{\mathrm{i}}\right)$ se infiere que se sobre-estiman un 53,3\% de los sujetos respecto al grupo (8 sobre 15), un $40 \%$ se considera por debajo de las consideraciones del grupo (6 sobre 15) y un 6,66 \% coinciden su autovaloración y la que formula el grupo respecto de él (1 sobre 15).

De los resultados se infiere que dentro del grupo prevalece la conducta Normal con el $60 \%$ (9 sujetos sobre 15) en contraposición a las conductas: Rechazadora con el 13,3\% (2 sujetos de 15); Normal/Rechazador con el 13,3\% (2 sujetos de 15) y Aceptador/Normal con el 13,3\% (2 sujetos de 15). No se observan la presencia de sujetos con conductas aceptadoras puras.

De los resultados se infiere que dentro del grupo tiene una alto porcentaje la conducta Normal con $86,6 \%$ (13 sujetos de 15) con respecto a la conducta Marginado con el $13,3 \%$ (2 sujetos de 15). No se observa ningún sujeto con conducta Importante.

\subsubsection{Procedimiento B:}

La interpretación de los resultados Sujeto-Grupo (Matriz MRDCI) se hace en base a las convenciones especificadas en las definiciones. De los resultados se infiere que dentro del grupo se aprecian conductas polarizadas: S1 y S2 = Rechazadores; S3 y S4 = Aceptadores; S1 y S2 = Importantes; y S3 y S4 = Marginados

\subsubsection{Procedimiento C:}

De los resultados prelimares obtenidos en el EVTC de experimentación, se observan elementos vinculantes con la educación a distancia, como así mismo aplicables a redes sociales, en donde los participantes cuentan con comunicaciones sincrónicas y 
asincrónicas. Los valores que conforman cada par (ejemplo: S2-S3, con mayor nivel de intercambio entre ambos) nos indica el grado de vinculación entre los participantes, cuanto menor es el valor, menor intercambio de mensajes y permite detectar la intervención del docente/tutor (ejemplo: S4-S1, con el menor nivel de intercambio entre ambos). 


\section{CONCLUSIONES}

En este capítulo se presentan valoraciones generales de la tesis (sección 6.1), se resumen las aportaciones de la tesis (sección 6.2), y se identifican futuras líneas de trabajo (sección 6.3).

\subsection{Valoraciones Generales}

Tradicionalmente en la disciplina informática los problemas se han clasificado como de "hardware" o de "software". Sin embargo, se empieza a vislumbrar en proyectos software una tercera dimensión de problemas vinculados a la Interacción humana, los llamados problemas de "humanware".

La sociometría provee instrumentos de diagnóstico que permiten al docente realizar acciones para mejorar el rendimiento de los grupos de trabajo áulico. Cuando el trabajo en grupo de la clase se traslada a los espacios virtuales, estos instrumentos deben ser repensados.

El trabajo se orienta a desarrollar instrumentos de análisis que pongan en evidencia la estructura subyacente del grupo mediado por EVTC, permitiendo plantear hipótesis con base cuantitativa sobre preferencias y rechazos de los individuos entre si y en relación a la tarea colaborativa [Cirigliano \& Villaverde, 1966].

El componente humano que interviene en la interacción mediada por EVTC propio de la dinámica grupal, genera efectos en los aprendizajes individuales, planteando la necesidad de disponer de instrumentos que asistan el análisis diagnostico para la necesaria intervención del docente en los procesos pedagógicos en espacios virtuales De los resultados prelimares obtenidos en el EVTC de experimentación, se observan elementos vinculantes con la educación a distancia, en donde los participantes cuentan con comunicaciones sincrónicas y asincrónicas. 
En este contexto, en esta tesis se ha explorado el marco teórico para la generación de instrumentos de diagnóstico (detección de roles), se ha inferido un modelo en base a un conjunto de indicadores propuestos, que permitiría de forma temprana la intervención del docente/tutor en un espacio virtual de trabajo colaborativo (EVTC) con el fin de generar un correcto encuadre pedagógico/didáctico sobre el grupo.

\subsection{Aportaciones de la Tesis}

Las aportaciones de esta tesis han surgido de la búsqueda de las respuestas a las preguntas de investigación formuladas:

Pregunta 1: ¿Se puede inferir un modelo de roles según SNA (Análisis de redes sociales) aplicable a un EVTC?

Pregunta 2: ¿De poder definir el modelo, que características posee o que roles son posibles de detectar?

Respuesta: Se pudo inferir un modelo de determinados roles (líder, marginado, aceptador, rechazador, normal), en foco con los sistemas sociométricos centrado en la colaboración, aunque es un modelo limitado según el tipo de rol a detectar, y que fue validado por casos de corroboración dentro de un EVTC.

Las características de los roles se encuentran definidos según el grado de interacción, en dos grupos:

a) Sujeto - Grupo:

Las reglas de decisión que se proponen en este trabajo son:

- $\mathrm{S}_{\mathrm{i}}$ es aceptador del grupo:

$$
\text { aceptador } \geq \text { normal }+ \text { rechazador }
$$

- $\mathrm{S}_{\mathrm{i}}$ es normal del grupo:

$$
\text { normal } \geq \text { aceptador }+ \text { rechazador }
$$


- $\mathrm{S}_{\mathrm{i}}$ es rechazador del grupo

$$
\text { rechazador } \geq \text { normal }+ \text { aceptador }
$$

b) Grupo - Sujeto:

- $\mathrm{S}_{\mathrm{i}}$ es líder del grupo

$$
\text { líder } \geq \text { normal + marginado }
$$

- $\mathrm{S}_{\mathrm{i}}$ es normal del grupo

$$
\text { normal } \geq \text { líder }+ \text { marginado }
$$

- $\mathrm{S}_{\mathrm{i}}$ es marginado del grupo

$$
\text { marginado } \geq \text { normal + líder }
$$

Pregunta 3: ¿De ser medible la interacción de los participantes por tecnología informática, que información de interés le reporta al docente la métrica?

Respuesta: Se pudieron definir los elementos básicos constitutivos de los roles predominantes en un grupo colaborativo mediado por tecnología informática dentro de un EVTC por medio del cual se re definieron indicadores sociométricos mediante la implementación de la tecnología.

La información de los resultados obtenidos permiten un abordaje sistémico por parte del docente/tutor en el acompañamiento del curso para la concreción de tareas en un EVTC.

Pregunta 4: ¿Se puede utilizar alguno de los formalismos de modelado informáticos, o desarrollar una extensión de los mismos para analizar los roles de los participantes dentro de un EVTC?

Respuesta: Se propuso el análisis de los tiempos de demora en las respuestas entre participantes de un EVTC.

El concepto de tiempo de demora y su respectiva ponderación, permite generar una idea marco, que aunada con la cantidad de mensajes 
enviados/recibidos dentro de una ventana temporal, cobra significado el rol de cada participante.

Esta idea "marco" nos permite estructurar el concepto y aplicarlo/replicarlo en otro tipo de dispositivo que permita la instrumentación tecnológica pertinente para adaptar los indicadores correspondientes.

Pregunta 5: La métrica desarrollada para la detección de roles de cada participante y la respectiva alerta temprana ¿qué información de interés le reporta al docente? ¿Puede abordar un seguimiento sobre los participantes con el fin de encauzar una intervención didáctica en la tarea?

Respuesta: Dentro del marco de los roles detectables en este trabajo, podemos destacar que, de la inferencia matemática, los roles de Marginado y Rechazador son aquellos en los cuales el docente deberá abordar un trabajo sistémico para integrar a dichos participantes en la propuesta de trabajo en equipo dentro de un EVTC.

La información obtenida de la detección de roles, le permite al docente abordar las estrategias de seguimiento de la tarea que decida convenientes. Los espacios mediados tecnológicamente disponen de otras formas de visibilidad de los actores, que se encuentran diferenciadas del especio áulico. Los instrumentos detallados en éste trabajo de tesis proponen acercar al docente a la actividad grupal y obtener un grado de visibilidad de las actividades y determinadas funciones de los participantes.

Pregunta 6: ¿Cuánto influye la alerta temprana en el grado de participación del grupo en una actividad propuesta dentro de un EVTC?

Respuesta: El grado de participación dentro de una actividad grupal, en un espacio convencional es guiada en muchas instancias por el docente/tutor para mejorar el resultado de la actividad. Dentro de un EVTC, como lo indica, 
la virtualidad es el momento pedagógico, el cual ahora se encuentra diferenciado del especio-tiempo de la actividad en el aula. La observación de la función y grado de participación de cada miembro del grupo desaparece, por lo tanto, en el caso de la alerta temprana de la función de cada participante, le permite al docente/tutor realizar una intervención en el momento que considere pertinente para que el resto del grupo redirecciones su tarea y permita al miembro alejado de la actividad, acercarlo a la misma.

\subsection{Futuras Líneas de Trabajo y Problemas Abiertos}

Dentro de las distintas propuestas no contempladas por el trabajo pero como futuras líneas de acción y análisis, podemos observar las concernientes al entorno educativo denominado b-learning (educación mediada por dispositivos tecnológicos y encuentros presenciales) y m-learning (educación medianda íntegramente por dispositivos tecnológicos móviles, desde tablets a teléfonos smarts), con su correspondiente implicancia en el empleo de la tecnología y las características sociotecnológicas-pedagógicas a cargo del docente/tutor del curso para una correcta intervención didáctica.

Durante el desarrollo de esta tesis se han identificado las siguientes líneas de trabajo y problemas abiertos:

[a] llevar adelante una validación sistemática de los indicadores en una muestra amplia de grupos de trabajo colaborativo en espacios virtuales;

[b] explorar la adaptación de otros indicadores sociométricos.

[c] identificar un conjunto de roles tipificados en SNA (Análisis de Redes Sociales) y no analizados en el presente trabajo.

[d] desagregar la información de interés que le reporta al docente la métrica de detección de roles de cada participante y la respectiva alerta temprana. 
[e] enriquecer los roles dentro de la dinámica colaborativa con otros indicadores propios de la tecnología informática a fin de detectar nuevas características de participación.

En este contexto emergen problemas abiertos vinculados a las siguientes preguntas de investigación:

[a] Las redes sociales como influyen en la generación de roles

[b] Los distintos elementos de intercambio de información cómo se los pondera o qué nivel de prioridad tiene cada uno al momento de inferir un modelo de rol:

i. Correo electrónico

ii. Skype

iii. Facebook

iv. Instagram

v. Grupos Google

vi. Snapchat

vii. WhatsApp

viii. Almacenamientos de datos:

$\circ$ Google Drive

○ Dropbox

○ OneDrive 


\section{REFERENCIAS}

Ackerman, M. (2000). The intellectual challenge of CSCW: the gap between social requirements and technical feasibility. Human-Computer Interaction, 15(2-3): 179-203.

Álvarez, M. (2007). El rol del tutor en las fases preactiva, interactiva y postactiva. Universidad Nacional de Santiago del Estero, Facultad de Ciencias Exactas y Tecnologías.

Anzieu, D. \& Martin, J. Y. (2000). La dynamique des groupes restreints. PUF 12 ème édition - Septiembre 2000.

Arango, M. L. (2003). Foros virtuales como estrategia de aprendizaje. Anexo 1. Universidad de los Andes. Departamento de Ingeniería de Sistemas y Computación. LIDIE. Laboratorio de Investigación y Desarrollo sobre Informática en Educación, Bogotá.

Araujo, R. \& Borges, M. (2001). Extending the Software Process Culture-An approach based on groupware and workflow. En Product Focused Software Process Improvement. Pág. 297-311. Springer.

Araujo, R., Santoro, F., \& Borges, M. (2002). The CSCW lab for groupware evaluation. En Groupware: Design, Implementation, and Use. Pág. 222-231. Springer.

Ayala, G. (1996). Intelligent Agents for Supporting the Effective Collaboration in CSCL Environment. Tesis doctoral, Universidad de Tokushima, Japón. 
Bain, K. (2011). What the best college teachers do. Harvard University Press.

Bannon, L. \& Schmidt, K. (1989). CSCW: Four Characters in Search of a Context. In Proc. First European Conf. on CSCW. Gatwick, UK, Sept.

Barberá, Elena. (2004). La educación en la red: actividades virtuales de enseñanza y aprendizaje. Barcelona: Paidós.

Bastín, G. (1966). Los test sociométricos. Kapeluz.

Benford, S. \& Fahlén, L. (1993). A spatial model of interaction in large virtual environments. Proceedings of the Third European Conference on Computer-Supported Cooperative Work. Pág. 109-124. Springer Netherlands.

Benford, S., Bullock, A., Cook, N., Harvey, P., Ingram R. \& Lee, O. (1993). From rooms to cyberspace: models of interaction in large virtual computer spaces. Interacting with Computers, 5(2), 217-237. ISSN 0953-5438.

Bodemer, D. \& Dehler, J. (2011). Group awareness in CSCL environments. Computers in Human Behavior, 27(3), 1043-1045.

Brass, D. (1984). Being in the Right Place: A Structural Analysis of Individual Influence in an Organization. Administrative Science Quarterly, 29, pp. 518-539.

Brass, D. (1995). A Social Network Perspective on Human Resources Management. Research in Personnel and Human Resources Management, 13, pp. 39-79. 
Breiger, R., Boorman, S. \& Arabie, P. (1975). An algorithm for clustering relational data, with applications to social network analysis and comparison with multidimensional scaling. Journal of Mathematical Psychology 12:328-383.

Breiger, R. \& Pattison, P. (1986). En Freeman, L. (2004). The development of social Network analysis- A study in the sociology of science. Empirical Press. Vancouver, BC Canada

Brown, J. S. \& Duguid, P. (2000). Social Life of Information. Cambridge, $M A$ Harvard Bussines School Press.

Burt, R. (1992). Structural Holes. Cambridge, MA: Harvard University Press. 1997. En The Contingent Value of Social Capital. Administrative Science Quarterly, 42, pp. 339-365.

Cabero Almenara, J. \& Cejudo, M. D. C. L. (2013). La aplicación del juicio de experto como técnica de evaluación de las tecnologías de la información y comunicación (TIC). Eduweb, 7(2), 11-22.

Cáceres, P. (2003). Análisis cualitativo de contenido: Una alternativa metodológica alcanzable. Psicoperspectivas. Individuo y Sociedad, Vol. II, 53-82.

Carley, K. (1991). A Theory of Group Stability. American Sociological Review, 56, pp. 331-354.

Casciaro, T. (1998). Seeing Things Clearly: Social Structure, Personality and Accuracy in Social Network Perception. Social Networks, 20, pp. 331-351. 
Charczuk, N., Rodríguez, D. \& García-Martínez, R. (2013). Propuesta de Técnicas de Diagnóstico Sociométrico de Dinámicas Grupales para Utilizar en Ambientes de Trabajo Colaborativo. Proceedings VIII TEYET. ISBN 978-987-1676-04-0. UNSE

Charczuk, N., Rodríguez, D. \& García-Martínez, R. (2014). Métricas de Participación en Ambientes de Trabajo Colaborativo Orientadas a la Generación de Intervenciones Didácticas. CACIC. ISBN 978987-3806-05-6. Universidad Nacional de La Matanza.

Charczuk, N., Rodríguez, D. \& García-Martínez, R. (2015). Participation Metrics within Virtual Collaborative Workspaces Oriented to Generation of Didactic Interventions. Computer Science \& Technology Series 2015: XX Argentine Congress of Computer Science Selected Papers / Ovaldo Spositto; Patricia Mabel Pesado; compilado por Ovaldo Spositto; Patricia Mabel Pesado. La Plata: EDULP - ISBN: 978-987-1985-71-5

Charczuk, N., Rodríguez, D. \& García-Martínez, R. (2015). Integración de Indicadores Sociométricos de Dinámicas Grupales en Ambientes Virtuales de Trabajo Colaborativo Orientados a Intervenciones Didácticas. XVIII Workshop Tecnología Informática Aplicada a la Educación. CACIC 2015, 5 al 9 de Octubre, Junín, Buenos Aires, UNNOBA

Cirigliano, G., Villaverde, A. (1966). Dinámica de Grupos y Educación. HVMANITAS.

Civarolo, M. M. (2008). La idea de Didáctica: Antecedentes, génesis y mutaciones. Buenos Aires: Editorial Magisterio. 
Cohen, S. \& Bailey, D. (1997). What Makes Team Work: Group Effectiveness Research from the Shop Floor to the Executive Suite. Journal of Management, 23(3): 239-290.

Cohen, D. \& Prusak, L. (2000). En Good Company: How Social Capital Makes Organizations Work. Boston: MA, Harvard Business School Press.

Coleman, J. (1988). Social Capital in the Creation of Human Capital. American Journal of Sociology, 94, pp. S95-S120.

Cols, S. (1977). Conducción del aprendizaje. Marymar.

Cornejo, J. (2003). Análisis Sociométrico. Universidad de Barcelona

Crooks, T. J. (1988). The impact of classroom evaluation practices on students. Review of educational research, 58(4), 438-481.

Cross, R. \& Borgatti, A. (2004). Making Invisible Work Visible: Using Social Network Analysis to Support Strategic Collaboration. McIntire School of Commerce University of Virginia Charlottesville. Boston College, Carroll School of Management IBM Institute for Knowledge Management

Daugherty, M. \& Turner, J. (2003). Sociometry: An approach for Assessing Group Dynamics in Web-Based Courses. Interactive Learning Environments, Vol 11, No.3, pp 263-275

De Ketele, J. (1980). En De Ketele, J., Roegiers, X. (1995). Metodología para la Recogida de Información. Editorial La Muralla. 
De Ketele, J. \& Roegiers, X. (1995). Metodología para la Recogida de Información. Editorial La Muralla.

Deleuze, G. (2014). El poder: curso sobre Foucault II. Editorial Cactus, Ciudad Autónoma de Buenos Aires.

Doreian, P. (1991). En Freeman, L. (2004), The development of social Network analysis- A study in the sociology of science. Empirical Press. Vancouver, BC Canada.

Drucker, P. (1986). Las Fronteras de la Administración, Donde las decisiones del mañana cobran forma hoy. Editorial Sudamericana.

Ellis, C., Gibbs, S. \& Rein, G. (1993). Groupware: Some Issues and Experiences. En: Readings in Groupware and ComputerSupported Cooperative Work. BAECKER, R., San Mateo CA: Morgan Kauffmann, 1993: pp. 9-28.

Engelbart, D. (1992). Toward high-performance organizations: A strategic role for groupware. Proceedings of the GroupWare, Vol. 92. Pág. $3-5$.

Etzkowitz, H. (2003). Research Groups as 'Quasi-firms': The Invention of the Entrepreneurial University. Research Policy, 32: 109-121.

Fainholc, Beatriz. (1999). La interactividad en la educación a distancia. Paidós

Faust, K. (1997). Centrality in affiliation networks. Social Networks $19157-$ 191 
Faust, K. (1998). En Freeman, L. (2004), The development of social Network analysis- A study in the sociology of science. Empirical Press. Vancouver, BC Canada

Freeman, L. (2004). The development of social Network analysis- A study in the sociology of science. Empirical Press. Vancouver, BC Canada

Friesen, N., \& Kuskis, A. (2013). Modes of interaction. Handbook of Distance Education, 351-371.

García Aretio, L. (1999). Fundamentos y Componentes de la Educación a Distancia. En RIED. Revista Iberoamericana de Educación a Distancia - Vol 2 - Nro 2. Madrid 1999

García, J. (2012). Análisis de interacciones para la detección dinámica y el soporte de roles participativos en entornos CSCL aplicando técnicas basadas en SNA. Universidad de Valladolid.

González, M., \& Vendrell, E. (1996). El grupo de experiencia como instrumento de formación. Manual didáctico para monitores de grupo. (Eds.) Barcelona: EUB, S.L.

Graham C., \& Misanchuk, M. (2004). Computer-mediated learning groups: Benefits and challenges to using groupwork in online learning environments. Online collaborative learning: Theory and practice, 1(8), 1-202.

Greenberg, S. (1991). Computer supported cooperative work and groupware: An introduction to the special edition. International Journal of Man Machine Studies, 34(2): 133-143. 
Gros-Salvat, B. (2007). El aprendizaje colaborativo a través de la red. Aula de Innovación Educativa, 15(162), 44-50.

Grudin, J. (1994a). Computer-Supported Cooperative Work: History and Focus. Computer, 27(5): 19-26.

Grudin, J. (1994b). Groupware and Social Dynamics: Eight Challenges for Developers. Communications of the ACM 37: 92-105.

Hansen, M. (1999). The Search-Transfer Problem: The Role of Weak Ties in Sharing Knowledge Across Organization Sub-Units. Administrative Science Quarterly, 44, pp. 82-111.

Harary, K. \& Robinson, E. (2006). Who Do You Think You Are?. Penguin. USA

Hernández Contreras, M. \& Amezcua Alcantar, J. \& Vega de la Garza, A. (2012). Aprendizaje colaborativo Derivado de la evaluación Elearning. Relada 6(2): 329-337,2012. ISSN: 1988-5822

Huh, S. (1998). An object-oriented database model for a change management framework in workgroup computing systems. Information and Software Technology, 40(2): 79-92.

Ibarra, H. (1992). Homophily and Differential Returns: Sex Differences in Network Structure and Access in an Advertising Firm. Administrative Science Quarterly, 36, pp. 471-501.

Ibarra, H. (1995). Race, Opportunity and Diversity of Social Circles in Managerial Networks. Academy of Management Journal, 38, pp. 673-703. 
In-Sook, L. (2000). Factors affecting learners' discourse perticipation in a computer conferencing. ERIC ED 439698.

Johnson-Lenz, P. \& Johnson-Lenz, T. (1991). Post-mechanistic groupware primitives: rhythms, boundaries and containers. International Journal of Man-Machine Studies, 34(3): 395-417.

Jonassen, D. H. (1999). Designing constructivist learning environments. Instructional design theories and models: A new paradigm of instructional theory. En: Reigeluth, Ch. (Editor) (1999) Instructional-design Theories and Model. A New Paradigm of Instructional Theory. Volume II, 215-239.

Keahey, K., Foster, I., Freeman, T., Zhang, X. \& Galron, D. (2005). Virtual workspaces in the grid. En Euro-Par 2005 Parallel Processing. Pág. 421-431. Springer.

Keahey, K., Freeman, T., Lauret, J. \& Olson, D. (2007). Virtual workspaces for scientific applications. Journal of Physics: Conference Series, 78: 012038. IOP Publishing.

Khoshafian, S. \& Buckiewicz, M. (1995). Introduction to groupware, workflow, and workgroup computing. John Wiley \& Sons.

Krackhardt, D. (1987). Cognitive Social Structures. Social Networks, 9, pp. 109-134. 
Krackhardt, D. (1990). Assessing the Political Landscape: Structure, Cognition, and Power in Organizations. Administrative Science Quarterly, 35, pp. 342-369.

Krackhardt, D. (1992). The Strength of Strong Ties: The Importance of Philos in Organizations. En Nohria N. \& Eccles R. (Eds) Networks and Organizations: Structure, Form and Action. Boston, MA: Harvard Business School Press.

Krackhardt, D. (1994) Constraints on the Interactive Organization as an Ideal Type. En Heckscher C. \& Donnellon's A. The Post-Bureaucratic Organization: New Perspectives on Organizational Change. Thousand Oaks, CA: Sage Publications.

Leibovich, É. (1980). Medida de la relación social en el aula. CINAE.

Leiner, B., Cerf, V., Clark, D., Kahn, R., Kleinrock, L., Lynch, D. Postel, J., Roberts, L. \& Wolf, S. (1999). Brief History of the Internet. CERN Document Server. Report Number cs .NI/9901011.

Leenders, R. \& Gabbay, S. (1999). Corporate Social Capital and Liability. Boston, MA: Kluwar.

Li C., \& Bernoff, J. (2008). Groundswell: Winning in a world transformed by social technologies. Harvard Business Press

Lin, N. (2001). Social Capital: A Theory of Social Structure and Action. Cambridge, UK: Cambridge University Press.

Lion, Carina. (2006). Imaginar con tecnologías. Buenos Aires: La Crujía. 
Litwin, E. (2011). El oficio de enseñar: condiciones y contextos. Buenos Aires: Paidós - Voces de la Educación.

Litwin, E. (2005). Tecnologías educativas en tiempos de Internet. Buenos Aires: Amorrortu.

Litwin, E. (2000). Las configuraciones didácticas. Una nueva agenda para la enseñanza superior. Buenos Aires: Paidós Educador.

Litwin, E.(compiladora) (2000). La educación a distancia. Colección Agenda educativa.

Lorrain, F. \& White, H. (2001). En Freeman, L. (2004), The development of social Network analysis- A study in the sociology of science. Empirical Press. Vancouver, BC Canada

Manso. M.; Libedinsky, M.; Pérez, P.; Light, D. \& Garzón, M. (2011). Las TIC en las aulas: Experiencias latinoamericanas. Buenos Aires: Paidós.

Marsden, P. (1988). Homogeneity in Confiding Relations. Social Networks, 10, pp. 57- 76 .

Martineau, H. (2009). The Positive Philosophy of Auguste Comte, 2 volumes, 1853 Cambridge University Press, Print Publication

Mena M. (1994). La convivencia institucional de las modalidades de educación presencial y a distancia: competencia o cooperación? En: Litwin. E., Maggio, M. y Roig, H. (Compiladoras). Educación a Distancia en los 90. Desarrollo, problemas y 
perspectivas. Buenos Aires: Facultad de Filosofia y Letras de la Universidad de Buenos Aires. Programa UBA XXI

Mena, M.; Rodríguez, L. \& Diez, M.L. (2005). El diseño de proyectos de educación a distancia. Editorial Stella.

Meddley, M. (1963). En De Ketele, J. \& Roegiers, X. (1995). Metodología para la Recogida de Información. Editorial La Muralla.

Moore, M. (1991). Distance education theory. The American Journal of Distance Education

Mouly, (1963). En De Ketele, J.-M. \& Roegiers, X. (1995). Metodología para la Recogida de Información. Editorial La Muralla.

Morin, E. (1980). Ciencia con Conciencia. Editorial Anthopos.

Nahapiet, J. \& Ghoshal, S. (1997). Social Capital, Intellectual Capital and the Creation of Value in Firms. Academy of Management Review, 22.

Novak, J. (1990). Teoría y Práctica de la Educación. Madrid: Alianza Universidad.

Pasel, S. \& Asborno, S. (1993). Aula-Taller. Aique Grupo Editor S.A.

Paternò, F., Mancini, C. \& Meniconi, S. (1997). ConcurTaskTrees: A Diagrammatic Notation for Specifying Task Models. Proceeding of Interact'97. 362-369.

Pattison, P. (1988). En Freeman, L. (2004), The development of social Network analysis- A study in the sociology of science. Empirical Press. Vancouver, BC Canada 
Pattison, P. (1991). En Freeman, L. (2004), The development of social Network analysis- A study in the sociology of science. Empirical Press. Vancouver, BC Canada

Paternò, F., Mancini, C., \& Meniconi. (1997). ConcurTaskTree: A diagrammatic notation for specifying task models. En S. Howard, J. Hammond, G. \& Lindgaard, (1997). Proceedings of IFIP TC 13 International Conference on Human-Computer Interaction Interact'97. Sydney, July 14-18, Kluwer Academic Publishers, Pp 362-369, Boston.

Paternò, F., Santoro, C., \& Tahmassebi, S. (1998). Formal model for cooperative tasks: Concepts and an application for en-route air traffic control. En Markopoulos P., \& Johnson P. (1998). Proc. of 5thInt. Workshop on Design, Specification, and Verification of Intractive Systems DSV-IS '98. Abingdon, June 3-5. SpringerVerlag, Pp 71-86, Vienna.

Pérez-Alvarez, S. (1991). El Diagnóstico de la Situación Educativa. Bs As: Braga $3^{\circ}$ Edición.

Pérez-Alvarez, S. (1991). Las investigaciones exploratorias y descriptivas en las Ciencias de la Educación. Editorial Braga.

Pérez, M. M. (2007). El trabajo colaborativo en el aula universitaria. Laurus, 13(23), 263-278.

Peters, (1988). En Williams, M., Paprock K., \& Covington B. (1999). Distance Learning The Essential Guide. Sage Publications. 
Podolny, J., \& Baron, J. (1997). Resources and Relationships: Social Networks and Mobility in the Workplace. American Sociological Review, 62, pp. 673-693.

Pons, C., Giandini, R., \& Pérez, G. (2010). Desarrollo de Software Dirigido por Modelos. Conceptos teóricos y su aplicación práctica. Edulp. ISBN 978-950-34-0630-4

Prieto Castillo, D. (2010). Mediación pedagógica de las tecnologías en el espacio de la educación superior. Mendoza.

Ranzoni, (1968). En De Ketele, J., \& Roegiers, X. (1995). Metodología para la Recogida de Información. Editorial La Muralla.

Reuchlin, (1969). En De Ketele, J., \& Roegiers, X. (1995). Metodología para la Recogida de Información. Editorial La Muralla.

Rivas, P. (compilador) (2011). Fraternidad y Conflicto: enfoques, debates y perspectivas. Editorial: Ciudad Nueva. Buenos Aires

Rodríguez, D. (2015). Conceptualización de Espacios Virtuales de Trabajo. Tesis Doctoral en Ciencias informáticas. Facultad de Informática. Universidad Nacional de La Plata.

Rodriguez, D., \& Garcia-Martinez, R. (2014). A Proposal of Interaction Modelling Formalisms in Virtual Collaborative Work Spaces. LNSE, 2(1): 76-80. ISSN-2301-3559.

Rodríguez, D., Baldizzoni, E., Martins, S., Charczuk, N., \& García-Martínez, R. (2014). Líneas de I+D+I del Laboratorio de Investigación y Desarrollo en Espacios Virtuales de Trabajo (LIDEVT GISI 
UNLa). Proceedings XVI Workshop de Investigadores en Ciencias de la Computación. Pág. 912-915. WICC 2014, 7 y 8 de Mayo, Ushuaia, Tierra del Fuego, UNTDF

Rodríguez, D., Charczuk, N., Garbarini, R., \& García-Martínez, R. (2012). Trabajo Colaborativo basado en Espacios Virtuales. Proceedings II Jornadas de Enseñanza de la Ingeniería. JEIN 2012. Pág. 192199. Programa de Tecnología Educativa y Enseñanza de la Ingeniería (TEyEI). Universidad Tecnológica Nacional. ISSN 2313-9056.

Rodríguez, D., García-Martínez, R., Merlino H., Charczuk, N., Lacabanne, M., Caracciolo, B., \& Iglesias. Espacios Virtuales para Trabajo Colaborativo. Proceedings del XV Workshop de Investigadores en Ciencias de la Computación, Pág. 1116-1120. WICC 2013, 18 y 19 de Abril del 2013, Paraná, Entre Ríos, UADER-ISBN 9789-872-81796-1.

Rossa de Riaño, M., Gallino, M., \& Sigeser, O. (2002). La configuración didáctica en entornos multimediales: desafíos y reflexiones sobre la práctica. Departamento Pedagógico. Facultad de Educación a Distancia. Instituto Universitario Aeronáutico. CórdobaArgentina

Rosenberg, M. (2001). E-Learning: Strategies for Delivering Knowledge in the Digital Age. McGraw Hill Companies, USA.

Rosenshine, (1973; 1986). En De Ketele, J., \& Roegiers, X. (1995). Metodología para la Recogida de Información. Editorial La Muralla. 
Salazar, C. (1999). Teletrabajo. Ingeniería informática, 4. ISSN 0717-4195.

Sales Ciges, A. (2009). La Tutorización de cursos online y la diversidad. Universitat Jaume I

Salinas, J. (2009). Hacia nuevas formas metodológicas en e-learning. Formación XXI. Revista de Formación y empleo, $n .12$ abril 2009.

http://formacionxxi.com/porqualMagazine/do/get/magazineArticl e/2009/03/text/xml/Hacia_nuevas_formas_metodologicas_en_e_l earning.xml.html. Consultado en Agosto, 2017.

Salinas, J. (2005). Nuevos escenarios de aprendizaje. En Grupo CIFO: IV Congreso de Formación para el Trabajo (pp. 421-431).

Schmuk, R., \& Schmuk, P. (1975). Group processes in the classroom. Editorial: McGraw Hill. Última Edición 2001

Schön, D. (1998). El profesional reflexivo. Barcelona: Paidós.

Sosa M., Zarco R., \& Postiglioni A. (2006). Modelando aspectos de grupo en entornos colaborativos para proyectos de investigación Departamento de Informática Facultad de Ciencias Exactas y Tecnologías Universidad Nacional de Santiago del Estero

Souto, M. (1993) Hacia una didáctica de lo grupal. Buenos Aires: Miño y Dávila Editores.

Souto, M. (1987). El grupo de aprendizaje como unidad de operación educativa. En: Revista Argentina de Educación. Año V. Nro. 8. 
Stahl, G. (2006). Group cognition: Computer support for building collaborative knowledge. Cambridge, MA: MIT Press.

Stahl, G., Koschmann, T., \& Suthers, D. (2006). Computer-supported collaborative learning: An historical perspective. Cambridge handbook of the learning sciences, 2006, 409-426.

Strijbos, J., Martens, R., Jochems, W., \& Broers, N. (2004). The effect of functional roles on group efficiency using multilevel modeling and content analysis to investigate computer-supported collaboration in small groups. Small Group Research, 35(2), $195-$ 229.

Tiffin, J., \& Ragasingham, L. (1997). En busca de la clase virtual: La educación en la sociedad de la información. Barcelona, Paidós.

Toffler, A., \& Toffler H. (1990). El cambio del Poder. Plaza \& Janés Editores, Barcelona.

Wang, W., Haake, J., \& Rubart, J., (2002). A Cooperative Visual Hypermedia Approach to Planning and Conducting Virtual Meetings. Fraunhofer Institute for Integrated Publication and Information Systems (IPSI). FernUniversitaet Hagen, Computer Science VI Informatikzentrum, Universitaetsstr. Germany

Wang, W., Haake, J., \& Rubart, J., (2004). Supporting virtual meetings in the overall business context. Computation Department, UMIST, Manchester M60 1QD, U.K. - FernUniversitaet in Hagen, Computer Science VI, Informatikzentrum, Universitaetsstr. 1, D58084 Hagen, Germany - Fraunhofer Institute Đ Integrated 
Publication and Information Systems (IPSI), Dolivostr. 15, 64293 Darmstadt, Germany

Wasserman, S., \& Anderson, K. (1987). En Freeman, L. (2004), The development of social Network analysis- A study in the sociology of science. Empirical Press. Vancouver, BC Canada

Wasserman, S., \& Faust, K. (1992). Blockmodels: Interpretation and evaluation. Social Networks 14 p. 5-61

Wasserman, S., \& Faust, K. (1994). Social Network Analysis: Methods and Applications. Cambridge: Cambridge University.

Weick,. (1968). En De Ketele, J., \& Roegiers, X. (1995). Metodología para la Recogida de Información. Editorial La Muralla.

White, H., Scott A., \& Ronald L. (1976). Social structure from multiple networks I: Blockmodels of roles and positions. American Journal of Sociology 81:730-781.

White, D., \& Karl, P. (1983). Graph and semigroup homomorphisms on networks of relations. Social Networks 5:193-234.

Williams, M., Paprock, K., \& Covington, B. (1999). Distance Learning The Essential Guide. Sage Publications.

Winship, C., (1988). En Freeman, L. (2004), The development of social Network analysis- A study in the sociology of science. Empirical Press. Vancouver, BC Canada

Winship, C., \& Mandell, M. (1983). Roles and positions: A critique and extension of the blockmodeling approach. Pp. 314-344 in 
Sociological Methodology, 1983-84. San Francisco: JosseyBass.

Zabalza, M. (1987). Diseño y desarrollo curricular. Madrid: Narcea.

Zacklad, M. (2003). Communities of action: a cognitive and social approach to the design of CSCW systems. Proceedings 2003 international ACM SIGGROUP conference on Supporting group work. Pág. 190-197. 
